\title{
Work participation and health in rheumatic and musculoskeletal diseases
}

Citation for published version (APA):

van der Burg, L. (2021). Work participation and health in rheumatic and musculoskeletal diseases: insights from longitudinal studies. [Doctoral Thesis, Maastricht University]. Ridderprint. https://doi.org/10.26481/dis.20210901lb

Document status and date:

Published: 01/01/2021

DOI:

$10.26481 /$ dis.20210901lb

Document Version:

Publisher's PDF, also known as Version of record

\section{Please check the document version of this publication:}

- A submitted manuscript is the version of the article upon submission and before peer-review. There can be important differences between the submitted version and the official published version of record.

People interested in the research are advised to contact the author for the final version of the publication, or visit the DOI to the publisher's website.

- The final author version and the galley proof are versions of the publication after peer review.

- The final published version features the final layout of the paper including the volume, issue and page numbers.

Link to publication

\footnotetext{
General rights rights.

- You may freely distribute the URL identifying the publication in the public portal. please follow below link for the End User Agreement:

www.umlib.nl/taverne-license

Take down policy

If you believe that this document breaches copyright please contact us at:

repository@maastrichtuniversity.nl

providing details and we will investigate your claim.
}

Copyright and moral rights for the publications made accessible in the public portal are retained by the authors and/or other copyright owners and it is a condition of accessing publications that users recognise and abide by the legal requirements associated with these

- Users may download and print one copy of any publication from the public portal for the purpose of private study or research.

- You may not further distribute the material or use it for any profit-making activity or commercial gain

If the publication is distributed under the terms of Article $25 \mathrm{fa}$ of the Dutch Copyright Act, indicated by the "Taverne" license above, 


\section{Work participation and health in rheumatic \& musculoskeletal diseases}

Insights from longitudinal studies 



\section{Work participation and health in rheumatic \& musculoskeletal diseases \\ Insights from longitudinal studies}


ISBN: 978-94-6416-499-2

Cover design and layout: (c) evelienjagtman.com

Printing: Ridderprint

Printing of this thesis was financially supported by Maastricht University and $\mathrm{SBOH}$, which is gratefully acknowledged.

Copyright (C) 2021 L.R.A. van der Burg

All rights reserved. No part of this thesis may be reproduced in any form without written permission of the author or copyright-owning journals for previously published chapters. 


\section{Work participation and health in rheumatic \& musculoskeletal diseases \\ Insights from longitudinal studies}

Proefschrift

ter verkrijging van de graad van doctor aan de Universiteit Maastricht,

op gezag van de Rector Magnificus, Prof. dr. Rianne M. Letschert volgens het besluit van het College van Decanen,

in het openbaar te verdedigen

op woensdag 1 september 2021 om 16.00 uur

door

Lennart Remy Anton van der Burg

geboren te Valkenswaard

in 1989 


\section{Promotores}

Prof. dr. A.E.R.C.H. Boonen

Prof. dr. G.J. Dinant

\section{Copromotor}

Dr. R.P.G. Ottenheijm

\section{Beoordelingscommissie}

Prof. dr. A.M.C.F. Verbunt (voorzitter)

Prof. dr. B. Fautrel (Sorbonne University, Parijs)

Prof. dr. M.H. Hemmelder

Prof. dr. B.W. Koes (Erasmus Medisch Centrum, Rotterdam) 



\section{CONTENT}

Chapter 1 General introduction 9

Chapter 2 Cardiovascular morbidity and premature mortality among 23 working individuals with rheumatic disease: results from a large prospective cohort study

Chapter 3 The effects of cardiovascular co-morbidities on work participation in rheumatic diseases: a prospective cohort study among working individuals

Chapter 4 Effect of biological therapy on work participation in patients with ankylosing spondylitis: a systematic review

Chapter 5 Long-term sickness absence in a working population: development and validation of a risk prediction model in a large Dutch prospective cohort

Chapter 6 Comparative construct validity of three presenteeism instruments in workers with musculoskeletal complaints: a prospective cohort study

Chapter 7 Summary and general discussion

Addendum Impact paragraph 153

$\begin{array}{ll}\text { Nederlandse samenvatting } & 161\end{array}$

$\begin{array}{ll}\text { Curriculum vitae } & 171\end{array}$

List of publications $\quad 175$

Dankwoord 181 

1

GENERAL INTRODUCTION 



\section{GENERAL INTRODUCTION}

The Global Burden of Diseases, Injuries, and Risk Factors Study 2016 (GBD 2016) reports that over 1.2 billion people worldwide are affected by musculoskeletal disorders in general. Disability-adjusted life years (DALYs) and years lived with disability (YLDs) are measurements of the burden of disease. In the GBD 2016, musculoskeletal disorders comprised the second highest global volume of DALYs (6\%) and YLDs were high (17\%). ${ }^{1-3}$ Rheumatic \& musculoskeletal diseases (RMDs) are very common in the working-age population of all European Union (EU) countries and responsible for a substantial burden on a person's economic, social and functional independence. ${ }^{3}$ While RMDs are a heterogeneous group of conditions, such as osteoarthritis (OA), low back pain (LBP) and rheumatoid arthritis (RA), they share common symptoms including pain, stiffness and increasing functional disability over the course of the disease. ${ }^{4}$ They are accountable for a large part of disability and form a crucial component of health expenditure in all EU countries, including the Netherlands. ${ }^{1,2,5}$ As many RMDs start during peak incomeearning years, they are a leading cause of restrictions in work participation, resulting in a substantial burden on patients, their families and society as a whole. The total costs of lost productivity attributable to RMDs among people of working age are as high as $2 \%$ of gross domestic product (GDP) in EU countries. ${ }^{6}$

With the aging of the population, pressure from policy makers emerges to improve longterm participation of people with chronic diseases. To accomplish this task, the needs of persons that are vulnerable on the labor market, such as the elderly and persons with disabilities or chronic diseases, need to be recognized and supported. Whilst work participation in RMDs has received much awareness from researchers in recent years, considerable knowledge gaps remain that require more attention. These are related to 1) our understanding of the complex relationship between RMDs, context and restrictions in work participation in the experience of health, and 2) approaches to improve early detection and treatment to prevent adverse work outcomes in RMDs.

\section{General background on work participation}

In 2001, the World Health Organization (WHO) endorsed the International Classification of Functioning, Disability and Health (ICF) throughout the world and across all disciplines of medicine as a framework and classification of health. ${ }^{7}$ This new framework replaced the disability-handicap model of health by the biopsychosocial model, emphasizing the complex interactions between disease conditions and contextual factors in the experience of health (Figure 1). 
Health condition

(disorder or disease)

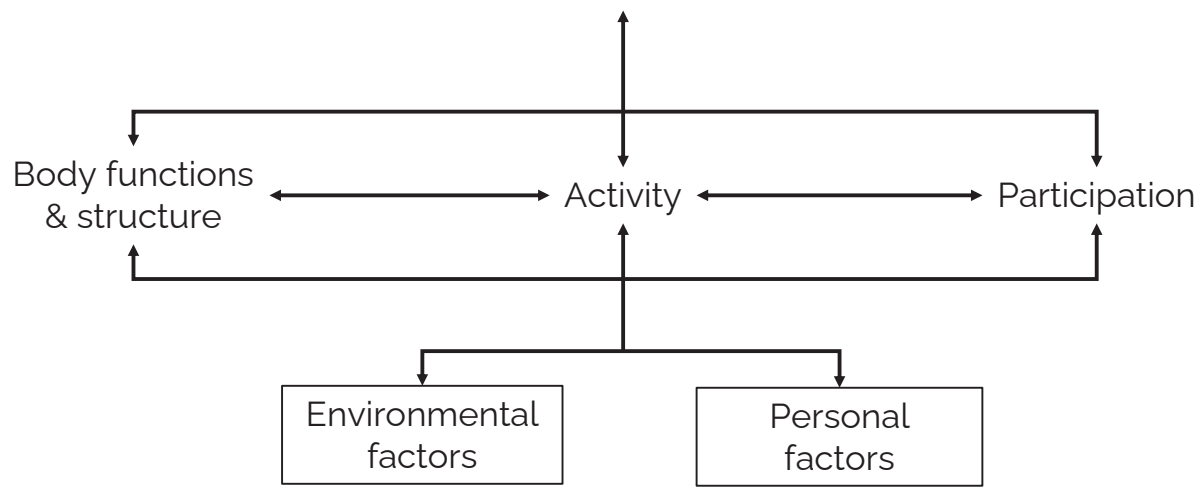

Contextual factors

Figure 1. The ICF-framework describes the complex relationships between disease conditions contextual factors and functioning according to the biopsychosocial model of health.

[Figure from World Health Organization. International Classification of Functioning, Disability, and Health: ICF. Geneva 2001]

The ICF distinguishes three levels of human functioning: the body (or body part), the whole person, and the person in their social context. ${ }^{8}$ In this model, participation restrictions are problems a person may experience while being involved in certain life situations (i.e. the social context), including participation in paid work. As a consequence, work participation is an integral part of health and can be defined as 'the active engagement in a work agreement for which one receives a compensation in kind or money'9.10 At the same time, the framework makes clear that health-related restrictions in work participation result from biological as well as contextual factors. It also highlights the bi-directionality of relationships, as work can influence health and context. For example, physically demanding jobs can lead to OA of the knees or accelerate progressive ankylosis of the spine.11.12 On the same line, participation in work can also influence attitudes of persons in the direct environment, as stigmatization of those work disabled or having frequent sick leave is still common.13.14

According to the ICF, two groups of contextual factors can be distinguished; personal factors (e.g. personal traits such as age and gender, lifestyle factors) and environmental characteristics (e.g. social support, getting effective treatments, social security system).7 Methodologically, according to the definition of the OMERACT (Outcome Measures in Rheumatology) initiative, contextual factors can modify 
(amplify or attenuate) the impact of a health condition on work participation and are therefore essential to measure to correctly interpret the complex relationships between RMDs and work participation.15-17

When participating in paid work, people suffering from (chronic) RMDs can encounter different levels of restrictions, reflected in the so-called 'worker continuum.'18 This ranges from normal participation in work at the beginning of the continuum, through reduced work productivity or work-ability while being at work (i.e. 'presenteeism') and temporary or long-term sickness absence (i.e. 'absenteeism'), up to complete withdrawal from work (e.g. permanent work disability or unemployment) at the end of the continuum (Figure 2).

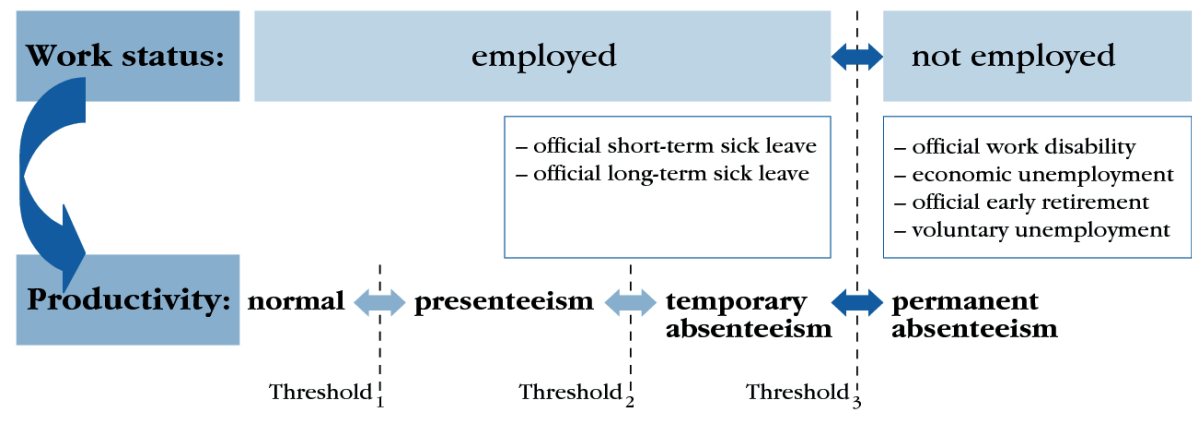

Figure 2. The so-called 'worker continuum', reflecting the different levels of restrictions people can encounter when participating in paid work.

[Figure from Boonen A, et al. Clinical Rheumatology 2011;30:3-8]

People can move back and forth across this continuum of work depending on several factors, including changes in (treatment of) the health condition or contextual factors such as the person's coping strategies or adjustments made at work to sustain or improve the work environment of the affected person.19,20

According to the European Working Conditions Survey (EWCS 2016), more than 40\% of Europeans go to work despite being unwell enough to take sickness absence (presenteeism). ${ }^{21}$ Half of all European absences from work and approximately $60 \%$ of permanent work disabilities are the result of RMDs. As mentioned previously, the total expenditures related to sick leave and work disability for society are as high as $2 \%$ of GDP in EU countries. ${ }^{6}$ Indirect costs resulting from reduced productivity and lost earnings are a major part of the total costs for society and probably outweigh the direct medical costs.22 Also in the Netherlands, RMDs and mental health problems are the leading causes of sickness absence and permanent work disability. ${ }^{23.24}$ 


\section{Cardiovascular co-morbidities and work participation}

As life-expectancy increases, mortality rates decline, diseases are detected at earlier stages and lifestyle-related risk factors for developing chronic diseases are increasing (e.g. obesity or a sedentary lifestyle), it is likely that more people in their work career will suffer from RMDs and other co-occurring chronic diseases, 1,2,25 This will probably result in an increasing burden on health and societal expenditures. However, few studies investigated the impact of co-occurring diseases with RMDs, either from the perspective of multimorbidity (i.e. having two or more chronic diseases of which none is more important than the other) or from the perspective of co-morbidity (i.e. one primary disease and one or more co-occurring disease(s) sometimes pathogenetically linked to the primary disease) ${ }^{26}$ In the latter perspective, the ICF framework would consider the co-occurring disease as a personal contextual factor. ${ }^{27}$ More specifically, few studies have explored whether cardiovascular diseases increase the risk of adverse work outcomes in persons who already suffer from RMDs. ${ }^{28}$ This is surprising because inflammatory RMDs, such as RA and spondyloarthritis (SpA) including psoriatic arthritis, are associated with a substantially increased risk of developing cardiovascular co-morbidities (e.g. ischemic heart disease, stroke), mainly through inflammation enhanced atherosclerotic plaque formation. ${ }^{29-31}$ With regard to work participation, premature cardiovascular mortality may contribute to reduced work participation in people of working-age with RMDs and this contribution may have been underestimated. ${ }^{32}$ Management of this cardiovascular risk, including more strict prevention of cardiovascular disease in the employed population additional to optimal control of disease activity, seems an interesting and essential approach to reduce the effects on health-related quality of life and adverse work outcomes in people suffering from those chronic inflammatory RMDs.

\section{Improving work participation}

Consistent with the ICF framework, impairments in body functions and structure, as well as limitations in activities, are important determinants of work participation. ${ }^{7.9}$ The introduction of biological disease modifying anti-rheumatic drugs ('biological therapies') for patients with inflammatory RMDs at the end of the $20^{\text {th }}$ century has significantly improved the ability to control the inflammatory process causing the disease, improving physical functioning and other aspects of health in the short- and long-term.33.34 However, biological therapies are expensive and usually administered for longer periods of time. Savings in indirect costs of disease by improving work participation might offset (part of) these high drug costs which can be relevant from a societal perspective. ${ }^{35}$ To understand the value of these drugs on work participation, a review of the available literature would be beneficial to inform healthcare professionals and policy makers. For RA, such a literature review has been performed and showed positive effects of biological therapies on presenteeism and absenteeism, and conflicting but promising 
results for employment status. ${ }^{36}$ However, axial SpA is typically diagnosed at a younger age (<40 years) as compared to RA, when one of someone's most important social roles is their professional career. Over time, axial SpA leads to increasing functional impairment during the rest of working life. Patients with axial SpA are therefore at risk of a greater lifetime economic burden which can possibly be prevented using biological therapies. ${ }^{37}$ If biological therapies would indeed improve work participation, one could argue that identifying working persons at highest risk of future long-term work restrictions can support healthcare professionals in their decision to initiate treatment with these drugs. To direct these expensive drugs to those patients who would be able to pay back indirectly through improved work participation would without doubt be unethical. However, for similar levels of disease activity, persons that have paid or unpaid work duties might be inclined to sooner agree to initiation of biological therapies in a shared decision making setting. Early identification of working persons at highest risk of future long-term work restrictions could be supported by multifactorial risk prediction models to ensure timely initiation of targeted interventions.

Risk prediction models are mathematical equations that use patient risk factor data to estimate the probability of a patient experiencing a specific healthcare outcome ${ }^{38}$ These risk prediction models are widely reported in medical literature for all kinds of diseases and outcomes, and some are routinely used in daily practice. For example, the Wells score can be calculated from patients' risk factor data and is used to determine if the risk of having a deep vein thrombosis is increased and additional diagnostic interventions are warranted. ${ }^{39}$ Published multifactorial risk prediction models for long-term adverse work outcomes in working persons have not shown adequate performance or have not been externally validated to be routinely implemented in daily practice and support healthcare professionals.

\section{Improving work outcome measurement}

Over the last decades, the OMERACT initiative has performed significant work regarding the evaluation of validity and clinimetric characteristics of clinical outcome measures and developed so-called 'core outcome sets' for clinical trials in rheumatology. ${ }^{40}$ Worker productivity is recognized as an important outcome to measure in different rheumatological diseases. For most individual candidate instruments under consideration by the OMERACT Worker Productivity Group, the characteristics and validity are known. ${ }^{15}$ Unfortunately, a direct comparison of the validity of candidate instruments in one population of working persons with RMDs is lacking. In addition, it is still unclear which outcome has the desired validity and best clinimetric characteristics for the specific study objective (e.g. patient vs. economic impact). The lack of homogeneity in worker productivity outcome measurement was also observed when reviewing the 
literature for biological therapies in RA, which made it impossible to perform a metaanalysis. ${ }^{36}$ Longitudinal studies comparing the validity and characteristics of worker productivity measurement instruments are therefore welcomed and will help to increase homogeneity of instruments used, while keeping in mind different needs depending on the study objective. In the long run, when studies start using similar outcomes measures, a meta-analysis can be performed to inform healthcare professionals and policy makers if initiated therapies indeed improve work outcomes in RMDs and reduce indirect costs of disease.

\section{Aims of this thesis}

To fill the abovementioned knowledge gaps, this thesis has the following aims:

1) To understand the influence of cardiovascular co-morbidities on work outcomes and premature cardiovascular mortality in patients with RMDs;

2) To evaluate the effect of biological therapies on work participation in axial SpA;

3) To improve early detection of long-term sickness absence in working persons;

4) To directly compare the construct validity and characteristics of presenteeism measurement instruments in RMDs. 


\section{THESIS OUTLINE}

Cardiovascular co-morbidities and mortality during working life may be an explanation of reduced work participation in persons with RMDs of working-age (first aim of this thesis). In Chapter 2 we describe the prevalence and risk of developing cardiovascular comorbidities and mortality in working persons with RMDs using the Maastricht Cohort Study. This prospective cohort study was performed among a large and representative sample of working persons in the south of the Netherlands including a large part of participants reporting RMDs. Next, in Chapter $\mathbf{3}$ the additional impact of these cardiovascular comorbidities on future temporary absenteeism and permanent work disability in persons who already suffer from RMDs are presented using the same study population.

Treatment of inflammatory RMDs, including axial SpA, with biological therapies has resulted in a significant improvement of physical function and health-related quality of life. However, these biological therapies are expensive treatment options, and their costs may be offset by reducing the indirect costs of axial SpA for society. In Chapter $\mathbf{4}$ the results of a systematic literature review summarizing the effects of biological therapies on work outcomes in axial SpA are shown (second aim of this thesis). Return to work, when temporary or permanent withdrawal from paid work has already occurred, is challenging. Earlier recognition of adverse work outcomes can be supported by a prognostic risk prediction model to initiate tailored interventions to prevent long-term restrictions in paid work. We have therefore developed and validated a multifactorial risk prediction model for long-term sickness absence in the coming year in a general population of working persons in Chapter $\mathbf{5}$ (third aim of this thesis). For this study, the prospective Study on Transitions in Employment, Ability and Motivation (STREAM) has been used, comprising a large and representative sample of working persons in the Netherlands.

In Chapter 6 the construct validity and characteristics of three different instruments to measure presenteeism are compared using the subsample of working persons in STREAM reporting musculoskeletal complaints (fourth aim of this thesis).

Finally, in Chapter $\mathbf{7}$ a summary and general discussion of the findings described in this thesis are presented, including future perspectives for work participation studies in RMDs resulting from our conclusions. A description of the impact of our findings on different stakeholders is provided in the Addendum of this thesis. 


\section{REFERENCES}

1. Hay SI, Abajobir AA, Abate KH, et al. Global, regional, and national disability-adjusted life-years (DALYs) for 333 diseases and injuries and healthy life expectancy (HALE) for 195 countries and territories, 1990-2016: a systematic analysis for the Global Burden of Disease Study 2016. The Lancet 2017:390(10100):1260-344.

2. Vos T, Abajobir AA, Abate $\mathrm{KH}$, et al. Global, regional, and national incidence, prevalence, and years lived with disability for 328 diseases and injuries for 195 countries, 1990-2016: a systematic analysis for the Global Burden of Disease Study 2016. The Lancet 2017:390(10100):1211-59.

3. Briggs AM, Woolf AD, Dreinhofer K, et al. Reducing the global burden of musculoskeletal conditions. Bull World Health Organ 2018;96(5):366-8.

4. van der Heijde D, Daikh DI. Betteridge N, et al. Common language description of the term rheumatic and musculoskeletal diseases (RMDs) for use in communication with the lay public, healthcare providers and other stakeholders endorsed by the European League Against Rheumatism (EULAR) and the American College of Rheumatology (ACR). Ann Rheum Dis 2018:77(6):829-32.

5. Social Expenditure Update 2019, Public social spending is high in many OECD countries. Paris: OECD Publishing; 2019.

6. Bevan S. Economic impact of musculoskeletal disorders (MSDs) on work in Europe. Best Pract Res Clin Rheumatol 2015:29(3):356-73.

7. International classification of functioning, disability, and health: ICF. Version 1.O. Geneva : World Health Organization, 2001.

8. Badley EM. Enhancing the conceptual clarity of the activity and participation components of the International Classification of Functioning, Disability, and Health. Soc Sci Med 2008;66(11):233545.

9. Martins AC. Using the International Classification of Functioning, Disability and Health (ICF) to address facilitators and barriers to participation at work. Work 2015:50(4):585-93.

10. Perenboom RJ, Chorus AM. Measuring participation according to the International Classification of Functioning, Disability and Health (ICF). Disabil Rehabil 2003:25(11-12):577-87.

11. Wang X, Perry TA, Arden N, et al. Occupational Risk in Knee Osteoarthritis: A Systematic Review and Meta-Analysis of Observational Studies. Arthritis Care Res (Hoboken) 2020:72(9):1213-23.

12. Ramiro S, Landewe R, van Tubergen A, et al. Lifestyle factors may modify the effect of disease activity on radiographic progression in patients with ankylosing spondylitis: a longitudinal analysis. RMD Open 2015;1(1):eo00153.

13. Toye F, Seers K, Allcock N, et al. A synthesis of qualitative research exploring the barriers to staying in work with chronic musculoskeletal pain. Disabil Rehabil 2016:38(6):566-72.

14. Froud R, Patterson S, Eldridge $\mathrm{S}$, et al. A systematic review and meta-synthesis of the impact of low back pain on people's lives. BMC Musculoskelet Disord 2014:15:50-

15. Beaton DE, Dyer S, Boonen A, et al. OMERACT Filter Evidence Supporting the Measurement of At-work Productivity Loss as an Outcome Measure in Rheumatology Research. J Rheumatol 2016:43(1):214-22.

16. Nielsen SM, Tugwell P, de Wit MPT, et al. Identifying Provisional Generic Contextual Factor Domains for Clinical Trials in Rheumatology: Results from an OMERACT Initiative. J Rheumatol 2019:46(9):1159-63. 
17. Nielsen SM, Uggen Rasmussen M, Boers M, et al. Towards consensus in defining and handling contextual factors within rheumatology trials: an initial qualitative study from an OMERACT working group. Ann Rheum Dis 2021;80:242-249.

18. Boonen A, Severens JL. The burden of illness of rheumatoid arthritis. Clin Rheumatol 2011;30 Suppl 1:S3-8.

19. Gobelet C, Luthi F, Al-Khodairy AT, et al. Work in inflammatory and degenerative joint diseases. Disabil Rehabil 2007:29(17):1331-9.

20. Wilkie R, Pransky G. Improving work participation for adults with musculoskeletal conditions. Best Pract Res Clin Rheumatol 2012;26(5):733-42.

21. Parent-Thirion A, Biletta I, Cabrita J, et al. Sixth European Working Conditions Survey - Overview report (2017 update). Publications Office of the European Union, Luxembourg 2017. ISBN: 97892-897-1597-3

22. Howard KJ. Howard JT, Smyth AF. The Problem of Absenteeism and Presenteeism in the Workplace. In: Gatchel RJ, Schultz IZ, editors. Handbook of Occupational Health and Wellness. Handbooks in Health, Work, and Disability. Springer 2012, Boston, MA.

23. van der Zee-Neuen A, Putrik P, Ramiro S, et al. Work outcome in persons with musculoskeletal diseases: comparison with other chronic diseases \& the role of musculoskeletal diseases in multimorbidity. BMC Musculoskelet Disord 2017:18(1):10

24. Hooftman WE, Mars GMJ, Janssen B, et al. Nationale Enquête Arbeidsomstandigheden (NEA) https://www.cbs.nl/-/media/_pdf/2017/19/nea2016-methodologisch-rapport.pdf: TNO Prevention, Work \& Health Centraal Bureau voor de Statistiek (CBS) Ministerie van Sociale Zaken en Werkgelegenheid (SZW); 2016.

25. Sebbag E, Felten R, Sagez F, et al L. The world-wide burden of musculoskeletal diseases: a systematic analysis of the World Health Organization Burden of Diseases Database. Ann Rheum Dis 2019:78(6):844.

26. van den Akker M, Buntinx F, Knottnerus JA. Comorbidity or multimorbidity. European Journal of General Practice 1996;2(2):65-70

27. Wijthuizen GJ, Perenboom RJ, Garre FG, et al. Impact of multimorbidity on functioning: evaluating the ICF Core Set approach in an empirical study of people with rheumatic diseases. J Rehabil Med 2012;44(8):664-8.

28. Verbrugge LM, Juarez L. Arthritis disability and heart disease disability. Arthritis Care Res (Hoboken) 2008;59(10):1445-57.

29. Aviña-Zubieta JA, Choi HK, Sadatsafavi M, et al. Risk of cardiovascular mortality in patients with rheumatoid arthritis: A meta-analysis of observational studies. Arthritis Care Res (Hoboken) 2008;59(12):1690-7

30. Bakland G, Gran JT, Nossent JC. Increased mortality in ankylosing spondylitis is related to disease activity. Ann Rheum Dis 2011:70(11):1921-5.

31. Jamnitski A, Visman IM. Peters MJ, et al. Prevalence of cardiovascular diseases in psoriatic arthritis resembles that of rheumatoid arthritis. Ann Rheum Dis 2011;70(5):875-6.

32. Pincus T, Gibson KA, Block JA. Premature Mortality: A Neglected Outcome in Rheumatic Diseases? Arthritis Care Res (Hoboken) 2015;67(8):1043-6.

33. Nam JL, Takase-Minegishi K, Ramiro S, et al. Efficacy of biological disease-modifying antirheumatic drugs: a systematic literature review informing the 2016 update of the EULAR recommendations for the management of rheumatoid arthritis. Ann Rheum Dis 2017:76(6):1113. 
34. Sepriano A, Regel A, van der Heijde D, et al. Efficacy and safety of biological and targetedsynthetic DMARDs: a systematic literature review informing the 2016 update of the ASAS/EULAR recommendations for the management of axial spondyloarthritis. RMD Open 2017:3(1):e000396.

35. Huscher D, Mittendorf T, von Hinüber U, et al. Evolution of cost structures in rheumatoid arthritis over the past decade. Ann Rheum Dis 2015:74(4):738.

36. ter Wee MM, Lems WF, Usan H, et al. The effect of biological agents on work participation in rheumatoid arthritis patients: a systematic review. Ann Rheum Dis 2012:71(2):161-71.

37. Boonen A, Mau W. The economic burden of disease: comparison between rheumatoid arthritis and ankylosing spondylitis. Clin Exp Rheumatol 2009;27(4 Suppl 55):S112-7.

38. Grant SW, Collins GS, Nashef SAM. Statistical Primer: developing and validating a risk prediction model. Eur J Cardiothorac Surg 2018:54(2):203-8

39. Wells PS, Owen C, Doucette S, et al. Does This Patient Have Deep Vein Thrombosis? JAMA 2006;295(2):199-207.

40. Tugwell P, Boers M, Brooks P, et al. OMERACT: an international initiative to improve outcome measurement in rheumatology. Trials 2007:8:38. 




\section{CARDIOVASCULAR MORBIDITY AND MORTALITY AMONG WORKING INDIVIDUALS WITH RHEUMATIC DISEASE: RESULTS FROM A LARGE PROSPECTIVE COHORT STUDY}

Lennart R.A. van der Burg

Ludovic G.P.M. van Amelsvoort

Annelies Boonen

Nicole Jansen

IJmert Kant

Robert B.M. Landewé

Journal of Clinical Rheumatology 2015;21: 359-363 


\section{ABSTRACT}

Background. Cardiovascular comorbidities are common in rheumatic diseases and are associated with an increased mortality risk but have not been studied in a working population, with less severe disease. Also, the impact of premature cardiovascular mortality on work participation has been neglected until now.

Objectives. The objectives of this study were to evaluate the cardiovascular risk in working individuals with inflammatory rheumatic diseases and to explore whether cardiovascular morbidity and mortality are associated with decreased work participation in this population.

Methods. Employees from 45 companies in The Netherlands $(n=12,140)$ were prospectively followed up from 1998 onward by annual questionnaires. Data covering 10 years of follow-up was available (1998-2008) for rheumatic and cardiovascular morbidities. Selfreported rheumatic and cardiovascular diseases were verified by clinical review in hospital records in a subsample living in 1 specific region of The Netherlands. Information on the vital status was obtained by linking our records to national registries. Cox proportional hazards models were used to determine the contribution of cardiovascular comorbidity on mortality, with adjustment for confounders.

Results. In the sample verified by clinical review, the 10-year risk of developing cardiovascular diseases tended to be increased in workers with inflammatory rheumatic diseases ( $n=17$ ) at baseline (relative risk, 2.30; 95\% confidence interval [Cl], 0.91-5.81) and was significantly increased in those with gout $(n=18)$ at baseline (relative risk, 3.64; $95 \% \mathrm{Cl}, 1.64-8.09$ ) as compared with those without inflammatory rheumatic diseases or gout, respectively. Gout ( $n=31$; hazard ratio, 4.19; $95 \% \mathrm{Cl}$. 1.33-13.25) and cardiovascular diseases ( $n=206$; hazard ratio, 2.19; 95\% Cl, 1.24-3.84) were significantly related to 10-year mortality. No deaths had occurred in individuals with inflammatory rheumatic diseases during follow-up.

Conclusions. In this study, gout was significantly associated with cardiovascular comorbidity and mortality, but inflammatory rheumatic diseases were not. Decreased work participation in workers with gout and potentially inflammatory rheumatic diseases can be expected because of an increased morbidity but not mortality risk. 


\section{INTRODUCTION}

The systemic inflammation in patients with inflammatory rheumatic diseases (e.g. rheumatoid arthritis [RA]) can contribute to a series of comorbidities of which the cardiovascular diseases (CVDs) are the most important.1-3 Patients with inflammatory rheumatic diseases have an increased risk of developing coronary artery disease or other CVDs. A meta-analysis of 24 studies indicated that the cardiovascular mortality is increased by $50 \%$ in patients with RA in comparison to the general population. ${ }^{4}$ Similar numbers have been found for ankylosing spondylitis, psoriatic arthritis, and gout, although there is less evidence available in the literature. ${ }^{5.6}$ Increased cardiovascular mortality is 1 of the main reasons to explain the age-dependent mortality gap between persons with inflammatory rheumatic diseases and the general population.7.8 Previous studies on increased cardiovascular mortality in patients with inflammatory rheumatic diseases have been performed in clinical cohorts, defining patients with relatively severe disease. Working individuals with inflammatory rheumatic diseases may have a milder disease course ("healthy worker effect"), and consequently, the prevalence of cardiovascular comorbidities could be lower. Along this line, it is unknown to what extent these cardiovascular comorbidities in such a working population with inflammatory diseases predispose for higher levels of mortality. We have recently shown that cardiovascular comorbidities were not associated with increased sick leave and work disability in those individuals with rheumatic diseases who remain at work. ${ }^{9}$ However, if premature mortality in those working individuals indeed occurs, it may help explain why persons with inflammatory rheumatic diseases may get lost for labor force during their working life. The occurrence of cardiovascular comorbidities and its impact on premature mortality in workers with inflammatory rheumatic diseases has not been studied until now. Therefore, this study aims to evaluate the increased risk of cardiovascular comorbidity and mortality in workers with inflammatory rheumatic diseases and to explore whether premature mortality may be an epidemiologic explanation of reduced work participation. 


\section{MATERIALS AND METHODS}

\section{Study Population}

Data from the ongoing Maastricht Cohort Study (MCS) that started in 1998 as a prospective cohort study among a large heterogeneous population of 12,140 employees from 45 different companies in The Netherlands were used. At baseline, employees from 687 different professions were working in different sectors and trades in The Netherlands, and this group has been followed up for more than 10 years by means of extensive, annual self-administered questionnaires. ${ }^{10}$ Employees with a temporary contract at the baseline measurement were excluded from the cohort because they may change jobs frequently. Foreigners and emigrants were excluded from the analyses because mortality data could not be acquired. After 10 years, 6069 study participants (50\%) were lost to follow-up for the questionnaires (mainly for unknown reasons $[n=5777]$ ). However, it is of importance to notice that the loss to follow-up for the mortality end point was much lower because data on the cause of death could be retrieved from the Dutch mortality register (see Ascertainment of Mortality Outcome). The MCS protocol is approved by the "Medisch Ethische Commissie azM/UM" under number MEC 08-4-032. All study participants gave written informed consent at the start of the study. The exact outline of the study design has been described elsewhere. ${ }^{10}$

\section{Assessment of Exposure Variables}

For this study, data from the questionnaires that were sent from May 1998 to October 2008 were used. Data on demographics, work-related factors, domestic and social factors, individual characteristics, and present morbidities were obtained annually by means of an extensive, self-administered questionnaire. The timing of the questionnaires is described in more detail in another publication.11

Using the May 1998 questionnaire, study participants with self-reported rheumatic or CVD at baseline were identified based on a positive response to the following checklist items: (1) rheumatism, arthritis of the hands or feet, osteoarthritis of the hips, knees, or hands (yes/no); (2) heart disease, myocardial infarction, or hypertension (yes/no); (3) (effects of ) stroke (yes/ no). The October 2008 questionnaire was used to identify incident disease retrospectively and consisted of the following checklist items: (1) arthritis or rheumatic disease (yes/no), (2) heart disease (yes/no), (3) (effects of ) stroke or brain infarction (yes/no).

\section{Ascertainment of Mortality Outcome}

The Dutch electronic municipality population registries were used to assess the vital status of the workers that were included in this study until December 2010. Another route for identification of vital status was by consulting a special registry for persons living in The 
Netherlands who had left The Netherlands by emigrating and reimmigrating. By linking the cohort data with the death certificate data that are stored at the Central Bureau of Statistics, we were able to retrieve the data on individual causes of death for all deceased study participants. Only the emigrated study participants were lost for that end point ( $n$ = 175). For all deceased workers, the cause of death was identified in this database and used for on-site analysis.

\section{Disease Verification}

For employees living in South Limburg ( $n=6103$ [50\%]), verification of self-reported rheumatic and CVD was sought by reviewing the electronic hospital records of the 3 hospitals in this region, including 1 academic hospital and 2 peripheral teaching hospitals. Self-reported rheumatic and CVDs in this specific region were verified because, based on the used checklist items, we were neither able to determine whether study participants had an inflammatory or a noninflammatory rheumatic condition, nor were we able to determine which specific cardiovascular condition they had. A diagnosis of psoriatic arthritis, RA, ankylosing spondylitis, gout, osteoarthritis, or fibromyalgia and a date of diagnosis were recorded if this was present in the electronic hospital records. Other rheumatologic diseases were excluded, as the prevalence of these conditions in this prospective cohort was too low for analysis. Similarly, diagnoses of nonhemorrhagic cerebrovascular accident, including stroke and coronary heart disease, such as myocardial infarction and coronary atherosclerosis, and the date of diagnosis were also recorded if present. Cardiovascular diseases that were considered unrelated to atherosclerosis, such as arrhythmias, were excluded. In addition, a random and representative sample of 200 hospital records of study participants who did not self-report either rheumatic or cardiovascular conditions was examined to investigate the false-negative rate of selfreport.

\section{Statistical Analysis}

The risk of developing CVD during follow-up was expressed as a relative risk (RR) with 95\% confidence interval ( $95 \% \mathrm{Cl}$ ). The additional mortality risk due to the presence of CVD at baseline was analyzed using Cox proportional hazards models with adjustment for variables that were identified as potentially confounding factors, comprising age, gender, educational level, weekly exercise, body mass index, and smoking. This analysis was first performed using baseline data based on self-report from all study participants $(n=12,140)$. Subsequently, analyses were limited to the subpopulation in which we have verified the self-reported morbidities in the electronic hospital records ( $n=6103$ ), by including incident diseases as time-dependent covariates in the model. The modeling of this time-dependent exposure was done as described by Ake and Carpenter. ${ }^{12}$ Gout was analyzed separately because the relationship between gout and CVD is considered 
to be different ("lifestyle") than the relationship between CVD and autoimmune rheumatic diseases. In the performed analyses, inflammatory rheumatic diseases included RA, ankylosing spondylitis, and psoriatic arthritis. If possible, 95\% Cls were calculated. SPSS version 15.0 (IBM Corp, Armonk, NY) (descriptive statistics) and SAS version 9.0 (SAS Institute Inc, Cary, NC) (Cox proportional hazards models) were used to analyze the data. 


\section{RESULTS}

A total of 12,140 employees aged between 18 and 65 years from 45 different companies and organizations in The Netherlands participated in this study. The subpopulation living in the region of South Limburg that was used to verify self-reported rheumatic and CVD consisted of 6103 working individuals (50\%). Self-reported rheumatic diseases and CVDs of these individuals were verified in the electronic hospital records. Study participants with self-reported rheumatic diseases at baseline were older, had lower education levels, and had more (cardiovascular) comorbidities present compared with study participants in the MCS without self-reported rheumatic diseases. In total, 144,240 person-years of follow-up were available for the mortality analyses in the entire cohort. Similarly, 75,420 person-years of follow-up were available in the subpopulation with verified data from the electronic hospital records (Table 1).

Table 1. Baseline Characteristics of Study Participants in the MCS

\begin{tabular}{|c|c|c|}
\hline Variable & $\begin{array}{l}\text { Total Cohort } \\
(n=12,140)\end{array}$ & $\begin{array}{l}\text { Self-Reported } \\
\text { Rheumatic Disease } \\
(n=514)\end{array}$ \\
\hline \multicolumn{3}{|l|}{ Individual characteristics } \\
\hline Age, mean (SD), y & $41.0(8.9)$ & $45.4(8.1)$ \\
\hline Male & $8874(73.1)$ & $352(68.4)$ \\
\hline \multicolumn{3}{|l|}{ Highest educational level } \\
\hline Low & $3899(33.1)$ & $237(48.6)$ \\
\hline Medium & $3819(32.5)$ & $166(34.0)$ \\
\hline High & $4051(34.5)$ & $85(17.5)$ \\
\hline \multicolumn{3}{|l|}{ Lifestyle-related factors } \\
\hline \multicolumn{3}{|c|}{ Frequency of weekly exercise } \\
\hline o-1 times & $4001(33.2)$ & $209(40.8)$ \\
\hline $2-7$ times & $7231(59.9)$ & $272(53.1)$ \\
\hline$>7$ times & $832(6.9)$ & $31(6.1)$ \\
\hline \multicolumn{3}{|c|}{ Alcohol consumption per week } \\
\hline o glasses & $3239(26.9)$ & $167(32.6)$ \\
\hline 1-14 glasses & $7471(61.9)$ & $297(58.0)$ \\
\hline 15-21 glasses & $1000(8.3)$ & $32(6.3)$ \\
\hline$>22$ glasses & $352(2.9)$ & $16(3.1)$ \\
\hline Smoking & $3322(27.4)$ & $176(34.4)$ \\
\hline \multicolumn{3}{|l|}{ Health-related factors } \\
\hline History of CVD & $639(5.3)$ & $73(14.2)$ \\
\hline Other chronic diseases & $2848(24.1)$ & $445(86.6)$ \\
\hline
\end{tabular}

Values are $n$ (percentages) unless otherwise indicated. 


\section{Medical Chart Verification of Self-reported Diseases}

Of the 512 individuals who reported the presence of rheumatic disease at baseline, 315 (5.2\% of the total cohort) lived in the area of South Limburg and were accessible for hospital record verification. Of these, 17 individuals had a diagnosis of inflammatory rheumatic disease, and 18 had at least 1 episode of gout documented in the medical history. During follow-up, an additional 18 individuals were diagnosed with a new inflammatory rheumatic disease, and another 13 individuals had at least 1 episode of gout.

Similar results were found for self-reported CVDs at baseline. Of the 338 (5.5\% of the total cohort) participants living in South Limburg in whom a self-reported diagnosis of CVD could be verified, we verified 5 individuals with stroke and 64 with CVDs based on atherosclerosis. Of those who reported a new CVD during follow-up, 20 individuals developed clinically manifest stroke, and an additional 117 individuals developed clinically manifest CVD. There were no false-negative cases of inflammatory rheumatic disease or CVD in the random sample of 200 individuals who did not self-report these conditions.

\section{Cardiovascular Risk Analyses}

Among study participants who self-reported rheumatic disease at baseline, the RR of developing self-reported CVD during follow-up was statistically significantly increased (RR, 1.61; 95\% Cl, 1.03-2.50)( $p=0.04)$, as compared with individuals without self-reported rheumatic diseases (Table 2). This finding is interesting because the self-reported conditions included both inflammatory and noninflammatory rheumatic conditions, and only for the inflammatory rheumatologic conditions an association with cardiovascular conditions is known. In the workers with verified inflammatory rheumatic diseases, the development of clinically manifest CVDs during follow-up was also increased ( $n=17$; RR, 2.30; 95\% Cl, 0.91-5.81), but this increase did not reach statistical significance $(p=0.08$ ). Workers who had verified gout at baseline had a significantly increased risk of developing CVD during follow-up ( $n=18 ; \mathrm{RR}, 3.64 ; 95 \% \mathrm{Cl}, 1.64-8.09)(p=0.002)$ (Table 2).

\section{Mortality Risk Analyses}

Table 3 shows the mortality risk after 12.6 years of follow-up for the self-reported diseases in the entire cohort $(n=12,140$ ) as well as for the verified diseases in the subsample verified by clinical review. The following variables were identified as potentially confounding factors in the analyses: age, gender, educational level, smoking, body mass index, and weekly exercise. 
Table 2. Risk of Incident CVD in Workers With Rheumatic Disease as Compared With Workers Without Rheumatic Disease

\begin{tabular}{lllll}
\hline Disease & $\boldsymbol{n}$ & $\mathbf{H R}^{\mathbf{a}}$ & $\mathbf{9 5 \%} \mathbf{C l}$ & $\boldsymbol{p}$ \\
\hline Self-reported rheumatic disease $^{\mathrm{b}}$ & 441 & 1.61 & $1.03-2.50$ & 0.04 \\
Verified rheumatic diseasec $^{c}$ & & & & \\
$\quad$ Inflammatory rheumatic disease & & & & \\
$\quad$ Gout & 17 & 2.30 & $0.91-5.81$ & 0.08 \\
\hline
\end{tabular}

${ }^{a}$ Adjusted for gender, age, educational level, smoking, body mass index, and weekly exercise.

${ }^{\text {bDenominator }}=12,140$.

'Denominator $=6103$

ancludes RA, ankylosing spondylitis, and psoriatic arthritis.

Table 3. Risk of Mortality in Workers With Self-reported or Verified Diseases in the MCS, as Compared With Workers Without Self-reported or Verified Diseases

\begin{tabular}{|c|c|c|c|c|c|c|c|}
\hline \multirow[b]{2}{*}{ Disease } & \multirow[b]{2}{*}{$n$} & \multicolumn{3}{|c|}{ Unadjusted } & \multicolumn{3}{|c|}{ Adjusted $^{\mathrm{a}}$} \\
\hline & & HR & $95 \% \mathrm{Cl}$ & $P$ & HR & $95 \% \mathrm{Cl}$ & $p$ \\
\hline \multicolumn{8}{|l|}{ Self-reported diseases ${ }^{b}$} \\
\hline Rheumatic disease & 441 & 1.25 & $0.74-2.09$ & 0.41 & 0.77 & $0.41-1.46$ & 0.43 \\
\hline CVD & 566 & 2.92 & $2.09-4.08$ & $<0.001$ & 1.58 & $1.08-2.31$ & 0.02 \\
\hline Rheumatic disease and CVD & 73 & 2.40 & $0.90-6.45$ & 0.08 & 1.31 & $0.49-3.54$ & 0.90 \\
\hline \multicolumn{8}{|l|}{ Verified diseases ${ }^{c}$} \\
\hline Inflammatory rheumatic disease ${ }^{d}$ & 35 & $\mathrm{~N} / \mathrm{A}$ & & & $N / A$ & & \\
\hline Gout & 31 & 4.48 & $1.43-14.03$ & 0.01 & 4.19 & $1.33-13.25$ & 0.01 \\
\hline CVDs & 206 & 4.36 & $2.60-7.31$ & $<0.001$ & 2.19 & $1.24-3.84$ & 0.007 \\
\hline
\end{tabular}

${ }^{a}$ Adjusted for gender, age, educational level, smoking, body mass index, and weekly exercise.

benominator $=12,140$.

'Denominator $=6103$

Includes RA, ankylosing spondylitis, and psoriatic arthritis.

N/A indicates not available.

\section{Self-reported Diseases}

Study participants with only self-reported rheumatic disease $(n=441)$ at baseline did not have an increased mortality (hazard ratio [HR], 0.77; 95\% Cl, 0.41-1.46), as compared with persons without self-reported rheumatic disease at baseline.

In study participants with only self-reported CVD at baseline $(n=566)$, mortality was significantly increased (HR, 1.58; 95\% Cl, 1.08-2.31) in comparison to study participants without self-reported CVD at baseline. In study participants with both self-reported rheumatic disease and self-reported CVD at baseline $(n=73)$, mortality was not significantly increased ( $\mathrm{HR}, 1.31 ; 95 \% \mathrm{Cl}, 0.49-3.54)$ 


\section{Verified Diseases}

No deaths were observed during follow-up in study participants with (nongouty) inflammatory rheumatic diseases. After adjusting for the previously mentioned confounding factors, mortality was significantly increased in study participants with gout (HR, 4.19; 95\% Cl, 1.33-13.25) and in those with CVDs (HR, 2.19; 95\% Cl, 1.24-3.84), as compared with workers without gout or CVDs, respectively. Because no deaths had occurred in participants with inflammatory rheumatic diseases, the interaction of cardiovascular comorbidity and mortality could not be tested. 


\section{DISCUSSION}

The aim of this study was to evaluate the increased cardiovascular risk among working individuals with rheumatic diseases, more specifically in those with inflammatory rheumatic diseases (i.e. RA, ankylosing spondylitis, and psoriatic arthritis). In this cohort including working individuals, we have found that gout is associated with incident CVDs, but the results did not reach statistical significance in inflammatory rheumatic diseases. Our findings indicate that, although the cardiovascular risk may be increased in these individuals, inflammation has not importantly contributed to increased mortality during the course of this study. A second aim of this study was to explore whether premature mortality during follow-up has an impact on work participation. Because of low levels of mortality during the course of this study, it is highly unlikely that premature mortality could be an explanation for reduced work participation in this study.

Several reasons might explain why our results did not reach statistical significance. First, in the verified sample, the number of identified persons with inflammatory rheumatic diseases, gout, and CVDs in the hospital records was lower than expected and may have resulted in insufficient statistical power (type II error). Alternatively, the systemic inflammation present in inflammatory rheumatic diseases that may accelerate the process of atherosclerosis, an important cause of coronary artery disease and stroke, takes years to evolve into clinically manifest CVDs and possibly death. ${ }^{13}$ Therefore, the follow-up period might have been insufficient for workers with inflammatory rheumatic diseases to develop these diseases. Finally, it is very likely that patients with most severe disease have not been included in this cohort because they were already lost for labor force (left censorship), leaving a population of workers with relatively mild inflammatory disease. 14.15 This hypothesis is in line with data from the literature showing that the risk of work disability is highest in the first 3 to 5 years after diagnosis and is related to the severity of the disease. ${ }^{16,17}$

Several studies have reported that cardiovascular mortality is significantly increased in patients with inflammatory rheumatic diseases, primarily due to coronary artery disease. ${ }^{4.5}$ Most likely, those figures do not stem from patients with RA who are still at work. Our study was performed in a cohort of relatively healthy workers, including those with manifest (inflammatory) rheumatic diseases and CVDs. The prevalence of these diseases at baseline and the incidence during follow-up were relatively low, and it is likely that "our workers" had relatively mild disease.

Our study has some strengths and limitations that need to be acknowledged. The MCS was not originally designed for this type of study, and consequently, the information collected through the self-administered questionnaires relevant for this study was brief. 
not validated and not specific and therefore requiring verification. Because $50 \%$ of the study participants lived in South Limburg, a small region in The Netherlands that is covered by 3 hospitals, verification in the electronic hospital records was feasible. Differences in baseline characteristics between this specific region and the entire MCS were not found (data not shown), indicating that the sample was representative. It is common in The Netherlands that persons with rheumatic or CVDs are referred to a secondary care physician in a hospital nearby. Therefore, we expected that study participants would attend a secondary care physician in the same region in line with the Dutch healthcare system. Although highly unlikely, patients are not bound to their region of residence and could have attended a physician in another part of The Netherlands. This would have resulted in an underestimation of the prevalence and incidence of study participants with verified rheumatic diseases or CVDs. Another issue of potential relevance is the exposure and outcome misclassification between the self-reported and verified diseases. Especially the baseline questions regarding the self-reported diseases may have overestimated the prevalence of the diseases of interest, because the baseline questions included hypertension and nonspecific joint problems that were not of interest for this study. Reassuringly, though, similar trends were seen in the self-reported and verified results, and it is therefore unlikely that such a misclassification has affected our results substantially.

Studies reporting an association between inflammatory diseases and cardiovascular consequences focus on patients with manifest and severe inflammatory disease, which may not always be an appropriate reflection of the usual clinical practice. Many patients with well treated inflammatory and gouty disease nowadays keep working, because the status of their disease allows them to do so. Our study has been performed in those patients with relatively less severe diseases, which were all still at work at baseline, and has demonstrated that the relationship between inflammatory rheumatic disease and cardiovascular consequences that currently receives much attention may have mitigated effects in populations of patients affected by milder forms or with better treatments, so that they keep working.

In conclusion, the incidence of cardiovascular comorbidities in working persons with inflammatory rheumatic diseases was not significantly increased and was not associated with higher mortality rates after more than 10 years. Cardiovascular comorbidities were significantly associated with gout and increased the 10-year mortality risk. It is likely that a large proportion of work loss due to disabling diseases has taken place before the start of this prospective cohort as the most affected workers already left the workforce (left censorship bias due to "healthy worker effects"). The impact of comorbidity and premature mortality on work participation in rheumatic diseases has been neglected until now but warrants more attention. 


\section{REFERENCES}

1. Michaud K,Wolfe F. Comorbidities in rheumatoid arthritis. Best Pract Res Clin Rheumatol 2007:21:885-906

2. Bisoendial RJ, Stroes ES, Tak PP. Where the immune response meets the vessel wall. Neth J Med 2009;67:328-333.

3. Gabriel SE, Michaud K. Epidemiological studies in incidence, prevalence, mortality, and comorbidity of the rheumatic diseases. Arthritis Res Ther 2009;11:229.

4. Aviña-Zubieta JA, Choi HK, Sadatsafavi M, et al. Risk of cardiovascular mortality in patients with rheumatoid arthritis: a meta-analysis of observational studies. Arthritis Rheum 2008:59:16901697.

5. Roifman I, Beck PL, Anderson TJ, et al. Chronic inflammatory diseases and cardiovascular risk: a systematic review. Can J Cardiol 2011:27:174-182.

6. Jamnitski A, Visman IM, Peters MJ, et al. Prevalence of cardiovascular diseases in psoriatic arthritis resembles that of rheumatoid arthritis. Ann Rheum Dis 2011;70:875-876.

7. Gonzalez A, Maradit Kremers H, Crowson CS, et al. The widening mortality gap between rheumatoid arthritis patients and the general population. Arthritis Rheum 2007:56:3583-3587.

8. Gabriel SE.Why do people with rheumatoid arthritis still die prematurely? Ann Rheum Dis 2008:67(Suppl 3):iii30-iii34.

9. van der Burg LR, Boonen A, van Amelsvoort LG, et al. The effects of cardiovascular comorbidities on work participation in rheumatic diseases: a prospective cohort study among working individuals. Arthritis Care Res (Hoboken) 2014;66:157-163.

10. Kant IJ, Bültmann U, Schröer KA, et al. An epidemiological approach to study fatigue in the working population: the Maastricht Cohort Study. Occup Environ Med 2003;60(Suppl 1):i32-i39.

11. Driesen $\mathrm{K}$, Jansen NW, van Amelsvoort LG, et al. The mutual relationship between shift work and depressive complaints-a prospective cohort study. Scand J Work Environ Health 2011;37:402410 .

12. Ake CF, Carpenter AL. Extending the use of PROC PHREG in survival analysis.2003. Available at: http://www.caloxy.com/papers/51-ExtendingPHREG.pdf\%5D. Accessed July 21, 2014

13. Radovits BJ, Fransen J, Al Shamma S, et al. Excess mortality emerges after 10 years in an inception cohort of early rheumatoid arthritis. Arthritis Care Res (Hoboken) 2010;62:362-370.

14. Pearce N, Checkoway H, Kriebel D. Bias in occupational epidemiology studies. Occup Environ Med 2007:64:562-568.

15. Li CY, Sung FC. A review of the healthy worker effect in occupational epidemiology. Occup Med (London) 1999:49:225-229.

16. Barrett EM, Scott DG, Wiles NJ, et al. The impact of rheumatoid arthritis on employment status in the early years of disease: a UK community-based study. Rheumatology (Oxford) 2000;39:14031409 .

17. Fex E, Larsson BM, Nived $\mathrm{K}$, et al. Effect of rheumatoid arthritis on work status and social and leisure time activities in patients followed 8 years from onset. J Rheumatol 1998:25:44-50. 



\section{EFFECTS OF CARDIOVASCULAR COMORBIDITIES ON WORK PARTICIPATION IN RHEUMATIC DISEASES: A PROSPECTIVE COHORT STUDY AMONG WORKING INDIVIDUALS}

Lennart R.A. van der Burg Annelies Boonen

Ludovic G.P.M. van Amelsvoort

Nicole W.H. Jansen

Robert B.M. Landewé

IJmert Kant

Arthritis Care \& Research (Hoboken) 2014;66:157-63 


\section{ABSTRACT}

Objective. To determine the risk of sick leave and work disability in relation to rheumatic diseases and cardiovascular comorbidities among working individuals.

Methods. Employees $(n=12,140$ ) from 45 companies in The Netherlands were prospectively followed up from 1998-2008. Questionnaires were used to assess selfreported diseases and employment status. Company records provided individual sick leave data for the first 2.5 years of follow-up. For a selected sample of the cohort (50\%), verification of self-reported diseases was sought through hospital record linkage. Poisson regressions and Cox proportional hazards models were applied to determine the impact of both self-reported and verified diseases on sick leave and work disability, respectively.

Results. The number of days and frequency of sick leave were increased in working individuals with self-reported rheumatic and cardiovascular disease $(p<0.001$ ), but self-reported cardiovascular comorbidity did not result in more sick leave in those who also self-reported rheumatic disease. Work disability was also increased for both selfreported rheumatic disease and cardiovascular disease $(p<0.001)$, but again, no additive effects were found. In the sample verified by clinical review, the frequency or number of days of sick leave was significantly higher in employees with cardiovascular disease ( $p<$ 0.001 ), inflammatory rheumatic disease $(p<0.05)$, and osteoarthritis $(p<0.05)$ compared to employees without these diseases. Work disability in the verified sample occurred especially in patients with osteoarthritis (hazard ratio [HR] 12.36 [95\% confidence interval (95\% Cl) 1.59-13.66]), fibromyalgia (HR 14.24 [95\% Cl 2.02-16.54]), and cardiovascular disease (HR 4.88 [95\% Cl 1.70-14.01]).

Conclusion. Rheumatic and cardiovascular diseases increased the risk of sick leave and work disability in a working population, but there was no indication that these effects convey an additive risk. 


\section{INTRODUCTION}

Rheumatic diseases are an important cause of sick leave and work disability in almost all Western societies. ${ }^{1-4}$ Most studies have investigated individuals with inflammatory rheumatic diseases, such as rheumatoid arthritis and ankylosing spondylitis, while fewer data are available about sick leave and work disability in people with osteoarthritis, fibromyalgia, or gout. ${ }^{5}$ The lack of research in these areas is surprising because the prevalence of these diseases is higher than the prevalence of inflammatory rheumatic diseases and as such, their societal burden might be higher. ${ }^{6} \mathrm{~A}$ better understanding of the impact of different rheumatic diseases on sick leave and work disability may result in an improved ability to identify and help those at risk for adverse work outcomes.

Cardiovascular diseases (CVDs) are common in the general population and are associated with a substantial burden. It is recognized that CVDs (e.g. myocardial infarction and stroke) are increased in inflammatory rheumatic diseases, ${ }^{7-10}$ but such an association has not yet been studied for osteoarthritis and fibromyalgia. Although it seems probable that cardiovascular comorbidities in people with rheumatic disease would have an adverse effect on work outcomes, there are almost no published studies in the literature on this topic. Only 1 previous study suggested that cardiovascular comorbidities have a small but significant adverse influence on employment in persons with arthritis or other rheumatic diseases. ${ }^{11}$ However, it remains unclear how extensive this possible impact is or which subgroups experience the most cardiovascular comorbidity. We hypothesized that cardiovascular comorbidities will have a significant additional impact on work outcomes in people with rheumatic disease, with a greater impact in those with inflammatory rheumatic disease because inflammation enhances atherosclerosis. ${ }^{12}$ If this hypothesis is true, it would justify additional attention being given to preventive CVD measures in people with rheumatic disease because the burden of CVD may be partly preventable. The aim of this study was to determine the risk of sick leave and work disability in employed individuals with rheumatic disease (i.e. inflammatory and noninflammatory) and to explore the contribution of cardiovascular comorbidity to the risk of sick leave and work disability. 


\section{MATERIALS AND METHODS}

\section{Study population}

The ongoing Maastricht Cohort Study (MCS) was started in 1998 as a prospective cohort study among a large heterogeneous population of 12,140 employees from 45 different companies in The Netherlands. The MCS was originally assembled to study long-term fatigue and its consequences in terms of sick leave and work disability in a working population, but because of the broad range of exposure variables that were collected, these data are also valuable for studying the impact of other diseases on work outcomes. At baseline, employees from 687 different professions in The Netherlands were working in different sectors and trades, and this group was followed up for 10 years by means of extensive self-administered questionnaires. ${ }^{13.14}$ Employees with a temporary contract at the baseline measurement were excluded from the study because they may change jobs frequently. After 10 years, 6,069 study participants (49.8\%) were lost to follow-up partly because of mortality ( $n=292$ ), but for the most part for unknown reasons ( $n=5.777)$. The longitudinal nonresponse was not related to reporting a rheumatic disorder at baseline (nonresponse $=50.0 \%$ ). All study participants gave written informed consent at the start of the study. A detailed outline of the study design has been described elsewhere. ${ }^{14}$

\section{Questionnaire data}

Data on demographics, work-related factors, domestic and social factors, and present morbidities were obtained yearly by means of an extensive self-administered questionnaire. Furthermore, between 1998 and 2001, the study participants completed 2 additional smaller questionnaires each year. The questionnaire data were available from May 1998 until the follow-up measurement in October 2008. The timing of the questionnaires is described in more detail in another publication. ${ }^{15}$

Using the May 1998 questionnaire, the study participants with self-reported rheumatic disease or CVD at baseline were identified based on a positive response to the following checklist items: 1) rheumatism, arthritis of the hands or feet, or osteoarthritis of the hips, knees, or hands (yes/no); 2) heart disease, myocardial infarction, or hypertension (yes/no); and 3) (effects of) stroke (yes/no). The October 2008 questionnaire was used to identify incident disease retrospectively and consisted of the following items: 1) arthritis or rheumatic disease (yes/no), 2) heart disease (yes/no), and 3) (effects of) stroke or brain infarction (yes/no).

\section{Assessment and definition of outcomes}

Company records provided individual data on sick leave for the first 2.5 years of follow-up and included the number of days and frequency of sick leave in 1 year. Sick leave data were available for 11,067 employees (91.2\%) in 1998, 9,101 employees (75.0\%) in 1999. 
and 7,610 employees (62.7\%) in 2000. Respondents on sick leave due to a work disability pension or maternity leave were not included in the calculation of sick leave. Work status, including the indication for a work disability pension, was determined prospectively through responses to questionnaires between May 1998 and October 2008. Work status was classified as 1) having a paid job, 2) being fully or partially work disabled, 3) being involuntarily unemployed, 4) not having a paid job, or 5) being retired from work. In The Netherlands, a person is entitled to receive a work disability pension if they have been unable to work either partially (35-80\% decrease in earnings) or fully (>80\% decrease in earnings) for 2 years. It is possible to receive a partial work disability pension and to remain employed, usually on a part-time basis. Before 2006, a person was entitled to receive a disability pension after being unable to work either partially (15-80\% decrease in earnings) or fully (>80\% decrease in earnings) for 1 year. ${ }^{16}$

\section{Disease verification}

For employees living in 1 specific region of The Netherlands ( $n=6,103$ [50\%]), verification of self-reported rheumatic disease and CVD was sought from electronic hospital records. This region is covered by 3 hospitals, including 1 academic hospital and 2 peripheral hospitals. Diagnoses of psoriatic arthritis, rheumatoid arthritis, ankylosing spondylitis, gout, osteoarthritis, or fibromyalgia and the date of the diagnosis were recorded if present in the electronic hospital records. Other rheumatologic conditions were excluded because the prevalence of these conditions in the MCS was too low to analyze. Similarly, diagnoses of nonhemorrhagic cerebrovascular accidents (including stroke) and coronary heart disease (such as myocardial infarction and coronary atherosclerosis) and their dates of diagnosis were also recorded if present. CVDs that were unrelated to the presence of atherosclerosis were excluded. In addition, a random and representative sample of 200 hospital records of study participants who did not self-report rheumatic or cardiovascular conditions was examined to investigate the false-negative rate of self-report.

\section{Statistical analysis}

The differences in the number of days and frequency of sick leave in 2.5 years across the different diagnostic subgroups were compared with data from employees without these diseases by using generalized models, assuming a Poisson distribution of the data with additional adjustment for age and sex, including an interaction term in the regression model testing specific interactions. Only preexisting conditions at the baseline measurement were examined in the analysis. Cox proportional hazards models were used to calculate the work disability risk after 10 years in diagnostic subgroups compared with cohort participants still at work. The potential confounders included in this model comprised sex, age, education level, smoking, body mass index, and weekly exercise. In addition, an analysis that included incident diseases as time-dependent covariates in 
the model was performed for the verified sample. The modeling of this time-dependent exposure was done as described by Ake and Carpenter. ${ }^{17}$ In this analysis, we adjusted the relationships studied for the time period in which study participants were at risk but not yet receiving disability pension (i.e. 1 year before 2006 and 2 years after 2006). If possible, 95\% confidence intervals (95\% Cls) were determined; otherwise, a significance level for all statistical tests was fixed at 0.05 (2-sided) to indicate statistical significance. SPSS, version 15.0 and SAS, version 9.0 were used to analyze the data. 


\section{RESULTS}

A total of 12,140 employees ages 18-65 years from 45 different companies and organizations in The Netherlands participated in this study, of which 6,103 employees (50.3\%) lived in South Limburg. The baseline characteristics of study participants from the entire cohort are shown in Table 1. Study participants with self-reported rheumatic diseases at baseline were older, had a lower level of education, had more comorbidities, had more problems at work due to health issues, and had a higher proportion of (perceived) physically demanding jobs as compared with the MCS cohort (Table 1). After 2 years of follow-up, 61 individuals (0.6\%) reported they were receiving either a full or partial work disability pension, and this number further increased to $68(0.8 \%)$ and 131 (2.2\%) after 5 and 10 years, respectively. For the work disability analysis, we observed 40,350 person-years of follow-up for the entire cohort $(n=12,140)$ and 23,442 personyears for the subsample verified in the hospital records $(n=6,103)$.

\section{Analysis in individuals with self-reported diseases}

Sick leave. The mean percentage of days on sick leave among the possible calendar days in 2.5 years between May 1998 and December 2000 was significantly increased in persons with self-reported rheumatic disease (mean 10.8\%) and CVD (mean 9.2\%) at baseline, as compared to individuals without those diseases (mean 5.2\%) (Table 2). The mean frequency of sick leave episodes per year was significantly increased for self-reported rheumatic disease (mean 1.2 times per year) and CVD (mean 1.2 times per year) compared to individuals without these diseases (mean 1.0 times per year; $p<0.001$ ). No significant differences were observed between workers with a self-reported rheumatic disease and workers with a self-reported rheumatic disease and a self-reported cardiovascular comorbidity, neither for the percentage of days on sick leave (mean 14.4 days; $p=0.06$ ) nor for the frequency of sick leave (mean 1.3 times per year; $p=0.50$ ).

Work disability. Table 3 shows the work disability risk after 10 years for the self-reported diseases before and after adjusting for the following confounding factors: sex, age (per year), education level, smoking, body mass index, and weekly exercise. The risk to be work disabled after 10 years was significantly increased in employees with self-reported rheumatic disease (hazard ratio [HR] 6.8 [95\% Cl 3.9-11.9]) or CVD (HR 4.2 [95\% Cl 2.3-7.6]) at baseline, as compared to individuals without those diseases at baseline (Table 3). Self-reported cardiovascular comorbidity did not further increase the work disability risk after 10 years in persons with self-reported rheumatic disease (HR 4.3 [95\% Cl 1.0-17.9]). 
Table 1. Baseline characteristics of study participants in the Maastricht Cohort Study*

\begin{tabular}{|c|c|c|}
\hline & $\begin{array}{l}\text { Total cohort } \\
(n=12,140)\end{array}$ & $\begin{array}{l}\text { Self-reported } \\
\text { rheumatic disease } \\
(n=514) t\end{array}$ \\
\hline \multicolumn{3}{|l|}{ Individual characteristics } \\
\hline Age, mean $\pm S D$ years & $41.0 \pm 8.9$ & $45.4 \pm 8.1$ \\
\hline Men, \% & 73.1 & 68.4 \\
\hline \multicolumn{3}{|l|}{ Highest education level } \\
\hline Low & $3.899(33.1)$ & $237(48.6)$ \\
\hline Medium & $3.819(32.5)$ & $166(34.0)$ \\
\hline High & $4,051(34.5)$ & $85(17.4)$ \\
\hline \multicolumn{3}{|l|}{ Health-related factors } \\
\hline History of cardiovascular disease or hypertension & $639(5.3)$ & $73(14.2)$ \\
\hline Other comorbiditiesł & $2,848(24.1)$ & 445 (86.6) \\
\hline \multicolumn{3}{|l|}{ Work-related factors } \\
\hline \multicolumn{3}{|l|}{ Working hours/week§ } \\
\hline$>40$ & $2,421(20.1)$ & $76(14.9)$ \\
\hline $36-40$ & $6.444(53.5)$ & $278(54.4)$ \\
\hline $26-35$ & $1,765(14.7)$ & $66(12.9)$ \\
\hline $16-25$ & $1,207(10.0)$ & $75(14.7)$ \\
\hline$<16$ & $202(1.7)$ & $16(3.1)$ \\
\hline \multicolumn{3}{|l|}{ Problems at work due to health issues } \\
\hline Yes & $3.054(25.4)$ & $307(60.4)$ \\
\hline No & $8.950(74.6)$ & $201(39.6)$ \\
\hline \multicolumn{3}{|l|}{ Overall work experience, years } \\
\hline$<5$ & $774(6.4)$ & $5(1.0)$ \\
\hline $5-10$ & $1,577(13.0)$ & $37(7.2)$ \\
\hline $11-20$ & $4,128(34.1)$ & $126(24.7)$ \\
\hline$>20$ & $5.626(46.5)$ & $343(67.1)$ \\
\hline \multicolumn{3}{|l|}{ Physically demanding job } \\
\hline Yes & $3,123(26.0)$ & 236 (46.0) \\
\hline No & $8.905(74.0)$ & $277(54.0)$ \\
\hline
\end{tabular}

\footnotetext{
* Values are number (percentage) unless otherwise indicated.
}

+ Self-reported rheumatic disease at baseline was defined as rheumatism, arthritis of the hands or feet, or osteoarthritis of the hips, knees, or hands.

* Other large groups of comorbidities were chronic back pain (29.0\%), migraine (10.3\%), psychological problems (9.1\%), and asthma (8.8\%).

§ Working hours/week excludes overtime work. 
Table 2. Percentage and frequency of sick leave in employees with self-reported or verified diseases at baseline between May 1998 and December 2000 in the Maastricht Cohort Study

\begin{tabular}{|c|c|c|c|}
\hline Diagnosis at baseline & $n$ & $\begin{array}{l}\text { Percentage } \\
\text { in } 2.5 \text { years, } \\
\text { mean } \pm S D\end{array}$ & $\begin{array}{l}\text { Frequency } \\
\text { per year, } \\
\text { mean } \pm S D\end{array}$ \\
\hline \multicolumn{4}{|l|}{ Self-reported disease } \\
\hline No disease & 9,270 & $5.2 \pm 10.5$ & $1.0 \pm 1.2$ \\
\hline Rheumatic diseases & 368 & $10.8 \pm 16.7^{*}$ & $1.2 \pm 1.4^{*}$ \\
\hline Cardiovascular diseases & 460 & $9.2 \pm 14.9^{*}$ & $1.2 \pm 1.3^{*}$ \\
\hline Rheumatic and cardiovascular diseases & 58 & $14.4 \pm 18.3$ & $1.3 \pm 1.2$ \\
\hline \multicolumn{4}{|l|}{ Verified disease } \\
\hline No disease & 5,267 & $6.8 \pm 12.3$ & $1.1 \pm 1.2$ \\
\hline Rheumatic diseases & 57 & $11.0 \pm 15.5 t$ & $1.2 \pm 1.7$ \\
\hline Inflammatory rheumatic diseasesł & 13 & $11.6 \pm 18.8$ & $1.8 \pm 2.8 t$ \\
\hline Gout & 13 & $9.5 \pm 13.8$ & $1.1 \pm 1.2$ \\
\hline Osteoarthritis & 21 & $13.5 \pm 16.3 t$ & $1.0 \pm 0.9$ \\
\hline Fibromyalgia & 10 & $8.8 \pm 13.0$ & $1.3 \pm 1.5$ \\
\hline Cardiovascular diseases & 55 & $14.6 \pm 17.5^{*}$ & $1.6 \pm 1.6^{*}$ \\
\hline
\end{tabular}


Table 3. Work disability risk after 10 years for employed individuals with self-reported and verified diseases as comp

$n$

$\begin{array}{ll}\text { Self-reported disease } & \\ \text { Rheumatic diseases } & 441 \\ \text { Cardiovascular diseases } & 566 \\ \text { Rheumatic and cardiovascular diseases } & 73 \\ \text { Verified disease } & \\ \text { Rheumatic diseases } & 148 \\ \text { Inflammatory rheumatic diseasesł } & 35 \\ \text { Gout } & 31 \\ \text { Osteoarthritis } & 54 \\ \text { Fibromyalgia } & 28 \\ \text { Cardiovascular diseases } & 206\end{array}$

* $\mathrm{HR}=$ hazard ratio; $95 \% \mathrm{Cl}=95 \%$ confidence interval.

+ Adjusted for sex, age, education level, smoking, body mass index, and weekly exercise.

\# Includes rheumatoid arthritis, ankylosing spondylitis, and psoriatic arthritis.

\section{Medical chart verification of self-reported diseases}

Of the 512 individuals that reported rheumatic disease at baseline, 315 (5.2\% of the total cohort) lived in South Limburg and the diagnosis could be verified by hospital record review. Of these individuals, there were 17 with a diagnosis of inflammatory rheumatic disease, 27 with osteoarthritis, 13 with fibromyalgia, and 18 with 1 episode of gout documented in the medical history. During follow-up, an additional 18 individuals were diagnosed with an inflammatory rheumatic disease, 18 were diagnosed with osteoarthritis, 15 were diagnosed with fibromyalgia, and 13 had 1 episode of gout.

Similar results were found for self-reported CVDs at baseline. Of the 338 participants living in South Limburg in whom a self-reported diagnosis of CVD could be verified by hospital record review (5.5\% of the total cohort), we verified 5 individuals who had a stroke and 64 with CVD based on atherosclerosis. Of the individuals who reported a new CVD during follow-up, 20 developed clinically manifest stroke and an additional 117 developed clinically manifest CVD. There were no false-negative cases of either rheumatic disease or CVD among the 200 individuals who did not report these conditions. 
ared to individuals without those diseases in the Maastricht Cohort Study*

\begin{tabular}{|c|c|c|c|}
\hline Unadjusted & & Adjusted $\nmid$ & \\
\hline HR $(95 \% \mathrm{Cl})$ & $p$ & $\mathrm{HR}(95 \% \mathrm{Cl})$ & $p$ \\
\hline $6.91(4.22-11.32)$ & $<0.001$ & $6.76(3.86-11.86)$ & $<0.001$ \\
\hline $4.13(2.45-6.98)$ & $<0.001$ & $4.19(2.31-7.59)$ & $<0.001$ \\
\hline $4.13(1.02-16.76)$ & 0.05 & $4.29(1.03-17.88)$ & 0.02 \\
\hline $13.37(6.06-29.51)$ & $<0.001$ & $10.48(4.38-25.10)$ & $<0.001$ \\
\hline $6.82(0.945-49.21)$ & 0.06 & $8.43(1.14-62.41)$ & 0.04 \\
\hline $6.03(0.84-43.54)$ & 0.07 & 5.08 (0.69-37.69) & 0.11 \\
\hline $16.41(5.12-52.62)$ & $<0.001$ & $12.36(1.59-13.66)$ & 0.005 \\
\hline $25.42(6.14-105.19)$ & $<0.001$ & $14.24(2.02-16.54)$ & 0.001 \\
\hline $6.48(2.35-17.86)$ & $<0.001$ & $4.88(1.70-14.01)$ & 0.003 \\
\hline
\end{tabular}

\section{Analysis in individuals with verified diseases}

Sick leave. Among individuals with verified self-reported conditions, sick leave days as a percentage of the possible working days between May 1998 and December 2000 were significantly increased in people with verified rheumatic disease (mean $11.0 \%$ ) or verified CVD (mean 14.6\%) as compared to individuals without those diseases (mean $6.8 \%$ ). The annual frequency of sick leave was not significantly increased in individuals with verified rheumatic diseases (mean 1.2 times per year; $p=0.3$ ), while it was significantly increased in individuals with verified CVD (mean 1.6 times per year; $p<0.001$ ) and those with inflammatory rheumatic diseases (mean 1.8 times per year; $p<0.05$ ), as compared to individuals without these diseases (mean 1.1 times per year).

Some variation in the proportion of sick leave days (as a percentage of the possible working days per year) over 2.5 years was observed. In the total group, the mean \pm SD percentage of sick leave days per year increased from $5.1 \% \pm 13.2 \%$ in 1998 to $9.7 \% \pm$ $19.1 \%$ in 2000 (specific data not shown). In the disease-specific groups, the mean \pm SD percentage of sick leave days per year decreased somewhat for fibromyalgia (from 11.5\% $\pm 21.9 \%$ in 1998 to $8.1 \% \pm 19.1 \%$ in 2000) and for osteoarthritis (from $11.1 \% \pm 19.5 \%$ in 1998 to $10.6 \% \pm 14.6 \%$ in 2000), while the mean \pm SD percentage of sick leave days increased for inflammatory rheumatic disease (from 4.3\% $\pm 6.3 \%$ in 1998 to $15.2 \% \pm 30.1 \%$ in 2000) and for CVD (from $13.5 \% \pm 21.6 \%$ in 1998 to $15.6 \% \pm 25.2 \%$ in 2000 ). 
Work disability. Table 3 shows the work disability risk after 10 years for the verified sample before and after adjusting for the following confounding factors: sex, age (per year), education level, smoking, body mass index, and weekly exercise. Compared to people without rheumatic disease and CVD, the work disability risk after 10 years was significantly increased among participants with verified rheumatic diseases (HR 10.5 [95\% Cl 4.4-25.1]) or CVDs (HR 4.88 [95\% Cl 1.7-14.0]). The following diagnostic subgroups conveyed a significantly increased work disability risk: inflammatory rheumatic diseases (HR 8.4 [95\% Cl 1.1-62.4]), osteoarthritis (HR 12.4 [95\% Cl 1.6-13.7]), and fibromyalgia (HR 14.2 [95\% Cl 2.0 $-16.5]$ ). 


\section{DISCUSSION}

The primary aim of this study was to compare the impact of different rheumatic diseases on labor participation in terms of sick leave and work disability in a working population. We confirmed that those who reported having a rheumatic disease at baseline had a significantly increased risk of sick leave and of becoming work disabled. When comparing the different diagnostic subgroups in the subsample of the study in which the diagnosis was verified, the risk for work disability in patients with fibromyalgia was remarkably high, but it was also obvious that the impact of osteoarthritis on sick leave and work disability was high. However, in contrast to what we hypothesized, self-reported cardiovascular comorbidity did not convey an additional risk of sick leave or work disability in individuals with self-reported rheumatic diseases. Because of the limited number of persons with verified rheumatic disease and CVD, our hypothesis that CVDs increase the risk for sick leave and work disability could neither be disproved nor confirmed.

In line with previous studies, the risk of work disability was high in this study for working individuals with inflammatory rheumatic diseases. ${ }^{4.18-21}$ The results with regard to inflammatory rheumatic disease became statistically significant only after adjusting for confounders, which points to the importance of confounding (such as age and sex) in this setting. Since 2002, when effective treatments with biologic agents for inflammatory rheumatic diseases were introduced, the rate of work disability in those with inflammatory rheumatic disease has importantly decreased. ${ }^{22-24}$ Overall, we found a higher impact of osteoarthritis on sick leave and work disability than has been reported in a recent review of knee and hip osteoarthritis studies. ${ }^{1}$ This may be explained by the fact that most previous studies have been cross-sectional with short follow-up periods in comparison with our study that prospectively followed individuals for 10 years.

The high occurrence of work disability in patients with fibromyalgia in our study is noteworthy. Sparse data have been published suggesting that work disability is high among patients with fibromyalgia, and that fibromyalgia poses a high burden on health care payers and society. ${ }^{25-27}$ In The Netherlands, disability pension is granted independently of an underlying disease and is based on the impact of the illness on work capacity. Therefore, interpretation of the high work disability rate in patients with fibromyalgia is challenging. It is likely that the multitude of symptoms and high reported levels of pain, fatigue, and malaise in the absence of effective treatments all contribute to the perceived inability of people with fibromyalgia to participate in the labor force. 
In our study, the risk of sick leave was not significantly increased for inflammatory rheumatic diseases, while previous studies on sick leave have shown an increased risk.2,28,29 This discrepancy is most likely explained by differences in the baseline selections of the cohorts. In The Netherlands, many patients with rheumatic diseases may work part time, ${ }^{20}$ and those with more severe disease may have left the labor force earlier, which may have resulted in a selection of relatively healthier workers. ${ }^{30.31}$ This healthy worker effect is confirmed by the low prevalence of rheumatic diseases and CVDs at baseline in our cohort. In The Netherlands, just before assembling our cohort, people with chronic diseases were able to qualify for a disability pension relatively easily, and it is likely that these individuals had already left the labor force. Sick leave in people with osteoarthritis was increased 2-fold compared with those not reporting osteoarthritis. Although these findings are in line with recent studies, we believe that the impact of osteoarthritis has been underestimated. Our study suggests that, with regard to work participation, osteoarthritis is not such a benign disease. Especially with the increasing pressure toward longer workforce participation, the effects that osteoarthritis may have on work participation should be taken more seriously.

The present study has limitations and strengths that need to be acknowledged. The first shortcoming of this study refers to the potential overreporting of morbidity. The core information of this study was obtained by questionnaires. Such patient-reported information may have incomplete recall (and thus may have introduced recall bias) and over- or underreporting of both rheumatic and cardiovascular morbidities. As suggested by the verification process, this was indeed the case in this study, but this did not have a major influence on the results. Although verification of self-reported disease was limited to participants living in 1 specific region of The Netherlands ( $n=6,103[50 \%]$ ), there were no appreciable differences in baseline characteristics between this specific region and the entire MCS, suggesting that the South Limburg population is representative of the whole sample. We also verified negative responses among a representative sample of 200 participants and did not identify any false-negative responses.

One may wonder how detrimental overreporting and recall problems of rheumatic and cardiovascular morbidities could have been with respect to the demonstrated association with sick leave and work disability. While there was a very important discrepancy in prevalence between self-reported and verified disease across almost all investigated categories of disease, the effects of these diseases, either self-reported or verified, on sick leave and work disability were remarkably similar, which adds to the credibility of our findings based on self-reported morbidities. While there were statistically significant differences between those who did and did not report rheumatic disease or CVD, a lack of power due to low numbers could have explained our inability to detect between-group 
differences in those with verified disease. One of the explanations for the low numbers could be that patients had already left the labor force because of one of these conditions (left censorship), therefore making it impossible to investigate interactive effects. Furthermore, one may argue that sick leave and work disability, particularly in countries with a social security system like that of The Netherlands, are rather consequences of feeling unable to work than of being unable to work.

A second shortcoming of this study could be that certain relevant morbidities were missed in the verification process for several reasons. In line with the Dutch health care system, study participants with rheumatic disease would be expected to visit a secondary care physician (e.g. a rheumatologist) in the same region. Although unlikely, people are not bound to their region of residence and could have visited a physician in another part of the country. Moreover, it is likely that many patients with noninflammatory diseases were not referred to a medical specialist by their general practitioner, particularly if their disease was mild. This would have resulted in an underestimation of the number of study participants with verified rheumatic diseases or CVDs.

To our knowledge, this is the first study that used a large prospective cohort study as a basis to identify working individuals with rheumatic disease or CVD and used study participants without these diseases as a direct comparator. The ability to compare the effects of self-reported conditions with verified conditions on work outcomes is one of the main strengths of this study, along with the previously mentioned longitudinal design. In addition, direct comparisons of work outcomes in persons with different rheumatologic conditions have rarely been performed.

The different employers provided sick leave data on an individual basis, which importantly adds to the credibility of these data. Thereafter, information on employment status was obtained by self-report. It is not likely that recall for work disability introduced bias; therefore, these data can be assumed to be valid. Last, follow-up was not complete for the total sample, as is common in longitudinal follow-up studies. However, the longitudinal nonresponse was comparable in subjects with and without rheumatic diseases, and it is unlikely that this nonresponse had a relevant impact on the reported findings.

In conclusion, sick leave and work disability are significantly increased in employed individuals with rheumatic diseases, particularly in those with osteoarthritis and fibromyalgia. Although CVD (e.g. myocardial infarction and stroke) is a common comorbidity in rheumatic diseases, people with rheumatic disease and cardiovascular comorbidity were not found to be at an additively higher risk of sick leave and work disability in this study. 


\section{REFERENCES}

1. Bieleman HJ, Bierma-Zeinstra SM, Oosterveld FG, et al. The effect of osteoarthritis of the hip or knee on work participation. J Rheumatol 2011;38:1835-43.

2. Geuskens GA, Burdorf A. Hazes JM. Consequences of rheumatoid arthritis for performance of social roles: a literature review. J Rheumatol 2007:34:1248-60.

3. Woolf AD, Pfleger B. Burden of major musculoskeletal conditions. Bull World Health Organ 2003:81:646-56.

4. Mau W, Listing J, Huscher D, et al. Employment across chronic inflammatory rheumatic diseases and comparison with the general population. J Rheumatol 2005:32:721-8.

5. Gobelet C, Luthi F, Al-Khodairy AT, et al. Work in inflammatory and degenerative joint diseases. Disabil Rehabil 2007:29:1331-9.

6. Gabriel SE, Michaud K. Epidemiological studies in incidence, prevalence, mortality, and comorbidity of the rheumatic diseases. Arthritis Res Ther 2009;11:229.

7. Avina-Zubieta JA, Choi HK, Sadatsafavi M, et al. Risk of cardiovascular mortality in patients with rheumatoid arthritis: a meta-analysis of observational studies. Arthritis Rheum 2008:59:1690-7.

8. Bisoendial RJ, Stroes ES, Tak PP. Where the immune response meets the vessel wall. Neth J Med 2009;67:328-33.

9. Jamnitski A, Visman IM, Peters MJ, et al. Prevalence of cardiovascular diseases in psoriatic arthritis resembles that of rheumatoid arthritis [letter]. Ann Rheum Dis 2011;70:875-6.

10. Roifman I, Beck PL, Anderson TJ, et al. Chronic inflammatory diseases and cardiovascular risk: a systematic review. Can J Cardiol 2011:27:174-82.

11. Verbrugge LM, Juarez L. Arthritis disability and heart disease disability. Arthritis Rheum 2008:59:1445-57.

12. Hansson GK. Inflammation, atherosclerosis, and coronary artery disease. N Engl J Med 2005:352:1685-95.

13. Bultmann U, Kant I, van Amelsvoort LG, et al. Differences in fatigue and psychological distress across occupations: results from the Maastricht Cohort Study of Fatigue at Work. J Occup Environ Med 2001:43:976-83.

14. Kant IJ, Bultmann U, Schroer KA, et al. An epidemiological approach to study fatigue in the working population: the Maastricht Cohort Study. Occup Environ Med 2003;60:i32-9.

15. Driesen $\mathrm{K}$, Jansen NW, van Amelsvoort LG, et al. The mutual relationship between shift work and depressive complaints:a prospective cohort study. Scand J Work Environ Health 2011:37:402-10.

16. Chorus AM, Miedema HS, Wevers CW, et al. Work factors and behavioural coping in relation to withdrawal from the labour force in patients with rheumatoid arthritis. Ann Rheum Dis 2001;60:1025-32

17. Ake C, Carpenter AL. Extending the use of PROC PHREG in survival analysis. 2003. URL: http:// www.caloxy.com/papers/51-ExtendingPHREG.pdf.

18. Verstappen SM, Bijlsma JW, Verkleij $H$, et al, on behalf of the Utrecht Rheumatoid Arthritis Cohort Study Group. Overview of work disability in rheumatoid arthritis patients as observed in cross-sectional and longitudinal surveys. Arthritis Rheum 2004:51:488-97.

19. Chorus AM, Miedema HS, Wevers CJ, et al. Labour force participation among patients with rheumatoid arthritis. Ann Rheum Dis 2000:59:549-54.

20. Boonen A, Chorus A, Miedema $\mathrm{H}$, et al. Withdrawal from labour force due to work disability in patients with ankylosing spondylitis. Ann Rheum Dis 2001;60:1033-9. 
21. Tillett W. de-Vries C, McHugh NJ. Work disability in psoriatic arthritis: a systematic review. Rheumatology (Oxford) 2012:51:275-83.

22. Boonen A, ter Wee MM. Employee participation by patients with rheumatoid arthritis and spondylarthritis: biologicals may have an effect on the loss of productivity. Ned Tijdschr Geneeskd 2011;155:A3503. In Dutch.

23. Ter Wee MM, Lems WF, Usan H, et al. The effect of biological agents on work participation in rheumatoid arthritis patients: a systematic review. Ann Rheum Dis 2012;71:161-71.

24. Van der Burg LR, ter Wee MM, Boonen A. Effect of biological therapy on work participation in patients with ankylosing spondylitis: a systematic review. Ann Rheum Dis 2012:71:1924-33.

25. Wolfe F, Anderson J, Harkness D, et al. Work and disability status of persons with fibromyalgia. J Rheumatol 1997;24:1171-8.

26. Annemans L, Le Lay K. Taieb C. Societal and patient burden of fibromyalgia syndrome. Pharmacoeconomics 2009;27:547-59.

27. Boonen A, van den Heuvel R, van Tubergen A, et al. Large differences in cost of illness and wellbeing between patients with fibromyalgia, chronic low back pain, or ankylosing spondylitis. Ann Rheum Dis 2005:64:396-402.

28. Burton W. Morrison A, Maclean R, et al. Systematic review of studies of productivity loss due to rheumatoid arthritis. Occup Med (London) 2006:56:18-27.

29. Boonen A, van der Heijde D, Landewe R, et al. Work status and productivity costs due to ankylosing spondylitis: comparison of three European countries. Ann Rheum Dis 2002;61:429-37.

30. Li CY, Sung FC. A review of the healthy worker effect in occupational epidemiology. Occup Med (London) 1999:49:225-9.

31. Pearce N, Checkoway H, Kriebel D. Bias in occupational epidemiology studies. Occup Environ Med 2007:64:562-8. 



\section{EFFECT OF BIOLOGICAL THERAPY} ON WORK PARTICIPATION IN PATIENTS WITH ANKYLOSING SPONDYLITIS: A SYSTEMATIC REVIEW

Lennart R.A. van der Burg*

Marieke M. ter Wee*

Annelies Boonen

* authors contributed equally 


\section{ABSTRACT}

Objectives. To review systematically the effect of biological treatment in patients with ankylosing spondylitis (AS) on three work outcomes: work status, absence from paid work and at-work productivity.

Methods. A systematic literature search was performed (Pubmed, Embase, Cochrane Library) to identify relevant articles. Risk of bias of included studies was assessed using the Cochrane guidelines for cohorts and randomised controlled trials (RCTs). Data were extracted using a self-composed data extraction form. Owing to extensive interstudy heterogeneity, narrative summaries were used to present the data.

Results. Nine studies were included (six uncontrolled cohorts, one population-controlled cohort and two RCTs) that reported on 39 comparisons. Overall, 961 patients were treated with three different tumour necrosis factor a inhibitors (etanercept, infliximab, adalimumab). For presenteeism and absence from work, most comparisons showed improvement in favour of biological agents, but not all comparisons were statistically significant and they usually concerned before-after analyses. For work status, changes were less often positive, but studies dealt with patients with longstanding AS, lacked power and had a relatively short follow-up.

Conclusions. Although trends towards beneficial effects of biological agents in longstanding AS were seen on all work outcomes, the methodological limitations in the studies included hampers clear conclusions. Since the majority of studies were (extensions of ) controlled trials, the generalisability of the effect of biological agents on work participation in real life should be further studied in larger ( population-controlled) studies. The effect of biological agents in patients with early disease has not yet been examined. 


\section{INTRODUCTION}

Several studies have shown substantial impact of ankylosing spondylitis (AS) on work participation before the introduction of biological treatment. ${ }^{1-6}$ Since the onset of AS is generally in the third decade of life it possibly has a large impact on patients and society owing to its long-term limitations. In population-controlled studies, a Dutch study showed that withdrawal from paid work in AS was three times higher than expected in the general population. ${ }^{1}$ In Argentina, 26\% of working age patients with AS were unemployed compared with $4.5 \%$ in the control group. ${ }^{2}$

Differences in employment among countries were confirmed in a European threenation study that reported the highest work-disability rate in the country with the most favourable work-disability allowances. ${ }^{4}$ When studying absence from paid work, 50\% of patients incurred sick leave in a European three-nation study during the 2-year follow-up period, and yearly sick leave days were higher than expected in the general population.5.6 About 53\% of working patients in the years before pre-biological agents reported that discomfort adversely influenced their work. Patients scored their at-work efficiency during hours worked as 7.7 on a scale of 0-10 (where 10 is normal). An extra 1.91h/2 weeks was perceived to be necessary to compensate for loss of production due to work inefficiency. ${ }^{5}$

With the introduction of biological agents for AS in 2002, the possibility of controlling disease activity and improving physical function and health-related quality of life in the short and long term, improved dramatically. ${ }^{7-10}$ However, costs of biological therapies are high. Indirect costs are the major part of the total costs of AS, especially the costs of work disability. Savings in indirect or productivity costs might offset drug costs.

To provide a comprehensive view of the possible effects of biological agents on work outcome in AS, all published articles were reviewed that aimed to quantify the effect of biological therapy on three domains of work participation that are relevant for productivity costs, including reduced productivity at work, absence from paid work and long-term work disability irrespective of study design and approach of outcome assessment. 


\section{METHODS}

\section{Search strategy}

A systematic search of the literature (Pubmed/Medline, Embase and Cochrane Library) was performed by two authors (LRAvdB, MMtW) to identify all articles from 2000 up until 12 April 2012 that quantified the effect of anti-tumour necrosis factor (TNF) treatment on presenteeism, absenteeism or work status in patients with AS. The search strategy is available as online supplementary text. Abstracts of articles were limited to studies in the Dutch, English, French or German language. References of retrieved articles were scanned for additional studies.

\section{Article selection}

Two authors carried out an initial screening of all titles and abstracts retrieved from the search (LRAvdB, MMtW). Articles were eligible for full-text assessment if they reported original data on patients with AS receiving biological therapy, and reported outcomes reflecting participation in paid work: either presenteeism, absence from paid work or employment/work disability status. In the next step, full-text articles were assessed for those in which the title and abstracts had not provided sufficient information, using the same selection criteria. If there was doubt about whether or not an article should be included, the third author (AB) was consulted to reach consensus.

\section{Risk of bias assessment}

The risk of bias of included studies was assessed using two checklists from the Cochrane Collaboration: a checklist for cohort studies and one for randomised controlled trials (RCTs) (see online supplementary text). ${ }^{11}$ Two criteria were added to the checklists as the authors considered these criteria to be important in a study on work outcomes: (1) if a recall period for absenteeism, presenteeism and work disability was reported, and (2) if authors reported whether the work participation outcome could be attributed to AS, general health or another disease. All criteria had three possible answers: yes (adequate information and appropriate approach), no (no adequate information or inappropriate approach) or unclear (insufficient information to determine that criterion). If a specific criterion could not be answered, and a reference was made to another article for the same study, the referenced article was retrieved and checked. Two authors (LRAvdB, MMtW) assessed the risk of bias in the included studies independently. In total, the two authors disagreed on 15 items of the 92 items (16.3\%) that were assessed. Discrepancies between both authors were discussed with the third author (AB) until consensus was reached. 


\section{Data extraction}

Data were extracted by one author (LRAvdB), and checked by another (MMtW) using a self-composed form to extract the following: (a) study design and country of study; (b) intervention population: number of patients included, gender, mean age, number of patients employed, disease duration, eligibility criterion for biological therapy; (c) type of biological agent; (d) control population: number of patients included, gender, mean age, number of patients employed, disease duration; (e) work-related outcome measure and follow-up period; ( $f$ ) statistical method used to quantify the effect of the biological agent on work outcome and (if applicable) confounders that were adjusted; and (g) results. Whenever possible the changes were presented to reflect differences between two groups (biological therapy compared with control) or two time points (after treatment compared with before treatment).

\section{Statistical analysis}

Owing to extensive interstudy heterogeneity in study populations, outcome measures and approaches to the reporting and analysis of outcomes, a meta-analysis to calculate an overall effect of biological treatment on work participation in patients with AS could not be performed. Therefore narrative summaries are provided. 


\section{RESULTS}

\section{Results of the search}

A total of 124 titles were found through an electronic search on Pubmed/Medline, Embase and the Cochrane Library (Figure 1). After deleting duplicates and screening titles and abstracts, 107 articles were excluded leaving 17 articles for full-paper review. Main reasons for exclusion were no work-related outcomes reported ( $n=59$ ), and no TNF therapy administered $(n=27)$. After a detailed full-paper review, another eight were excluded. Thus nine studies were included in this review: seven cohort studies, of which one was a controlled cohort study, ${ }^{12-17,20}$ and two randomised clinical trials. ${ }^{18,19}$ Scanning references of included studies retrieved no additional articles.

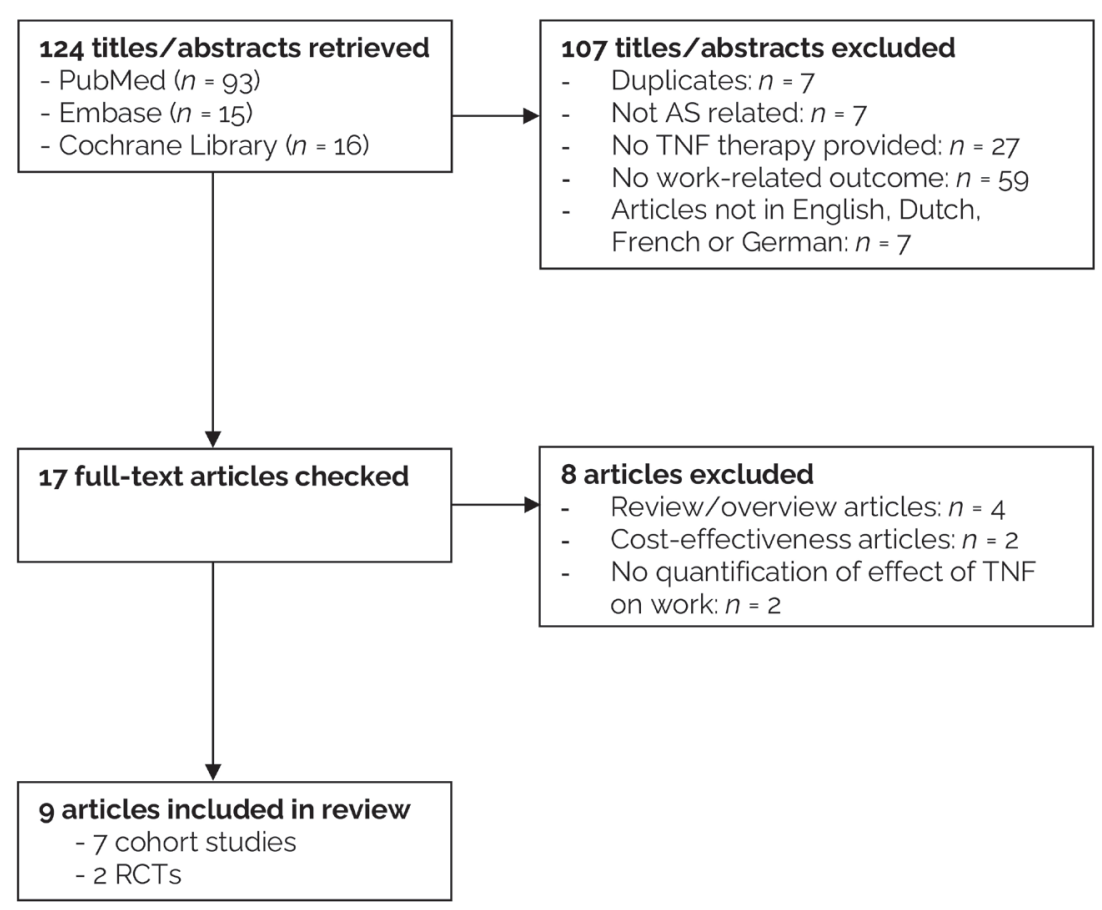

Figure 1. Flowchart of study selection and inclusion.

AS, ankylosing spondylitis; RCT, randomised controlled trial; TNF, tumour necrosis factor 


\section{Characteristics of included studies}

In total 961 patients were treated with biological agents: 851 patients (89\%) in cohort studies and 110 patients (11\%) in RCTs. Only TNFa inhibitors were used: infliximab in three articles, ${ }^{12,15,19}$ etanercept in two, ${ }^{18,20}$ adalimumab in one, ${ }^{16}$ and the above three TNF inhibitors considered as one group in three articles. ${ }^{13,14.17}$ Of the seven cohort studies, five studies were performed in a single country (UK, Germany or Sweden), 12-15,17 and two were multinational studies (USA and Europe). ${ }^{16,20}$ Four of the seven cohort studies were openlabel extensions of an RCT, 12,15,16,20 two were registers of biological agents ${ }^{14,17}$ and one was a retrospective study. ${ }^{13}$ Of the two RCTs, one was a single country study (UK), ${ }^{18}$ and the other a multinational study (USA, Canada and Europe). ${ }^{19}$ In the cohorts, the average age of patients ranged from 39.5 to 49.9 years and disease duration from 10.6 to 16.4 years. For the RCTs this was 40.3 year and 11.0 years, respectively. Tables 1 and 2 show characteristics and extracted data for cohorts and RCTs separately.

\section{Risk of bias in included studies}

As can be seen in tables $3 a$ and $3 b$, most risk of bias items were considered to be appropriately accounted for in the included studies. In four of the seven cohort studies an inappropriate approach was used in the selection of study participants (selection bias).12,15.17,20 Selective loss to follow-up was not appropriately accounted for in two cohort studies, and insufficiently reported in one. ${ }^{13.16 .17}$ Four cohort studies did not adjust for potential confounders in the analysis.13.15.17.20 Four cohort studies did not report whether the work participation outcome could be attributed to AS, general health or another disease. 14,15,17,20 In one RCT insufficient information on whether all groups were similar at baseline was provided. ${ }^{19}$ In both RCTs, it was unclear if all groups were treated equally, apart from the biological agent. In one RCT, it was unclear which recall period for the work participation outcome measures was used. ${ }^{18}$ 
Table 1. Characteristics and results of cohort studies reporting the impact of biological therapy on work participation in patients with ankylosing spondylitis

\begin{tabular}{|c|c|}
\hline Study & Characteristics \\
\hline $\begin{array}{l}\text { Study design } \\
\text { Country }\end{array}$ & $\begin{array}{l}\mathrm{N}_{\text {total }}\left(\mathrm{N}_{\mathrm{t}}\right) \text { and/or } \mathrm{N}_{\text {employed }}\left(\mathrm{N}_{\mathrm{e}}\right) \text {; } \\
\text { (o": \%); Age, mean (SD); Disease } \\
\text { duration (Dd), mean (SD) }\end{array}$ \\
\hline \multicolumn{2}{|c|}{ Uncontrolled cohort studies } \\
\hline Moots 20 & Etanercept \\
\hline (concise report) & NSAID failures, anti-TNF naive \\
\hline Open label extension & $\mathrm{Nt}=84(84.5 \%$ male $)$ \\
\hline of RCT (ASCEND), & $\mathrm{Ne}=58(69 \%$ of total $)$ \\
\hline prospective & Age: $42.7(10.5)$ \\
\hline Multinational & Dd: 7.6 (range $0-45$ years) \\
\hline
\end{tabular}

\section{Outcome assessment}

Domain (outcome measure)

Recall period, disease attribution

Assessment interval, follow-up
Absenteeism
1. \% on sick leave
2. mean number of sick days lost

\section{Employment status}
1. Full-time employment rate
2. mean number working days in
those employed after one year
Unclear measurement approach;
Past 12 weeks (for baseline pas 12
months), AS attribution unclear:
Assessment interval: 12 weeks
Follow-up: 48 or 52 weeks

$\begin{array}{ll}\text { Maksymowych }{ }^{16} & \text { Adalimumab } \\ \text { Open label extension } & \text { NSAID failures, anti-TNF naive } \\ \text { of RCT (ATLAS), } & \mathrm{N}_{\mathrm{t}}=305 \text { (82\% male) } \\ \text { prospective } & \mathrm{N}_{\mathrm{e}}=205 \text { (67\% of total) } \\ \text { Multinational } & \text { Age: } 40.8(11.0) \\ & \text { Dd: } 10.6(9.2)\end{array}$

Presenteeism; percentage of

impairment while working due to AS.

Absenteeism; percentage of work

time missed due to AS.

\section{Overall work impairment:}

percentage of work time lost due to absenteeism and presenteeism due to AS

WPAI-SHP, self-report;

Past 7 days, AS attributed:

Assessment interval: week 24, 52, 76,

104, 128 and 156

Follow-up: 156 weeks

\begin{tabular}{ll}
\hline Verstappen ${ }^{17}$ & Infliximab, Etanercept, \\
BSR Biologics & Adalimumab \\
Register (BSRBR), & NSAID failures, anti-TNF naive \\
prospective & $\mathrm{N}_{\mathrm{t}}=229$ (79\% male) \\
United Kingdom & $\mathrm{N}_{\mathrm{e}}=125(55 \%$ of total) \\
& Age: $44(10)$ \\
& Dd: $14(10)$
\end{tabular}

\section{Employment status}

1. change percentage of employed;

2. work disabled and

3. full-time working study participants.

Questionnaire, self-report;

At this moment, AS attribution unclear:

Assessment interval: 156 weeks

Follow-up: 156 weeks 
Method: Descriptive and comparison of (mean) change in \% on sick leave, - average days sick leave and average working days at endpoint as compared to baseline No comparison performed for regaining full employment. Statistical comparison methods unclear.

Confounders: None

\section{Absenteeism ( $n=58)$}

1. Proportion on sick leave at baseline: $47.3 \% \rightarrow$ proportion on sick leave after 48 weeks: $39.3 \%(-8 \%, N S)$

2. Days sick leave past year: $\Delta-22.3$ days/ year $(p=0.008)$

Employment status $(n=84)$

1. Full time work baseline $n=36 \rightarrow$ full time work at week $52: n=40(+6.8 \%)$

2. Working days after 52 weeks: $\Delta+15$ days $(p=0.144)$
Method: Comparisons mean change from

baseline (percentage) in employed patients for absenteeism/presenteeism, and all patients in overall impairment.

No statistical comparison with baseline.

Confounders: none
Presenteeism $(n=205)$

Week 24: $\Delta-17.24 \%$ in past 7 days

Week 156: $\Delta-23.72 \%$ (= $9.5 \mathrm{~h} \mathrm{improved}$ productivity/ week*)

Absenteeism, ( $n=205)$

- Week 24: $\triangle-2.7 \%$ in past 7 days

- Week 156: $\Delta-4.24 \%$ (= $1.7 \mathrm{~h}$ work time gained/ week* $^{*}$ )

Overall work productivity impairment $(n=305)$

- Week 24: $\triangle-16.22 \%$ in past 7 days

- Week 156: $\triangle-23.35 \%$ (= 9.3 hours productivity gained/ per week*)
Method: Descriptive statistics only, no statistical comparison with baseline

Confounders: none

\section{Employment status}

1. Working at baseline $(n=125) \rightarrow$ work disabled at 3 years: $n=5(4.0 \%)$

2. Work disabled at baseline $(n=94) \rightarrow$ working at 3 years: $n=8(8.5 \%)$

3. Working full-time at baseline $(n=99) \rightarrow$ working full-time after 3 years: $n=87$ (87.9\%) 
Table 1. Continued

\begin{tabular}{|c|c|c|}
\hline Study & Characteristics & Outcome assessment \\
\hline $\begin{array}{l}\text { Haibel }^{12} \\
\text { Open label trial, } \\
\text { prospective } \\
\text { Germany }\end{array}$ & $\begin{array}{l}\text { Infliximab } \\
\text { NSAID-refractory, anti-TNF } \\
\text { naive } \\
\mathrm{N}_{\mathrm{t}}=101 \text { (78\% male) } \\
\mathrm{N}_{\mathrm{e}}=62(61 \% \text { of total) } \\
\text { Age: } 49.9 \text { (range } 21-67) \\
\text { Dd: } 15.5 \text { (range } 0.6-4.6)\end{array}$ & $\begin{array}{l}\text { Presenteeism; productivity } \\
\text { impairment at work due to AS after } \\
28 \text { weeks. } \\
\text { Absenteeism; missed hours at work } \\
\text { during the last week due to AS after } \\
24 \text { weeks. } \\
\text { Employment status; changes in } \\
\text { employed, temporary disabled (\%) } \\
\text { after } 24 \text { weeks. } \\
\text { WPAI-SHP, self-report; } \\
\text { Past } 7 \text { days, AS attributed; } \\
\text { Employment questionnaire, self- } \\
\text { report } \\
\text { Assessment interval: week 2, 12, 24, } 28 \\
\text { Follow-up: } 28 \text { weeks }\end{array}$ \\
\hline $\begin{array}{l}\text { Keat }{ }^{13} \\
\text { Retrospective study } \\
\text { in patients currently } \\
\text { receiving biological } \\
\text { therapy } \\
\text { United Kingdom }\end{array}$ & $\begin{array}{l}\text { Infliximab, Etanercept, } \\
\text { Adalimumab } \\
\text { Currently receiving anti-TNF for } \\
3 \text { - } 56 \text { months } \\
\mathrm{N}_{\mathrm{t}}=65 \text { (72\% male) of which } 33 \\
\text { had } 12 \text { mo FU } \\
\text { Age: } 46.1 \text { (range } 29 \text { - 64) } \\
\text { Dd: } 14.06 \text { (range } 1 \text { - 50) } \\
\mathrm{N}_{\mathrm{e}}=46 \text { of which } 21 \text { had } 12 \text { mo FU }\end{array}$ & $\begin{array}{l}\text { Presenteeism: adverse impact of AS } \\
\text { on work capacity (O-10: worse impact } \\
\text { on capacity) } \\
\text { Absenteeism: a. mean sickness } \\
\text { absence over previous } 12 \text { months } \\
\text { at baseline and cumulative post } \\
\text { treatment; b. hours working currently } \\
\text { Employment status; changes in } \\
\text { full-time/part-time employment, } \\
\text { temporarily disabled or retired on } \\
\text { health grounds currently and pre- } \\
\text { treatment. } \\
\text { Questionnaire, self-report; } \\
\text { Past } 3 \text {-56 months, AS attributed; } \\
\text { Assessment interval: not applicable } \\
\text { Follow-up: not applicable }\end{array}$ \\
\hline
\end{tabular}




\section{Statistical analysis}

Method: Non-parametric Wilcoxon signed rank test; to compare baseline and after treatment values.

Paired t-test; to compare subgroups

(ITT-LOCF)

Confounders: none

\section{Results}

Presenteeism ( $n=62)$, after 28 weeks

$\Delta=-2.9$ points on the WPAI-SHP $(p<0.001)$

Absenteeism ( $n=62)$, after 24 weeks

$\Delta=-2$ missed work hours per week $(p=n s)$

Employment status ( $n=62$ ), after 24 weeks

- Working at baseline $\mathrm{n}-62) \rightarrow$ working at 24 weeks: $n=75(\Delta=+13(+7.9 \%, p<0.001)$

- Working at baseline $(n=62) \rightarrow$ work disabled at 24 weeks: $n=4(6.5 \%)$
Method: Descriptive statistics of outcomes, non-statistical comparison of on-treatment with pre-treatment (days absent compared to baseline in those with work and at least 12 mo follow-up; hours working at FU in those working)

\section{Confounders: none}

Presenteeism $(n=46$ baseline and $n=50$ at follow=up)

- $\quad$ Pre-treatment $7.1 \rightarrow$ post treatment $=2.9$ points $(\triangle-4.2)$

Absenteeism in those with 12 mo FU

a. $\quad$ Days absent pre-treatment $(n=21 / 46)$ : 15 days $\rightarrow$ on-treatment $(n=24 / 50): 0.91$ days

b. Hours worked (per week) pre-treatment $37.8 \mathrm{~h} \rightarrow$ on-treatment: $39.3(\Delta+1.5 \mathrm{~h})$

Employment status

- Working pre-treatment $71 \%(n=46) \rightarrow 77 \%$ $(n=50)$ post treatment

- $\quad$ Full-time pre-treatment $58.5 \%(n=38) \rightarrow$ on-treatment: $67.7(n=44)(\Delta+6$ patients $(9.2 \%))$

- Part-time pre-treatment $12.3 \%(n=8) \rightarrow$ on treatment: $9.2 \%(n=6)(\Delta-2$ patients $(3.1 \%))$

- $\quad$ Temporary disabled pre-treatment 3.1\% (n = 2) $\rightarrow$ on-treatment: 0\% ( $\triangle-2$ (3.1\%))

- $\quad$ Retired pre-treatment 16.9\% $(n=11) \rightarrow$ ontreatment: $16.9 \%(n=11)($ no $\triangle)$ 
Table 1. Continued

\begin{tabular}{|c|c|c|}
\hline Study & Characteristics & Outcome assessment \\
\hline Listing ${ }^{15}$ & Infliximab & Absenteeism; a. sick leave yes/no \\
\hline $\begin{array}{l}\text { Open label extension } \\
\text { of an RCT, } \\
\text { prospective }\end{array}$ & $\begin{array}{l}\text { TNF naïe, DMARD/ } \\
\text { corticosteroid withdrawal } \\
\mathrm{N}_{\mathrm{t}}=70(66 \% \text { male) }\end{array}$ & $\begin{array}{l}\text { and b. days sick leave last } 12 \text { mo (at } \\
\text { baselinel) or last } 3 \text { months (follow- } \\
\text { up). }\end{array}$ \\
\hline \multirow[t]{5}{*}{ Germany } & $N_{e}=38(54 \%)$ & \\
\hline & $(n=28 \mathrm{TNF}-$ completers & questionnaire, self-report; \\
\hline & $n=10 \mathrm{TNF}$-withdrawers) & Past 3 months, not AS attributed; \\
\hline & Age: 39.5 (8.6) & Assessment interval: 12 weeks \\
\hline & Dd: 16.4 (8.3) & Follow-up: 102 weeks \\
\hline
\end{tabular}




\section{Statistical analysis}

Method: McNemar's test or Wilxoxon's rank sum test; comparison before and after start of treatment within groups in TNF-completers and TNF-withdrawers separately

a. Percentage of persons on sick leave

b. Days of sick leave in past year.

\section{Confounders: none}

\section{Results}

Absenteeism ( $\triangle$ compared to baseline)

a. Proportion with sick leave

TNF-completers $(n=28)$

- Baseline: 16 patients (57\%)

- $\rightarrow 52$ weeks: 10 patients (36\%) ( $p=0.031)$

- $\rightarrow 102$ weeks: 4 (4\%) $(p<0.001)$

TNF-withdrawers $(n=10)$

- Baseline: 5 patients (50\%)

- $\rightarrow 52$ weeks: $7(70 \%)(+20 \%)(p=$ n.s.)

b. $\quad$ Days sick leave last year

TNF-completers $(n=28)$

- Baseline: mean 31.3 days (range 0-365)

- $\rightarrow 52$ weeks: $\Delta-18.8$ days compared to $\mathrm{BL}(p=0.009)$

- $\rightarrow 102$ weeks: $\Delta-26.6$ days compared to $\mathrm{BL}(p=0.002)$

TNF-withdrawers $(n=10)$

- Baseline: mean 67.6 days (0-365)

- $\rightarrow 52$ weeks: $\Delta-1.1$ days compared to BL (n.s.) 
Table 1. Continued

\begin{tabular}{|c|c|c|c|}
\hline Study & Characteristics & Comparator & $\begin{array}{l}\text { Outcome } \\
\text { assessment }\end{array}$ \\
\hline \multicolumn{4}{|c|}{ Controlled cohort studies } \\
\hline $\begin{array}{l}\text { Study design } \\
\text { Country }\end{array}$ & $\begin{array}{l}\mathrm{N}_{\text {total }}\left(\mathrm{N}_{\mathrm{t}}\right) \text { and/or } \\
\mathrm{N}_{\text {employed }}\left(\mathrm{N}_{\mathrm{e}}\right),\left(\mathrm{o}^{\text {: }: \%)}\right. \\
\text { Age, mean (SD) } \\
\text { Disease duration (Dd), } \\
\text { mean (SD) }\end{array}$ & $\begin{array}{l}\text { Background } \\
\text { population }\end{array}$ & $\begin{array}{l}\text { Domain (method) } \\
\text { Recall period, disease } \\
\text { attribution } \\
\text { Assessment interval, } \\
\text { follow-up }\end{array}$ \\
\hline $\begin{array}{l}\text { Kristensen }{ }^{14} \\
\text { AS biological register } \\
\text { cohort (SSATG), } \\
\text { retrospective } \\
\text { Sweden }\end{array}$ & $\begin{array}{l}\text { Infliximab, Etanercept, } \\
\text { Adalumimab } \\
\text { Anti-TNF naive } \\
\mathrm{N}_{\mathrm{t}}=139 \text { (78\% male) } \\
\text { Age: } 41 \text { (10) } \\
\text { Dd: } 14 \text { (11) }\end{array}$ & $\begin{array}{l}\text { Subjects from general } \\
\text { population matched } \\
\text { for age, sex, area of } \\
\text { residence and time } \\
\text { period of observation. } \\
\text { AS-patient: general } \\
\text { population }(1: 4) \text {. }\end{array}$ & $\begin{array}{l}\text { Absenteeism, } \\
\text { receiving a sick leave } \\
\text { benefit (> } 14 \text { days sick } \\
\text { leave) and days sick } \\
\text { leave (after the first } 14 \\
\text { days). } \\
\text { Employment status, } \\
\text { receiving disability } \\
\text { pension from the } \\
\text { SSIA. } \\
\text { Linkage with data } \\
\text { from Swedish } \\
\text { Social Insurance } \\
\text { Agency (SSIA). No } \\
\text { recall, unknown AS } \\
\text { attribution } \\
\text { Assessment interval: } \\
30 \text { days } \\
\text { Follow-up: } 52 \text { weeks }\end{array}$ \\
\hline
\end{tabular}




\section{Method}

McNemar's test; to compare proportion of patients on sick leave.

Absenteeism
a. Proportion patients with sick leave benefit
b. Relative risk to be on sick leave compared to background population +
c. Net amount of sick leave expressed as \% of full-time working
d. Proportion on sick leave benefit stratified for disease duration and age

Employment status
A. Proportion patients on disability pension
B. Relative risk to be on disability pension compared to background population
C. amount of disability days expressed as \% of full-time working
D. Proportion on disability pension stratified for disease duration and age

Relative risk of being on sick leave compared to background population Univariable co-variance analysis; to analyze sick leave trends during study period

\section{Stratification analysis:}

Stratified according median age, and disease duration

\section{Absenteeism}

a. Proportion of AS patients with sick leave benefit

- 1-3 months before start TNF: $24 \%$

- At start TNF: 28\%

- After 1 year TNF: 12\%

- Change from 1-3 months before treatment to 10-12 month after treatment: mean $\triangle 14 \%(p<0.001)$

b. Relative risk to be on sick leave compared to background population

- 1-3 months before start: RR 8.0 195\% Cl 4.6. 13.9]

- $\quad$ At start TNF: RR 9.2 [95\% Cl 5.4. 15.7]

- After 1 year TNF: RR 4.0 [95\% Cl 2.1. 6.3]

c. Net amount of sick leave

- AS patients, at start TNF: $18.1 \%$

- AS patients after 1 year TNF: $\triangle-8.1 \%$ $(p<0.001)$

- Background population, at start TNF: $2.9 \%$

- Background population after 1 year TNF: $\triangle-0.4 \%(p=0.623)$

d. Stratified analysis for proportion on sick leave benefit

- $\quad<14$ yrs. disease duration: $\Delta-18 \%$ after 1 year TNF

- $\quad>14$ yrs. disease duration: $\triangle-12 \%$ after 1 year TNF $(p=0.337)$

- $>40$ yrs. old: $\triangle-21 \%$ after 1 year TNF

- <40 yrs. old: $\triangle-10 \%$ after 1 year TNF ( $p$ $=0.097$ ) 
Table 1. Continued

$\begin{array}{lll}\text { Study Characteristics Comparator } & \begin{array}{l}\text { Outcome } \\ \text { assessment }\end{array}\end{array}$

"Based on a full-time week of 40 hours. + Compared to background population. AS = Ankylosing Spondylitis; ATLAS = Adalimumab Trial Evaluating Long-Term Efficacy and Safety; BSR = British Society for Rheumatology; DMARD = Disease-Modifying Anti-Rheumatic Drug; INF = Infliximab; n.s. = not significant; NSAID = Non-Steroidal Anti-Inflammatory Drug; 


\section{Results}

Employment status

A. Proportion of AS patients with disability benefit

- 12 months before start TNF: $19 \%$

- 12 months after start TNF: 26\% ( $p=$ $0.887)$

B. RR of disability pension

- At start TNF: RR 4.4 [95\% Cl 2.8, 6.7]

- After 1 year treatment: RR 5.1 195\% Cl 3.3. 8.1]

C. Net amount of disability pension (\%)

- AS patients, at start TNF: $20.6 \%$

- AS patients after 1 year treatment: $\Delta$ $+1.1 \%(p=0.923)$

- Background population, at start TNF: $6.7 \%$

- Background population after 1 year treatment: $\Delta-0.7 \%(p=0.281)$

D. Stratified analysis for disability pension

- >14 yrs. disease duration: $\Delta+1 \%$ after 1 year TNF $(p=0.652)$

- $\quad<14$ yrs. disease duration: $\triangle+7 \%$ after 1 year TNF $(p=0.004)$

- $>40$ yrs. old: $\Delta+3 \%$ after 1 year TNF ( $p$ $=0.522)$

- $\quad<40$ yrs. old: $\triangle+5 \%$ after 1 year TNF $(p$ $=0.228$ )

$\mathrm{RR}=$ Relative Risk; RCT = Randomized Clinical Trial; SD = Standard Deviation; SSATG = South Swedish Arthritis Treatment Group; TNF = Tumour Necrosis Factor; WPAI-SHP = Work Productivity and Activity Impairment Specific Health Problem questionnaire. 
Table 2. Characteristics and results of randomised controlled trials reporting the impact of biological therapy on work participation in patients with AS

\begin{tabular}{|c|c|c|}
\hline Study & Intervention & Comparator \\
\hline $\begin{array}{l}\text { Authors } \\
\text { Study design } \\
\text { Country }\end{array}$ & $\begin{array}{l}N_{\text {total }}\left(N_{\mathrm{t}}\right), N_{\text {employed }}\left(N_{e}\right)\left(0^{\top}: \%\right) ; \\
\text { Age, mean (SD); } \\
\text { Disease duration (Dd), mean } \\
\text { (SD) }\end{array}$ & $\begin{array}{l}N_{\text {total }}\left(N_{t}\right), N_{\text {employed }}\left(N_{e}\right)\left(0^{3}:\right. \\
\text { Age, mean (SD); } \\
\text { Disease duration (Dd), } m \\
\text { (SD) }\end{array}$ \\
\hline $\begin{array}{l}\text { Barkham }{ }^{18} \\
\text { Double-blind, placebo- } \\
\text { controlled, single centre trial } \\
\text { United Kingdom }\end{array}$ & $\begin{array}{l}\text { Etanercept } \\
+ \text { DMARD continuing } \\
\text { DMARD failures } \\
\mathrm{N}_{\mathrm{t}}=\mathrm{N}_{\mathrm{e}}=20(75.0 \% \text { male) } \\
\text { Age: } 40.8(9.7) \\
\text { Dd: } 11.0 \text { (range } 2.08-45)\end{array}$ & $\begin{array}{l}\text { Placebo } \\
+ \text { DMARD continuing } \\
\text { DMARD failures } \\
\mathrm{N}_{\mathrm{t}}=\mathrm{N}_{\mathrm{e}}=20(85.0 \% \text { male) } \\
\text { Age: } 39.4(10.1) \\
\text { Dd: } 20 \text { (range } 0.58-30)\end{array}$ \\
\hline
\end{tabular}




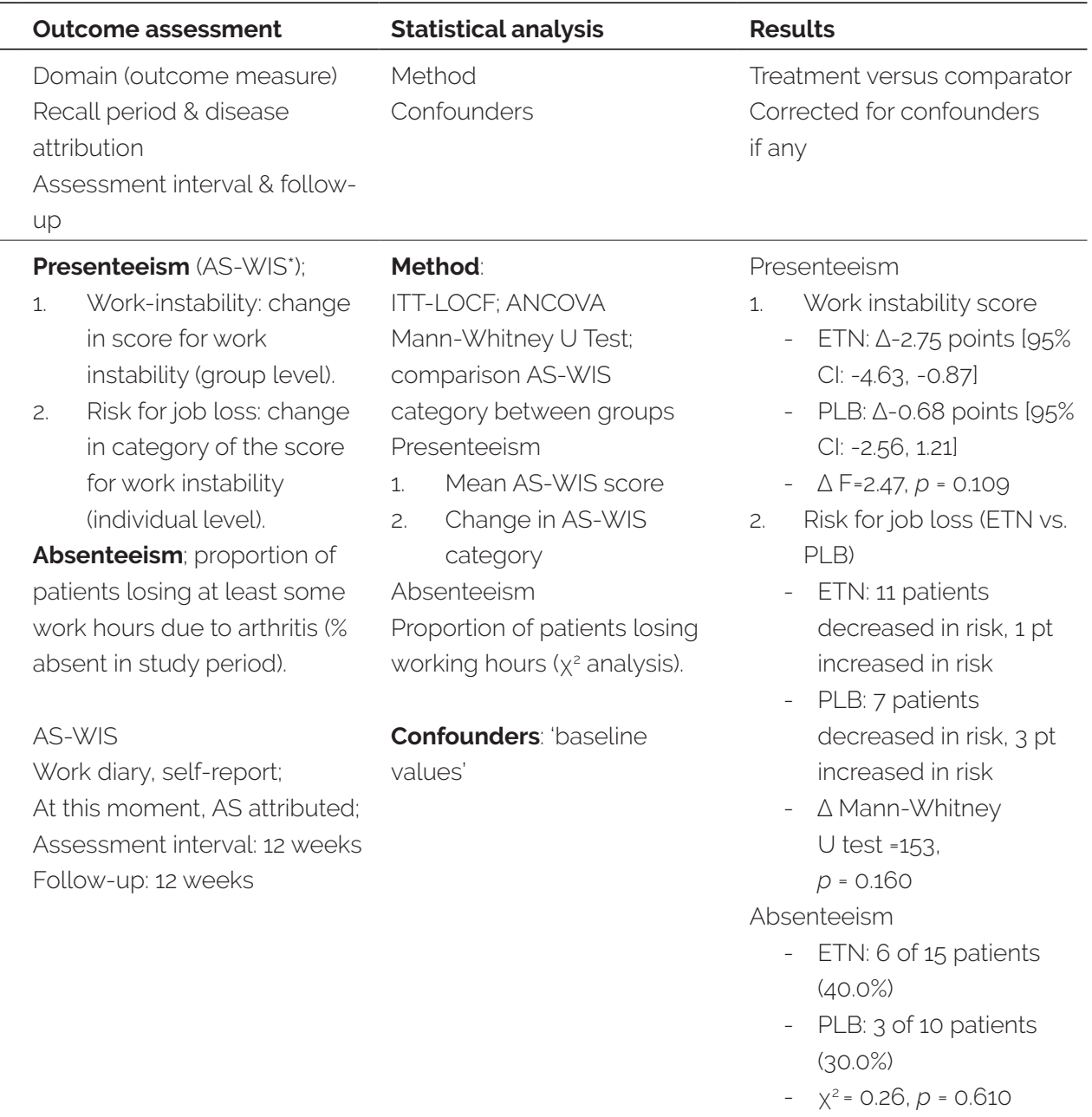


Table 2. Continued

\begin{tabular}{lll}
\hline Study & Intervention & Comparator \\
\hline Van der Heijde ${ }^{19}$ & Infliximab & Placebo \\
Double-blind, placebo- & NSAID failures, anti-TNF naive & NSAID failures, anti-TNF naive \\
controlled, multicenter trial & $\mathrm{N}_{\mathrm{t}}=201(78 \%$ male) & $\mathrm{N}_{\mathrm{t}}=78(87 \%$ male) \\
(ASSERT) & $\mathrm{N}_{e}=123(61 \%)$ & $\mathrm{N}_{\mathrm{e}}=41(53 \%)$ \\
USA, Canada, Europe & $\mathrm{N}_{\mathrm{e}}$ full-time $=94(49 \%)$ & $\mathrm{N}_{\mathrm{e}}$ full-time $=28(38 \%)$ \\
& Age: $39.6 \pm 10.6$ & Age: $40 \pm 9.4$ \\
& Dd: median $7.7($ IQR 3.3.14.9 & Dd: median 13.2 (IQR 3.7. 17.9)
\end{tabular}

"AS-WIS (validated) with a score of 0-20, where <11 indicates low risk of job loss, 11-18 indicates medium risk, 19-20 indicates high risk. "* Compared to placebo.

AS = Ankylosing Spondylitis; ANCOVA = Analysis of Covariance; ASSERT = Ankylosing Spondylitis Study for the Evaluation of Recombinant Infliximab Therapy; AS-WIS = Ankylosing Spondylitis 


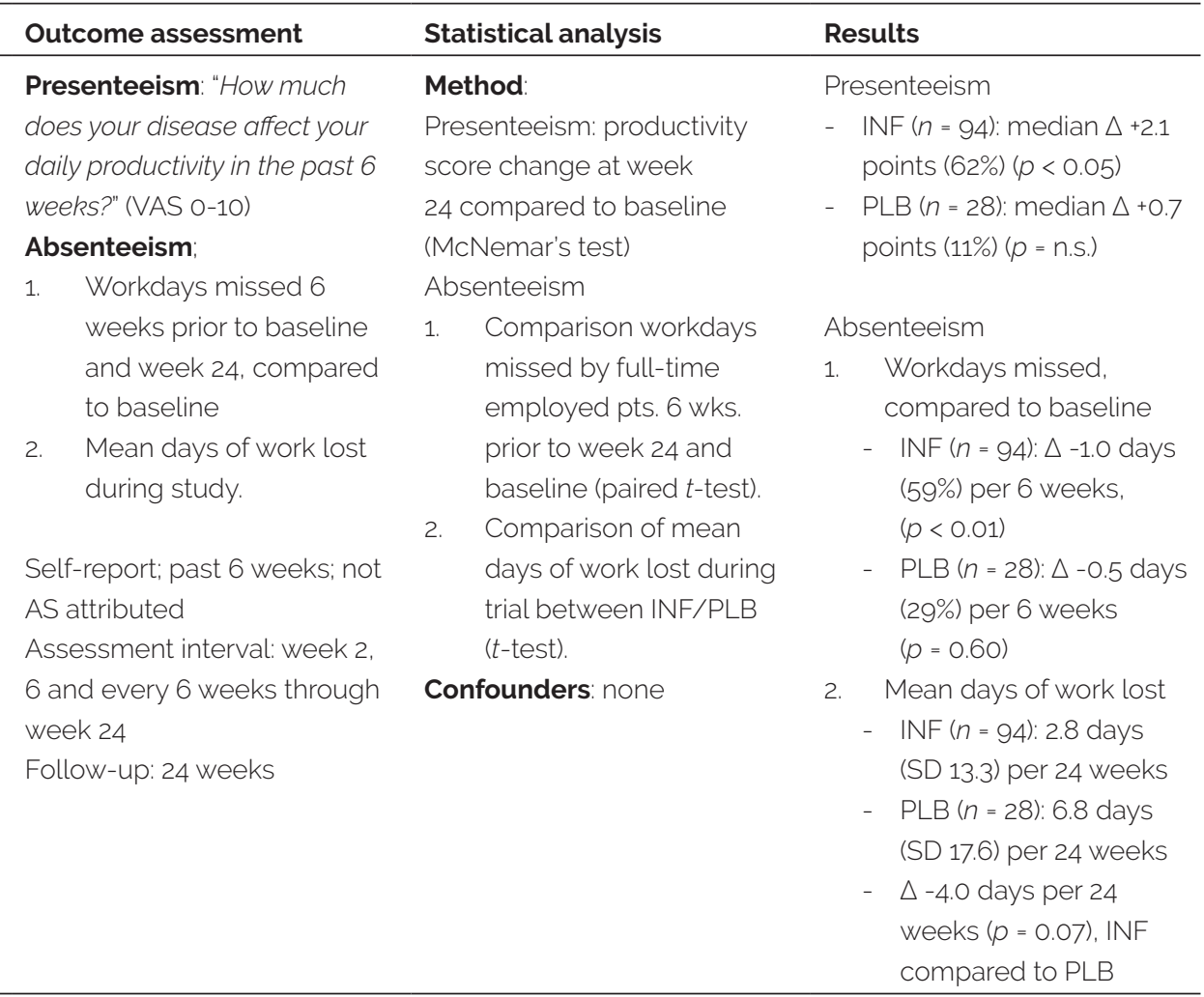

Work Instability Scale; DMARD = Disease Modifying Anti-Rheumatic Drug; ETN = Etanercept; INF = Infliximab; ITT-LOCF = Intention To Treat-analysis with Last Observation Carried Forward for missing values; NSAID = Non-Steroidal Anti-Inflammatory Drug; PLB = Placebo; SD = Standard Deviation; TNF = Tumour Necrosis Factor; VAS = Visual Analogue Scale. 
Table 3a. Risk of bias in the included cohort studies that reported the impact of biological therapy on work participation in patients with ankylosing spondylitis (AS)*

\begin{tabular}{|c|c|c|c|c|c|c|c|c|c|c|}
\hline Authors & 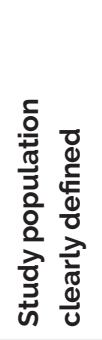 & 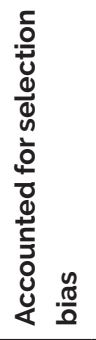 & 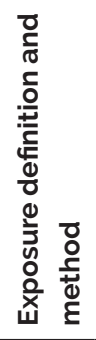 & 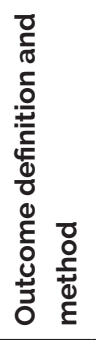 & 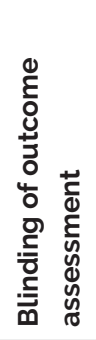 & 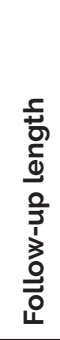 & 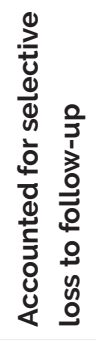 & 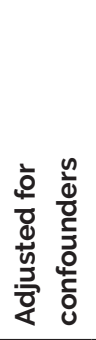 & 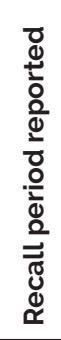 & 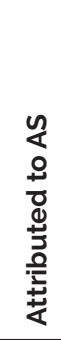 \\
\hline Moots $^{20}$ & ? & & + & 0 & + & + & + & $?$ & + & \\
\hline Maksymowych ${ }^{16}$ & + & + & + & + & + & + & & + & + & F \\
\hline Verstappen ${ }^{17}$ & + & & + & + & + & + & & & + & \\
\hline Haibe $^{12}$ & + & & + & + & + & ? & + & + & + & \\
\hline Keat $^{13}$ & + & + & + & + & + & + & ? & & + & \\
\hline Listing $^{15}$ & + & & + & + & + & + & + & & + & \\
\hline Kristensen ${ }^{14}$ & + & + & + & + & + & + & + & + & + & \\
\hline
\end{tabular}

Table $\mathbf{3 b}$. Risk of bias in the included randomised controlled trials that reported the impact of biological therapy on work participation in patients with ankylosing spondylitis (AS)*

\begin{tabular}{|c|c|c|c|c|c|c|c|c|c|c|c|}
\hline Authors & 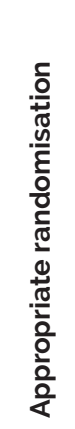 & 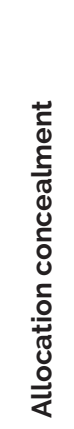 & 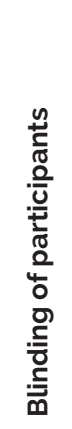 & 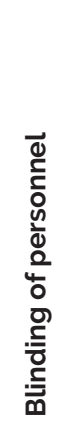 & 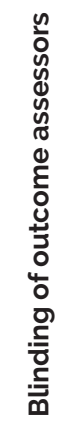 & 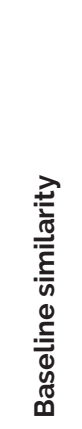 & 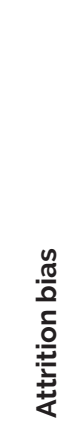 & 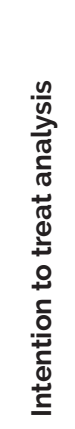 & 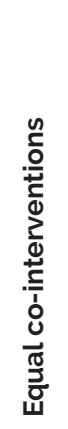 & 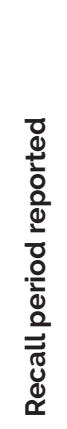 & 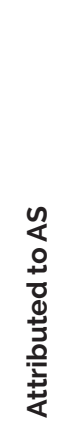 \\
\hline Barkham ${ }^{18}$ & + & + & + & $\oplus$ & + & + & + & + & $?$ & $?$ & + \\
\hline Van der Heijde ${ }^{19}$ & + & + & + & $\oplus$ & + & $\Theta$ & + & + & $?$ & + & + \\
\hline
\end{tabular}

* Each item corresponds to the criteria in the checklists (appendix 2) with adequate information or adequate approach represented as a + , insufficient information to determine criterion as a ? no adequate information or inadequate approach as a - 


\section{Presenteeism}

Change in productivity while at work (presenteeism) was studied in three uncontrolled cohort studies, ${ }^{12,13,16}$ and in both RCTs.18,19 Follow-up ranged from 12 to 156 weeks. In an open extension study ( $n=205,156$ weeks) a decrease in percentage of impairment while working due to AS, compared with baseline, was seen of $17.2 \%$ and $23.7 \%$ after 24 and 156 weeks treatment, respectively. Assuming a working week of $40 \mathrm{~h}$, the end of study result would translate into $9.5 \mathrm{~h}$ of improved productivity per week. No significance level was presented. ${ }^{16}$ An open-label study ( $n=101,28$ weeks) showed a significant decrease in impairment in work productivity of 2.9 points on the Work Productivity and Activity Impairment Specific Health Problem questionnaire (WPAI-SHP) compared with baseline

$(p<0.001)^{12}$ Finally, in a register of biological agents, patients indicated retrospectively that work capacity had improved by 4.2 points, but no significance level was presented.13

One RCT ( $n=94,24$ weeks) reported a significant improvement of 2.1 points on a Visual Analogue Scale (VAS) (62\%) on self-reported productivity at work $(p<0.05) .{ }^{19}$ No significant improvement was found in the placebo group. The between-group difference was not reported. In the second RCT, in which presenteeism was expressed as an AS-related Work Instability Scale (AS-WIS) score, no significant improvement was found in patients treated with etanercept for 12 weeks compared with placebo $(n=20, p=0.109) .{ }^{18}$

\section{Absence from paid work}

Absence from paid work was the outcome most often studied. Six out of seven cohorts (five uncontrolled 12,13,15,16,20 and one controlled cohort study ${ }^{14}$ ), and both RCTs ${ }^{18,19}$ quantified the effect of biological therapy on absence from paid work. The follow-up varied from 12 to 156 weeks.

All cohorts reported a reduction in absence from paid work, although this was not always statistically tested. One small uncontrolled cohort ( $n=28,102$ weeks) showed that the percentage of people on sick leave and number of days on sick leave significantly reduced when patients continued to receive treatment $(p<0.001$, and $p=0.002$, respectively). ${ }^{15}$ These reductions were not seen in those who had to stop treatment at a certain point during the study $(n=11)$. In another uncontrolled cohort, the mean number of sick days decreased significantly from 37.4 to 15.1 days after treatment ( $p=0.008$ ). ${ }^{20}$ Two uncontrolled cohorts used the WPAI-SHP to assess absence from work. One of these found a decrease of 4.24\% of work time missed while at work owing to AS after 156 weeks' treatment $(n=205)$, but the significance level was not tested. Based on a working week of $40 \mathrm{~h}$, this improvement would correspond to $1.7 \mathrm{~h}$ of work time gained per week. ${ }^{16}$ The other cohort applying the WPAI ( $n=62,28$ weeks) reported a nonsignificant decrease of two missed work hours due to AS compared with baseline. ${ }^{12}$ 
Table 4. Overview of results and statistical analyses for each of the work outcomes and all comparisons across of all included studies

\begin{tabular}{|c|c|c|c|c|}
\hline & \multicolumn{3}{|l|}{ Presenteeism } & \multirow{2}{*}{$\begin{array}{l}\text { Absenteeism } \\
\text { Result }\end{array}$} \\
\hline & Result & Compared with* & $\begin{array}{l}\text { Significant } \\
\text { difference }\end{array}$ & \\
\hline \multicolumn{5}{|c|}{ Uncontrolled cohort studies } \\
\hline Moots 20 & & & & Improvement \\
\hline Maksymowych ${ }^{16}$ & Improvement & Baseline (2) & Not tested & Improvement \\
\hline \multicolumn{5}{|l|}{ Verstappen ${ }^{17}$} \\
\hline Haibel 12 & Improvement & Baseline (1) & Significant & Improvement \\
\hline Keat ${ }^{13}$ & Improvement & Baseline (1) & Not tested & Improvement \\
\hline Listing 15 & & & & Improvement \\
\hline \multicolumn{5}{|c|}{ Controlled cohort study } \\
\hline Kristensen ${ }^{14}$ & & & & Improvement \\
\hline \multicolumn{5}{|c|}{ Randomised controlled trial studies } \\
\hline Barkham ${ }^{18}$ & Improvement & Between groups (2) & Not significant & Deterioration \\
\hline Van der Heijde ${ }^{19}$ & Improvement & Baseline (1) & Significant & Improvement \\
\hline
\end{tabular}

"Number between brackets indicate number of comparisons (with a total of 39 comparisons).

A retrospective biologics register with variable follow-up found that patients who were currently receiving anti-TNF treatment had 14 fewer days mean sickness absence in the previous 12 months as compared with before treatment, but this was not tested for significance. ${ }^{13}$ The population-controlled cohort $\left(n_{t}=139\right)$ showed that the relative risk (RR) of being on sick leave, compared with the background population, was reduced after 1 year of treatment ( $\mathrm{RR}=4.0,95 \% \mathrm{Cl} 2.0$ to 6.3) as compared with treatment start ( $R \mathrm{R}=9.2,95 \%$ $\mathrm{Cl} 5.4$ to 15.7). The overlapping $\mathrm{Cl}$ indicates that the change is not significant. It should be mentioned that 1 year before starting a biological agent, the RR for sick leave was 8.0 (95\% Cl 4.6 to 13.9), suggesting regression to the mean after the start of TNF inhibition. Within patients, the amount of sick leave, expressed as the percentage of full-time at work, was significantly reduced (mean change $-8.1 \%, p<0.001$ ) as compared with treatment start (18.1\% sick leave). ${ }^{14}$ 


\section{Work status}

\begin{tabular}{lllll} 
Compared with* & $\begin{array}{l}\text { Significant } \\
\text { difference }\end{array}$ & Result & Compared with* & $\begin{array}{l}\text { Significant } \\
\text { difference }\end{array}$ \\
\hline Baseline (2) & $\begin{array}{l}\text { Significant (1) } \\
\text { Not significant (1) }\end{array}$ & Improvement & Baseline (2) & $\begin{array}{l}\text { Not tested (1) } \\
\text { Not significant (1) }\end{array}$ \\
\hline Baseline (2) & Not tested & & & Not tested \\
\hline Baseline (1) & Not significant & Improvement & Baseline (2) & Significant (1) \\
& Not tested & Improvement & Baseline (5) & Not tested \\
\hline Baseline (2) & Significant & & & \\
\hline Baseline (4) & & & & Noterioration \\
\hline & Significant (2) & Deterioration & Baseline (2) \\
Baseline (2) & & Between groups (1) & Not significant (1) \\
\hline Between groups (1) & Not significant (1) & & &
\end{tabular}

$\begin{array}{ll}\text { Between groups (1) } & \text { Not significant } \\ \text { Baseline (1) } & \text { Significant } \\ \text { Between groups (1) } & \text { Not significant }\end{array}$

One RCT ( $n=163,24$ weeks) showed a significant reduction in work days missed ( -1 day in the 6 weeks before a visit, $p<0.01$ ) compared with baseline. In the placebo group a non-significant reduction of 0.5 days was reported. The between-group difference was not reported. ${ }^{19}$ The second RCT showed that the proportion of patients losing work hours owing to AS was 40\% (6/15 patients) in the etanercept group, compared with 30\% (3/10 patients) in the placebo group. However, follow-up was only 12 weeks and the difference between groups was not significant $(p=0.610) .{ }^{18}$

\section{Work status}

The effect of anti-TNF treatment on work status was reported in four uncontrolled cohort studies, 12,13,17,20 and in the controlled cohort study. ${ }^{14}$ Follow-up varied from 28 to 156 weeks. 
Of the three prospective cohorts, one uncontrolled study ( $n=101,28$ weeks) showed a significant improvement in the proportion of patients employed $(+7.9 \%, p<0.001)^{12}$ In a prospective biologics register, the number of patients who were work disabled at the start $(n=94)$ and became employed after 3 years $(n=8 ;+8.5 \%)$, was higher than the proportion who were employed at baseline $(n=94)$ and became work disabled $(n=5 ; 4.0 \%)^{17}$ In an open extension study ( $n=84,52$ weeks) the full-time employment rate increased by $6.8 \%$. Additionally, the mean number of work days increased for employed patients $(n=58)$ from 226 days to 241 days $(p=0.144) .^{20}$ In the retrospective register $(n=65)$ it was shown that after 3-56 months the proportions of patients working full time increased $(+9.2 \%)$, while the proportion of patients working part time and being temporarily disabled decreased. Since the proportion of patients in retirement remained stable, the observation indicates that the number of patients improving their work status outweighs those for whom work status worsened. ${ }^{13}$ Finally, the prospective population-controlled cohort showed that after the start of treatment, the risk of receiving work disability pension compared with the general population continued to increase slightly to a RR of 5.1 (95\% Cl 3.3 to 8) after 1 year compared with a RR of 4.4 (95\% Cl 2.8 to 6.7) at the start of the TNF inhibition. ${ }^{14}$ 


\section{DISCUSSION}

This study reviewed all published articles assessing the impact of biological therapies on work participation in patients with AS, comprising short-term productivity loss at work (presenteeism), absence from paid work (sick leave) and long-term employment status. In total, 39 comparisons were explored in nine articles comparing end points either with baseline or with a comparator group, and using different outcomes or assessing different time points after initiation of TNF. As can be seen in table 4 most comparisons suggest a positive work outcome (32/39), but these positive effects were often not tested for significance (14/32) or proved not significant (7/32). As in a comparable review of the effect of biological agents on work participation in RA, heterogeneity in study design, outcome measures and included patients, and the quality of studies hampered indepth interpretation of results and the ability to reach strong conclusions. ${ }^{21,22}$ The lack of standardisation of outcomes is striking and was the main reason a meta-analysis could not be performed. A second important methodological problem concerns the sample sizes since work participation was never a primary outcome and therefore sample size calculations were not based on work outcomes. This probably explains why the observed changes were often not significant or the significance testing was not presented.

Despite the above-mentioned restrictions, a summary of the results shows that presenteeism in prospective studies improved 1 year after initiation of TNF by 1.7-2.9 points on a 0-10 VAS, the proportion of patients with sick leave decreased by $10-20 \%$ after 1 year of treatment and days absent from work decreased from 8.7 to 22.3 days per year. ${ }^{12,16,18-20}$ These results are impressive. However, it should be emphasised that the above data are usually based on before-after comparisons and do not take into account a placebo effect and regression to the mean. Both RCTs either showed no significant changes between groups or did not test statistical differences between groups. The largest variation in outcome measurement was seen for work status. Although difficult to summarise, overall effects in work status were much smaller than in the other two outcomes. It is important to emphasise that follow-up was often too short to assess longterm changes. Only two studies assessing work status had a follow-up period of more than 1 year. ${ }^{13.17}$ Even more important, patients included in all studies had long disease duration (8-14 years) and the proportion of patients not employed at baseline was also considerable in all studies. This suggests that the negative impact of the disease on employment status had already occurred before starting treatment with TNF inhibitors, leaving limited opportunity for improvement. 
The study performing a stratified analysis based on disease duration, showed better effects on sick leave, but especially on work disability, in those with shorter disease duration. ${ }^{14}$ The use of a population as a control group is in our view the most acceptable solution to performing long-term employment studies using a comparator with adjustment for secular trends. Therefore, the study by Kristensen et al. is of considerable interest. While the RR to be on sick leave compared with the general population improved dramatically after the start of TNF inhibition, they also showed that the increased risk of sick leave returned to the same level as 1 year before the start of treatment. This suggests that regression to the mean in patients with flareups, accounts for part of the large effect. TNF inhibition could not prevent a small (insignificant) increase in the risk of work disability compared with the background population. ${ }^{14}$

One paper compared the possible gain in working time due to presenteeism with sick leave by assuming a linear relation between self-reported productivity and time lost. ${ }^{16}$ This suggests that potential savings in productivity costs due to TNF inhibition by improving presenteeism exceed the savings due to reduction in absence from work. It should be emphasised that there is still discussion as to whether self-reported productivity on a VAS is a valid proxy for 'true' productivity loss. Scarce research suggests that the relation is not linear and probably highly dependent on job and workplace characteristics. ${ }^{23.24}$ Therefore, while improvements in presenteeism are definitely important from a patient perspective, one should be cautious about converting self-reported productivity linearly to changes in productivity costs.

In summary, within the methodological limitations of the included studies, it remains unclear whether TNF inhibition in patients with longstanding AS improves presenteeism, absence from paid work or work status. Studies in patients with shorter disease duration, longer follow-up periods and preferably adjusted for secular trends using the general population as a control group to understand employment outcome, are urgently needed. 


\section{REFERENCES}

1. Boonen A, Chorus A, Miedema H, et al. Employment, work disability, and work days lost in patients with ankylosing spondylitis: a cross sectional study of Dutch patients. Ann Rheum Dis 2001;60:353-8.

2. Marengo MF, Schneeberger EE, Citera G, et al. Work status among patients with ankylosing spondylitis in Argentina. J Clin Rheumatol 2008;14:273-7.

3. Mau W, Listing J, Huscher D, et al. Employment across chronic inflammatory rheumatic diseases and comparison with the general population. J Rheumatol 2005:32:721-8.

4. Boonen A, van der Heijde D, Landewe R, et al. Work status and productivity costs due to ankylosing spondylitis: comparison of three European countries. Ann Rheum Dis 2002;61:429-37.

5. Boonen A, Severens JL. Ankylosing spondylitis: what is the cost to society, and can it be reduced? Best Pract Res Clin Rheumatol 2002;16:691-705

6. Boonen A. Socioeconomic consequences of ankylosing spondylitis. Clin Exp Rheumatol 2002:20(6 Suppl 28):S23-6.

7. Davis JC Jr, van der Heijde DM, Braun J, et al. Efficacy and safety of up to 192 weeks of etanercept therapy in patients with ankylosing spondylitis. Ann Rheum Dis 2008:67:346-52.

8. Heldmann F, Brandt J, van der Horst-Bruinsma IE, et al. The European ankylosing spondylitis infliximab cohort (EASIC): a European multicentre study of long term outcomes in patients with ankylosing spondylitis treated with infliximab. Clin Exp Rheumatol 2011;29:672-80.

9. McLeod C, Bagust A, Boland A, et al. Adalimumab, etanercept and infliximab for the treatment of ankylosing spondylitis: a systematic review and economic evaluation. Health Technol Assess 2007:11:1-iv.

10. van der Heijde DM, Revicki DA, Gooch KL, et al. Physical function, disease activity, and healthrelated quality-of-life outcomes after 3 years of adalimumab treatment in patients with ankylosing spondylitis. Arthritis Res Ther 2009;11:R124.

11. Dutch Cochrane Centre. Checklists risk of bias assessment RCTs and cohort studies. 23 July 2012 http://dcc.cochrane.org/beoordelingsformulieren-en-anderedownloadsm

12. Haibel $\mathrm{H}$, Song $\mathbb{I H}$, Rudwaleit $\mathrm{M}$, et al. Multicenter open-label study with infliximab in active ankylosing spondylitis over 28 weeks in daily practice. Clin Exp Rheumatol 2008:26:247-52.

13. Keat AC, Gaffney K, Gilbert AK, et al. Influence of biologic therapy on return to work in people with work disability due to ankylosing spondylitis. Rheumatology (Oxford) 2008;47:481-3.

14. Kristensen LE, Petersson IF, Geborek P, et al. Sick leave in patients with ankylosing spondylitis before and after anti-TNF therapy: a population-based cohort study. Rheumatology (Oxford) 2012:51:243-9.

15. Listing J, Brandt J, Rudwaleit M, et al. Impact of anti-tumour necrosis factor alphatreatment on admissions to hospital and days of sick leave in patients with ankylosing spondylitis. Ann Rheum Dis 2004:63:1670-2.

16. Maksymowych WP, Gooch KL, Wong RL, et al. Impact of age, sex, physical function, healthrelated quality of life, and treatment with adalimumab on work status and work productivity of patients with ankylosing spondylitis. J Rheumatol 2010;37:385-92.

17. Verstappen SM, Watson KD, Lunt M, et al. Working status in patients with rheumatoid arthritis, ankylosing spondylitis and psoriatic arthritis: results from the British Society for Rheumatology Biologics Register. Rheumatology (Oxford) 2010;49:1570-7. 
18. Barkham N, Coates LC, Keen H, et al. Double-blind placebo-controlled trial of etanercept in the prevention of work disability in ankylosing spondylitis. Ann Rheum Dis 2010;69:1926-8.

19. van der Heijde D, Han C, DeVlam K, et al. Infliximab improves productivity and reduces workday loss in patients with ankylosing spondylitis: results from a randomized, placebo-controlled trial. Arthritis Rheum 2006:55:569-74

20. Moots RJ, Ostor AJ, Loft AG, et al. Reduction of direct and indirect costs in patients with AS receiving etanercept: results from an open-label 36-week extension of the ASCEND study in four European countries. Rheumatology (Oxford) 2012:51:393-6.

21. ter Wee MM, Lems WF, Usan H, et al. The effect of biological agents on work participation in rheumatoid arthritis patients: a systematic review. Ann Rheum Dis 2012;71:161-71.

22. Verstappen SM, Fautrel B, Dadoun S, et al. Methodological issues when measuring paid productivity loss in patients with arthritis using biologic therapies: an overview of the literature. Rheumatology (Oxford) 2012:51:216-29

23. Kessler RC, Ames M, Hymel PA, et al. Using the World Health Organization Health and Work Performance Questionnaire (HPQ) to evaluate the indirect workplace costs of illness. J Occup Environ Med 2004:46(6 Suppl):S23-37.

24. Lerner D, Amick BC III, Rogers WH, et al. The Work Limitations Questionnaire. Med Care 2001:39 :72-85 


\section{SUPPLEMENTARY INFORMATION}

APPENDIX 1: Search strategy for PubMed, Embase and the Cochrane Database

\section{Search PubMed}

\#1 Spondylitis, Ankylosing

\#2 biological OR anti TNF OR TNF inhibitor OR etanercept OR infliximab OR anakinra OR adalimumab OR abatacept OR golimumab OR rituximab OR certolizumab OR tocilizumab OR anti tumor necrosis factor

\#3 employment OR work disability OR disability OR sick leave OR productivity OR employability OR work ability OR absenteeism OR presenteeism OR sick absence OR work instability OR return to work OR economic consequence OR occupational health

\#1 AND \#2 AND \#3

\section{Search Embase}

\#1: ankylosing AND ('spondylitis'/exp OR spondylitis) OR as

\#2: biological OR anti AND tnf OR tnf AND inhibitor OR 'etanercept'/ exp OR etanercept OR 'infliximab'/exp OR infliximab OR 'anakinra'/exp OR anakinra OR'adalimumab'/exp OR adalimumab OR 'abatacept'/exp OR abatacept OR 'golimumab'/exp OR golimumab OR 'rituximab'/exp OR rituximab OR certolizumab OR'tocilizumab'/exp OR tocilizumab OR 'anti tumour necrosis factor'/exp OR anti tumour necrosis factor

\#3: 'employment'/exp OR employment OR 'work'/exp OR work AND ('disability'/ $\exp$ OR disability) OR 'disability'/exp OR disability OR 'productivity'/exp OR productivity OR 'employability'/exp OR employability OR working AND ('ability'/ exp OR ability) OR 'absenteeism'/exp OR absenteeism OR sick AND leave OR presenteeism OR 'sickness'/exp OR sickness AND ('absence'/exp OR absence) OR 'work'/exp OR work AND instability OR return AND to AND ('work'/exp OR work) OR economic AND consequence OR occupational AND ('health'/exp OR health) OR 'work'/exp OR work AND instability

\#1 AND \#2 AND \#3

\section{Search Cochrane Database}

\#1 (Spondylitis, Ankylosing):ti,ab,kw

\#2 (biological OR anti TNF OR TNF inhibitor OR etanercept OR infliximab OR anakinra OR adalimumab OR abatacept OR golimumab OR rituximab OR certolizumab OR tocilizumab OR anti tumor necrosis factor):ti,ab,kw 
\#3 (employment OR work disability OR disability OR sick leave OR productivity OR employability OR work ability OR absenteeism OR presenteeism OR sick absence OR work instability OR return to work OR economic consequence OR occupational health):ti,ab,kw

(\#1 AND \#2 AND \#3)

APPENDIX 2: Quality checklists for cohort studies and randomized controlled trials (RCTs).

\section{Quality assessment of cohort studies}

1) Is/are the study population(s) that are compared clearly defined?

2) Was selection bias sufficiently accounted for?

3) Was the exposure clearly defined and was the method for measuring the exposure appropriate?

4) Was the outcome clearly defined and was the method for measuring the outcome appropriate?

5) Was the outcome blind assessed? If the outcome was not blinded, did this influence the outcome?

6) Was the follow-up period sufficiently long?

7) Was selective loss to follow-up appropriately accounted for?

8) Are the most important confounders identified and is this adequately accounted for in the design and analyses?

9) Was a recall period for absenteeism, presenteeism and work disability reported?

10) Was it reported whether the work participation outcome was assessed with interference of AS?

\section{Quality assessment of RCTs}

1) Was assigning of the intervention done by randomisation?

2) The person who includes patients should not know the randomisation sequence. Was that the case?

3) Were patients blinded for the treatment?

4) Were treating physicians blinded for the treatment?

5) Were effect assessors blinded for the treatment?

6) Were the groups similar at baseline? Extra answer option: a) no, but corrected for or b) no and not corrected for.

7) Is a complete follow-up period available for a sufficient proportion of the included patients? If the answer is no: is selective loss to follow-up appropriately accounted for?

8) Were all included patients analysed in the group randomised in (IIT population)?

9) Were the groups equally treated, apart from the intervention?

10) Was a recall period for absenteeism, presenteeism and work disability reported?

11) Was it indicated whether work participation outcomes were assessed with interference of AS? 




\section{LONG-TERM SICKNESS ABSENCE IN A WORKING POPULATION: DEVELOPMENT AND VALIDATION OF A RISK PREDICTION MODEL IN A LARGE DUTCH PROSPECTIVE COHORT}

Lennart R.A. van der Burg

Sander M.J. van Kuijk

Marieke M. ter Wee

Martijn W. Heymans

Angelique E. de Rijk

Goedele A. Geuskens

Ramon P.G. Ottenheijm

Geert-Jan Dinant

Annelies Boonen 


\section{ABSTRACT}

Background. Societal expenditures on work-disability benefits is high in most Western countries. As a precursor of long-term work restrictions, long-term sickness absence (LTSA) is under continuous attention of policy makers. Different healthcare professionals can play a role in identification of persons at risk of LTSA but are not well trained. A risk prediction model can support risk stratification to initiate preventative interventions. Unfortunately, current models lack generalizability or do not include a comprehensive set of potential predictors for LTSA. This study is set out to develop and validate a multivariable risk prediction model for LTSA in the coming year in a working population aged 45-64 years.

Methods. Data from 11,221 working persons included in the prospective Study on Transitions in Employment, Ability and Motivation (STREAM) conducted in the Netherlands were used to develop a multivariable risk prediction model for LTSA lasting $\geq 28$ accumulated working days in the coming year. Missing data were imputed using multiple imputation. A full statistical model including 27 pre-selected predictors was reduced to a practical model using backward stepwise elimination in a logistic regression analysis across all imputed datasets. Predictive performance of the final model was evaluated using the Area Under the Curve (AUC), calibration plots and the Hosmer-Lemeshow (H\&L) test. External validation was performed in a second cohort of 5604 newly recruited working persons

Results. Eleven variables in the final model predicted LTSA: older age, female gender, lower level of education, poor self-rated physical health, low weekly physical activity, high self-rated physical job load, knowledge and skills not matching the job, high number of major life events in the previous year, poor self-rated work ability, high number of sickness absence days in the previous year and being self-employed. The model showed

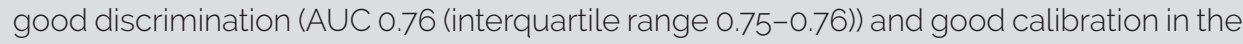
external validation cohort (H\&L test: $p=0.41$ )

Conclusions. This multivariable risk prediction model distinguishes well between older workers with high- and low-risk for LTSA in the coming year. Being easy to administer, it can support healthcare professionals in determining which persons should be targeted for tailored preventative interventions 


\section{BACKGROUND}

Participation in paid work is one of the most important social roles of individuals in our society. Paid work is a source of income, protects against social exclusion and gives meaning to life. ${ }^{1-3}$ Moreover, restrictions in work participation (e.g. sickness absence or permanent work disability) cause a substantial burden on societal expenditures in most Organisation for Economic Cooperation and Development (OECD) countries. ${ }^{4}$ Worker productivity is a continuum, ranging from normal productivity over presenteeism and prolonged sick leave to withdrawal from paid work. It is recognized that return to work is unlikely when individuals have become work disabled. ${ }^{5.6}$ Early recognition and prevention of long-term restrictions in work participation, e.g. long-term sickness absence (LTSA) (usually defined as more than 4-6 weeks of sickness absence), have therefore become an important target in several countries, including the Netherlands.7 Most healthcare professionals, such as general practitioners who are usually first consulted when a (medical) problem arises, are not well trained in identifying individuals at risk for restrictions in work participation. Risk prediction models could support early identification by those healthcare professionals, and ensure timely initiation of targeted interventions to prevent long-term work restrictions. . $^{6.89}$

There are few studies that have published multifactorial risk prediction models that identify working persons at risk of LTSA. ${ }^{10}$ However, these models frequently address selected professional groups or work sectors and not a broader general working population. ${ }^{11-15}$ Other limitations of those studies were that the risk prediction model was not externally validated, ${ }^{16}$ was mostly developed in Scandinavian cohorts and likely not generalizable to other countries, or did not include a comprehensive set of variables relevant for sustainable work participation in their available dataset for prediction model development. ${ }^{16-18}$

The Study on TRansitions in Employment, Ability and Motivation (STREAM) conducted in the Netherlands is suitable for development and external validation of a prediction model for LTSA in a general working population aged $45-64$ years. The strength of STREAM is that a wide variety of variables important for sustainable work participation were collected that are not currently included in most occupational health surveys. Therefore, this study set out to develop and externally validate an easy-to-assess multivariable risk prediction model for LTSA in the coming year in a general working population aged 45-64 years. 


\section{METHODS}

\section{Study design and participants}

STREAM is an ongoing prospective cohort among persons aged 45 to 64 years in the Netherlands stratified by age and employment status. From the inception of the cohort in 2010 (T1) onwards, participants completed an online questionnaire on topics such as work characteristics, health, employment status and transitions, work ability, and work productivity. A more detailed description of the STREAM study design has been published previously. ${ }^{19}$ At the time of the fifth measurement of the STREAM cohort (2015), a second cohort of participants was recruited, consisting of persons aged 45-49 years and employed persons in the other age groups (50-54, 55-59, 60-64).

For development of the current risk prediction model, data from the first ( $T 1,2010)$ and the second $(T 2,2011)$ measurement were used. This cohort comprised 15,118 persons who participated in STREAM of which $82.2 \%$ responded at T2 $(n=12,430)$. Subjects were included in the analyses if they were employed at time of inclusion (including selfemployment), but were excluded if they received a fulltime disability pension, or had been on LTSA in the previous year (see definition below).

For external validation, data from the second cohort recruited at the time of the scheduled fifth measurement $(T 5,2015)$ and 1 year follow-up $(T 6,2016)$ were used. This cohort consisted of 6728 persons at T5 and $77.4 \%$ responded at T6 $(n=5218)$.

\section{Definition of long-term sickness absence}

LTSA in the year of follow up was defined as $\geq 28$ accumulated working days and was assessed through self-report in the follow-up survey.

\section{Predictor variables of long-term sickness absence}

Available predictors

The online questionnaire included a wide variety of variables covering fourteen different domains: demographic characteristics (e.g. age), health and well-being (e.g. perceived health), work-related factors (e.g. working conditions), knowledge and skills (e.g. developmental proactivity), social factors (e.g. work-family balance), financial factors (e.g. household income), motivation to work (e.g. job satisfaction), ability to work (e.g. Work Ability Index (WAI)), opportunity to work (e.g. support by colleagues), productivity at work (e.g. presenteeism), employment status and transitions, mastery (i.e. Pearlin Mastery Scale), job intentions (e.g. to stop working) and coping styles (i.e. Utrecht Coping List). A more detailed description of all (sub) domains and questionnaires included in 
STREAM has been published previously. ${ }^{19}$ Most of the (sub) domains have been shown in previous publications to be important for sustainable employability and cover the different components of the International Classification of Functioning, Disability, and Health (ICF). ${ }^{1}$

\section{Selection of candidate predictors for the model}

Variables available at $T 1$ were included as candidate predictors if they had been inquired among working participants, including self-employed participants. This resulted in 141 candidate predictors from 11 different domains. Several steps were undertaken to further reduce the amount of candidate predictors to be included in the full statistical model. First, a literature search was performed to identify previously published prediction models and individual predictors specific for LTSA. ${ }^{11-13,16-18,20}$ These predictors were recorded and similar or identical variables in STREAM were identified. Thereafter, an expert consensus group meeting including all authors listed above was organized to reach consensus which variables available in STREAM should be included in the full statistical model. As a guiding principle, it was agreed that (at least) one candidate predictor from each applicable domain should be included in the full statistical model. To inform the expert consensus group, members had insight into all univariate associations between the predictor variables and the outcome as well as results from the literature search (data not shown). If two or more predictors within a domain showed overlap in content or were statistically highly correlated, the most feasible predictor for a clinical setting was selected. For example, the self-rated SF-12 Mental Component Score (MCS) and Center for Epidemiologic Studies Depression scale (CES-D-10) showed great overlap in content, an equally strong association with the outcome and a strong statistical correlation between them. The MCS was eventually chosen because it requires less items to complete (6 vs. 10 items). Finally, it was pre-specified to maintain the variables age, gender and level of education in the model because these predictors were frequently included in previously published models (face validity). This expert meeting resulted in 27 candidate predictors across 11 domains that were included in the full statistical model (description in Additional file 1)

\section{Statistical analysis}

Missing data in the development and the validation cohort were imputed using multiple imputation techniques according to the method described by Van Buren et al. ${ }^{21} \mathrm{We}$ created $m=30$ imputed datasets and used predictive mean matching for imputing continuous predictors, polytomous regression for categorical predictors and logistic regression for dichotomous predictors. All 27 candidate predictors and the outcome LTSA were included in the imputation model. 
A logistic regression analysis was performed to estimate regression coefficients of the association between predictors and LTSA during the coming year. First, the 'full statistical model' was computed including all 27 candidate predictors in each of the imputed datasets. We then used backward stepwise elimination across all imputed datasets using $p>0.05$ as a rule to remove predictors from the model to create a smaller and therefore more practical final prediction model.

The performance of the final prediction model was evaluated using the Area Under the Receiver Operating Characteristic (ROC) Curve (AUC), which reflects how well the model discriminates between those persons with and without LTSA in the coming year. The AUC has a range from 0.5 (i.e. no discriminative ability) to 1.0 (perfect discriminative ability). Calibration of the final prediction model, i.e. the correspondence of the predicted and observed probabilities, was evaluated using calibration plots and the Hosmer-Lemeshow goodness of fit test. To assess the degree of overfitting we used bootstrapping techniques for internal validation with 1000 bootstrap samples in each of the imputed datasets. The estimated shrinkage factor was applied to the regression coefficients to arrive at the final model.

Sensitivity analyses included: 1) complete case analyses (i.e. participants with no missing values on any of the predictor variables or outcome), for both model development and validation, and 2) stratified analyses for employed and self-employed participants. To externally validate the final prediction model, we assessed its predictive performance and calibration in the validation cohort. All analyses were performed with R version 3.4.4. in RStudio 1.1.442 (RStudio Inc, Boston, MA) using the following packages: mice, rms and psfmi. 


\section{RESULTS}

After exclusion of participants currently not working, receiving a fulltime disability pension or with LTSA in the previous year, 11,221 of the 15,118 participants at $\mathrm{T} 1$ (74.2\%) were included in the development cohort. Similarly, 5604 of the 6728 participants at T5 (83.3\%) were included in the validation cohort (see Fig. 1). Participants in the validation cohort were on average younger, less frequently male, and reported a somewhat better physical health (see Table 1). After 1 year of follow-up, 495 participants (5.7\%) in the development cohort and 238 participants $(5.7 \%)$ in the validation cohort reported LTSA.

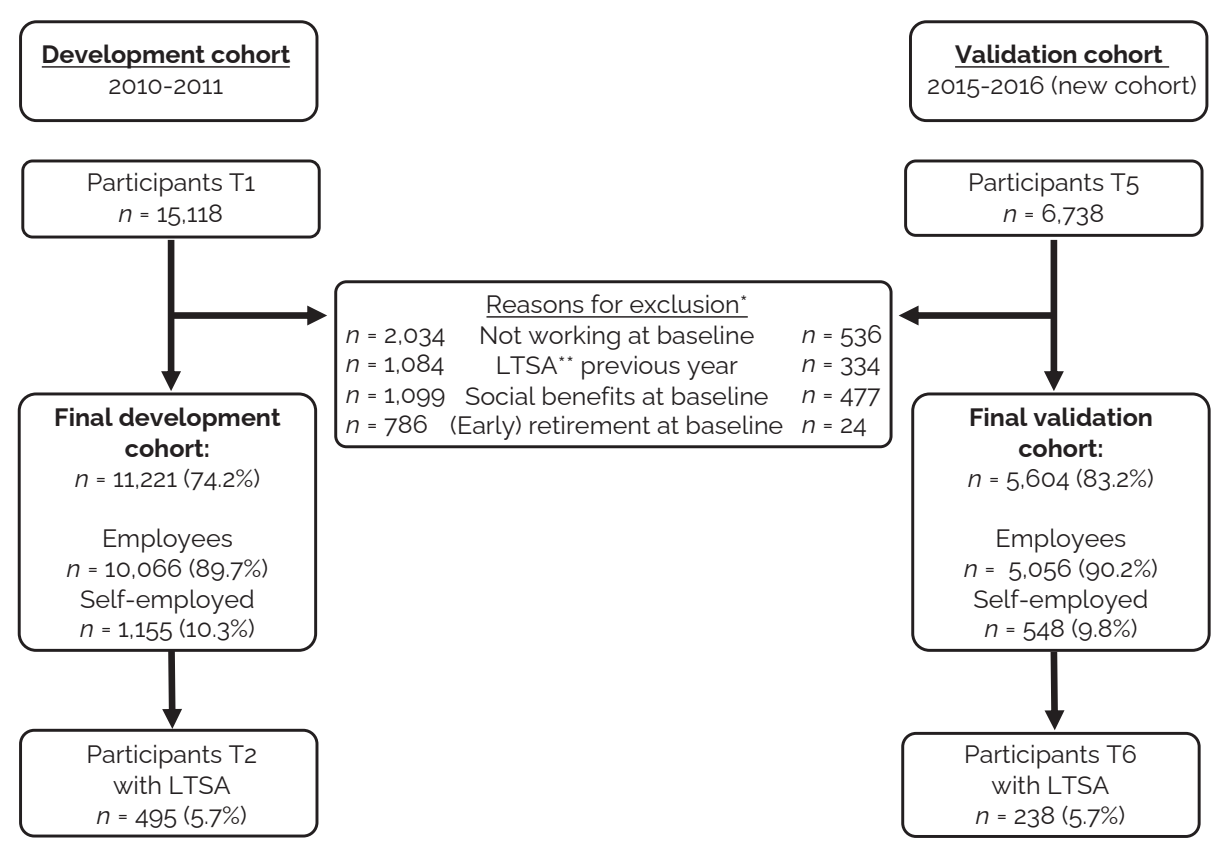

Figure 1. Flow chart of the development and validation cohort used for the analyses in this study. *More than one reason can apply to one participant. " ${ }^{*}$ Long-term sickness absence (LTSA) waS defined as $\geq 28$ accumulated work days of sick leave during 1 year of follow-up 
Table 1. Baseline characteristics of participants in the development and validation cohort

\section{Level}

Female, (\%)

Age, mean(SD)

Educational levela $\mathrm{n}(\%)$

Low

Medium

High

SF-12 physical health ${ }^{b}$, mean(SD)

Physically fitc, $n(\%)$

Physical job loadd ${ }^{d}$, mean(SD)

Knowledge and skills match the job, n(\%)

$\mathrm{Bad} /$ mediocre

Reasonable/good

Major life events previous year, n(\%)

0

1

$\geq 2$

Work abilitye, mean(SD)

Sickness absence days previous year, mean(SD)

Employment status, $\mathrm{n}(\%)$

Employee

Self-employed

$\mathrm{SD}=$ standard deviation, $\mathrm{SF}=$ Short Form Health Survey

a Low: lower general secondary educational, preparatory secondary vocational education.

Medium: intermediate vocational training, higher general secondary education, pre-university education. High: higher vocational education, university education.

b Weighted summary score (range 0-100) assessing physical health using 6 items of the 12-Item Short-Form Health Survey. Higher scores indicating better perceived health. 
Development cohort

\begin{tabular}{|c|c|c|}
\hline$n=11,221$ & $n=5,604$ & $p$-value \\
\hline 4819 (42.9) & $2753(49.1)$ & $<0.001$ \\
\hline $53.9(5.4)$ & $50.2(5.2)$ & $<0.001$ \\
\hline $2924(26.1)$ & $1390(24.8)$ & 0.12 \\
\hline 4349 (38.8) & $2253(40.2)$ & \\
\hline 3948 (35.2) & $1961(35.0)$ & \\
\hline $52.4(7.0)$ & $52.2(7.4)$ & 0.07 \\
\hline $4502(40.4)$ & $2535(45.4)$ & $<0.001$ \\
\hline $1.8(0.9)$ & $1.9(0.9)$ & $<0.001$ \\
\hline $488(4.4)$ & $255(4.6)$ & 0.54 \\
\hline $10,687(95.6)$ & $5323(95.4)$ & \\
\hline $5877(52.4)$ & $3239(57.8)$ & $<0.001$ \\
\hline 3577 (31.9) & $1640(29.3)$ & \\
\hline $1767(15.7)$ & 725 (12.9) & \\
\hline $8.0(1.4)$ & $8.1(1.4)$ & 0.10 \\
\hline $2.9(5.1)$ & $2.7(4.9)$ & 0.01 \\
\hline 10,066 (89.7) & $5056(90.2)$ & 0.30 \\
\hline $1155(10.3)$ & $548(9.8)$ & \\
\hline
\end{tabular}

c Intensive physical exercise at least $\geq 3$ days per week for $\geq 20$ minutes.

${ }^{d}$ Average of five items (range: 1 = never, 5 = always) from the Dutch Musculoskeletal Questionnaire.22

e Measured with the first item of the Work Ability Index (WAI). ${ }^{23}$ 
Table 2. Univariate associations and multivariable regression coefficients of the predictors in the final model of the development cohort

Predictor

Female gender

Age, per year

Educational levelc (ref: low)

SF-12 physical health ${ }^{d}$ (ref: 1st quartile, poorest health)

Physically fit

Physical job load' (ref: $1^{\text {st }}-3^{\text {rd }}$ quartile, less demanding)

Knowledge and skills match the job (ref: bad/mediocre)

Major life events previous year (ref: none)

Work abilityg (ref: good)

Sickness absence days previous year (ref: none)

\section{Level}

$$
\begin{aligned}
& \text { Medium } \\
& \text { High } \\
& 2^{\text {nd }} \text { quartile } \\
& 3^{\text {rd }} \text { quartile } \\
& 4^{\text {th }} \text { quartile }
\end{aligned}
$$

$4^{\text {th }}$ quartile

Reasonable/good

1

$\geq 2$

Average

Poor

$1-5$

$6-10$

$11-27$

Self-employed

Intercept

a Pooled Odds Ratio (95\% confidence interval) from the $m=30$ multiple imputed datasets.

b Pooled regression coefficients and intercept from the $m=30$ multiple imputed datasets An individuals predicted probability can be computed using the logistic regression formula $P(L T S A)=1 /(1+\exp (-L P)$, in which 'exp' denotes e-raised-to-the-power-of. The LP is the linear predictor, i.e. the linear sum of all predictor values multiplied by their regression coefficients. or $-2.55+0.09^{*}$ gender (female $\left.=1\right)+0.007^{*}$ age (years) $-0.13^{*}$ education (medium education $=1$ ) $-0.19^{*}$ education (high education $\left.=1\right)-0.59^{*}$ physical health $\left(2^{\text {nd }}\right.$ quartile $\left.=1\right)-0.87^{*}$ physical health $\left(3^{\text {rd }}\right.$ quartile $\left.=1\right)-0.90$ * physical health $\left(4^{\text {th }}\right.$ quartile $\left.=1\right)-0.22^{*}$ physically fit (yes $\left.=1\right)+0.29^{*}$ physical job load $\left(4^{\text {th }}\right.$ quartile $\left.=1\right)-0.48^{*} \mathrm{knowledge}($ reasonable $/ \mathrm{good}=1)+0.11^{*}$ major life events (one event = 1) $+0.35^{*}$ major life events (two or more $\left.=1\right)+0.10^{*}$ work ability (average $\left.=1\right)+0.82^{*}$ work ability (poor $=1)+0.33^{*}$ sickness absence $(1-5$ days $=1)+0.93^{*}$ sickness absence $(6-10$ days $=1)+1.35^{*}$ sickness absence (11-27 days $=1)-0.57^{*}$ employment status (self-employed $=1$ ) 


\begin{tabular}{|c|c|c|}
\hline Univariate & & \\
\hline OR $(95 \% \mathrm{Cl})^{\mathrm{a}}$ & OR & Coefficient $^{\mathrm{b}}$ \\
\hline $1.26(1.05-1.51)$ & 1.10 & 0.09 \\
\hline $1.02(1.00-1.03)$ & 1.00 & 0.007 \\
\hline $1.00(0.84-1.19)$ & 0.88 & -0.13 \\
\hline $0.75(0.62-0.91)$ & 0.83 & -0.19 \\
\hline $0.97(0.80-1.18)$ & 0.55 & -0.59 \\
\hline $0.51(0.41-0.65)$ & 0.42 & -0.87 \\
\hline $0.46(0.36-0.59)$ & 0.41 & -0.90 \\
\hline $0.77(0.64-0.94)$ & 0.80 & -0.22 \\
\hline $1.63(1.35-1.98)$ & 1.33 & 0.29 \\
\hline $0.43(0.30-0.59)$ & 0.62 & -0.48 \\
\hline $1.10(0.92-1.33)$ & 1.12 & 0.11 \\
\hline $1.62(1.32-2.00)$ & 1.43 & 0.35 \\
\hline $1.40(1.14-1.71)$ & 1.10 & 0.10 \\
\hline $4.70(3.50-6.30)$ & 2.28 & 0.82 \\
\hline $0.90(0.73-1.12)$ & 1.39 & 0.33 \\
\hline $2.25(1.76-2.87)$ & 2.53 & 0.93 \\
\hline $4.68(3.77-5.80)$ & 3.84 & 1.35 \\
\hline \multirow[t]{2}{*}{$0.49(0.33-0.73)$} & 0.57 & -0.57 \\
\hline & & -2.55 \\
\hline
\end{tabular}

c Low: lower general secondary educational, preparatory secondary vocational education. Medium: intermediate vocational training, higher general secondary education, pre-university education. High: higher vocational education, university education.

'Weighted summary score (range 0-100) assessing physical health using 6 items of the 12-Item Short-Form Health Survey. Higher scores indicating better perceived physical health. $1^{\text {st }}$ quartile $<46.1,2^{\text {nd }}$ quartile $=46.1-54.1,3^{\text {rd }}$ quartile $=54.2-56.5,4^{\text {th }}$ quartile $\rangle=56.6$

e Intensive physical exercise $\geq 3$ days per week for $\geq 20$ minutes.

${ }^{f}$ Average of five items (range: 1 = never, 5 = always) from the Dutch Musculoskeletal Questionnaire. ${ }^{22}$ $1^{\text {st }-3^{\text {rd }}}$ quartile $<2.4,4^{\text {th }}$ quartile $>=2.4$

g Measured with the first item of the Work Ability Index (WAI).[23] Good $=8-10$, average $=6 / 7$, poor $=0-5$ 
Numbers of missing values were low for all candidate predictor variables (less than $3 \%$ for each variable, see Additional file 1). Follow-up data for the outcome variable were missing from 2540 of the 11,221 participants (22.6\%) in the development cohort and from 1432 of the 5604 participants (25.6\%) in the validation cohort. To examine possible selective loss to follow-up, we compared baseline characteristics of participants missing at the follow-up measurement with participants that were not missing. Table 3 in Additional file 1 shows some statistically significant differences which are not clinically relevant. All candidate predictors and the outcome in both the development and validation cohort were imputed using the methods described above.

\section{Development of the prediction model}

Eleven of the 27 predictors were retained in the final prediction model: age (continuous), gender (male vs. female), education (low vs. medium; low vs. high), self-rated physical health (SF-12 Physical Component Score (PCS)), quartiles of increasing good health, lowest/poorest quartile is reference), being physically fit (at least 3 days of intensive physical exercise for more than 20 min or more, no vs. yes), amount of physical job load (average of 6 items, lowest three quartiles combined vs. highest quartile), knowledge and skills matching the job (bad/mediocre vs, reasonable/good), self-rated work ability (first item of the WAI, good (score 8-10) vs. average (6/7), good vs. poor (0-5)), the number of sickness absence days in the previous year (none vs. 1-5 days, none vs. 6-10 days, none vs. 11-27 days), being self-employed (no vs. yes) and the number of major life events in the previous year (none vs. 1 event, none vs. 2 or more events). Good self-rated physical health (odds ratio (OR) 0.46 (95\%-confidence interval (CI) 0.36-0.59), lowest quartile vs. highest quartile), with poor self-rated work ability (OR 4.70 ( $95 \% \mathrm{Cl} 3.50-6.30)$, good vs. poor) and a high number of sickness absence days in the previous year (OR 4.68 (95\% Cl 3.77-5.80), none vs. 11-27 days) showed the strongest univariate associations with LTSA in the development cohort (see Table 2). Sensitivity analyses using the complete cases resulted in the same predictor variables retained in the final prediction model and similar univariate associations with LTSA (see Additional file 1, table 4). We found similar results for employed and self-employed persons and therefore decided to develop one prediction model that included both groups and with self-employment as one of the predictor variables (data not shown).

\section{Validation of the prediction model}

Internal validation of the prediction model using bootstrapping across $m=30$ imputed datasets showed good discriminative ability: pooled median AUC 0.73 (interquartile range (IQR) 0.73-0.74) for predicting LTSA in the coming year. In the validation cohort, discrimination remained similar as observed in the development cohort: pooled median AUC 0.76 (IQR 0.75-0.76). The prediction model showed good calibration (predicted LTSA 
risks by the model plotted against the observed LTSA frequencies) in the validation cohort (see Fig. 2, H\&L test: $p=0.41$ ). No further updating of the prediction model was necessary. Sensitivity analyses using the complete cases in the validation cohort yielded similar results (see Additional file 1, table 4 and Fig. 1).

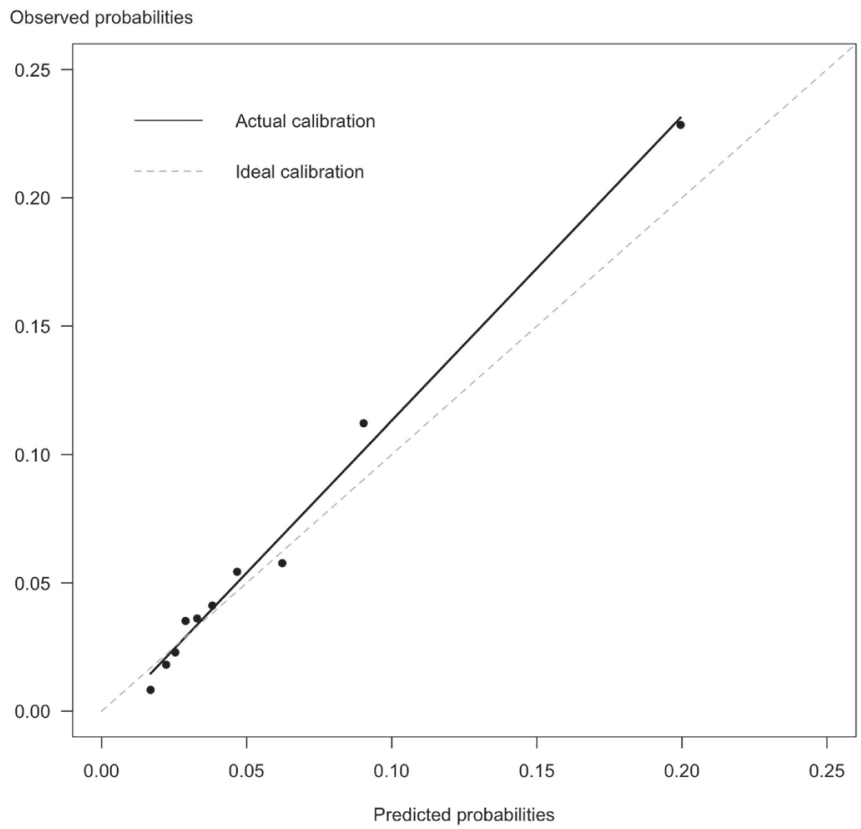

Figure 2. Calibration plot visualizing the mean predicted LTSA by the model against observed frequencies per decile of predicted risk in the validation cohort. Hosmer-Lemeshow test: $p=0.41$ 


\section{DISCUSSION}

We developed and externally validated a model to predict LTSA of 28 or more work days in the coming year in a general working population aged 45-64 years. The following eleven easy to assess predictors were retained in the final multivariable model: older age, female gender, lower level of education, poor self-rated physical health, low weekly physical activity, high self-rated physicaljob load, knowledge and skills not matching the job, high number of major life events in the previous year, poor self-rated work ability, high number of sickness absence days in the previous year and not being self-employed. The prediction model discriminates well between working persons with and without LTSA and showed good calibration in the external validation cohort.

Previously published prediction models, mostly developed within routinely collected occupational health datasets, found that low physical health, prior (long-term) sickness absences and having mental health issues are important predictors of future LTSA.11,13.16,17 However, mental health was not a predictor of LTSA in our model, possibly due to some collinearity with other variables in the full multivariable model (e.g. major life events, emotional job demands) or due to the constitution of the cohort which included only older working persons and diverse professional sectors and different contract types. Also, mental health issues may be more important in certain working populations or sectors (e.g. younger persons, white collar workers) but this should be confirmed in future studies updating this prediction model. Our model confirms the role of previous sickness absence and self-reported physical health in predicting future LTSA. It is of note that the level of perceived limitations in physical functioning predict future LTSA better than the health condition possibly underlying these limitations, such as musculoskeletal disease or multimorbidity, which were eliminated from the full multivariable model that included self-reported physical health and physical job load. Predictors assessing social and financial factors, emotional job demands and autonomy were eliminated from the full multivariable model, although some of these have been shown to be predictors of LTSA in a few previous studies. ${ }^{11,16,17}$ Possibly the broader professional background but also older age of this cohort might account for these differences. We found that other factors are important for predicting LTSA which were not included in previous studies. Knowledge and skills matching the current job, the number of major life events in the previous year, and not being self-employment proved to be strong predictors of future LTSA. We found no important effect modification by employment status (employee vs. self-employed) and therefore decided to develop one prediction model that included both groups. However, not being self-employed was an important predictor for future LTSA and was therefore included in our final multivariable model. 
One of the strengths of the present study is that the STREAM cohort includes a number of new candidate predictors for LTSA not previously addressed in occupational health surveys. Secondly, this large and prospective population-based study provides sufficient statistical power to develop and validate an accurate prediction model. Another strength was that the feasibility of candidate predictors, i.e. how easily can the information be collected by a healthcare professional, was regarded as important to ensure future practical purposes. All methods used for model development and validation in this study are in accordance with the Transparent Reporting of a multivariable prediction model for Individual Prognosis Or Diagnosis (TRIPOD) statement. ${ }^{24}$

One limitation of this study was that loss to follow-up was present in both the development and validation cohort which could have introduced attrition bias. However, the participants that were lost to follow-up did not differ importantly from participants that were not lost to follow-up, we used multiple imputation techniques to deal with the missing values and sensitivity analysis on complete cases yielded similar results. The impact of the social security system or the working culture within a nation on the risk of sickness absence and disability pension has been shown to be different in the Netherlands compared to other European countries. ${ }^{25-27}$ This prediction model was developed and validated in a cohort of working persons aged 45 to 64 years and therefore potentially not generalizable to younger age-groups because other factors may also be relevant in younger working persons (e.g. family-work balance, job security). ${ }^{28}$ It is possible that this prediction model needs to be adjusted (e.g. adjusting regression coefficients/intercept, adding or removing predictors) for use in other countries and transferability can be an interesting topic for future research.

\section{Practical implications and directions for future research}

This prediction model was developed to support healthcare professionals, such as general practitioners, public health workers and occupational specialists, in identifying working persons of 45 years or older at high risk of LTSA in the coming year. After identification, supportive interventions should be considered, ranging from raising awareness or providing simple advice for modifying lifestyle or working conditions, referral to a medical or occupational specialist, or a preventative rehabilitation program in case of a complex problem. Given the low prevalence of LTSA in the working population, and thus the risk for a high false-positive rate, it is essential to have a simple screening tool and low cost interventions for the persons at risk ${ }^{10}$ The impact of the proposed prediction model on clinical decision making and short- and long-term patient outcome and cost-effectiveness should be studied in a (cluster) randomized design. Before such a study is designed some facilitators and barriers to further improve the ease of use of this prediction model should be taken into account. ${ }^{29}$ Firstly, automated calculations (e.g. 
in a web-based format or integration in the electronic patient records) will ease the use for healthcare professionals. Secondly, an optimal cut-off point needs to be determined (i.e. balance between the harm of a false-positive classification and the benefit of a truepositive classification) while also taking into account the availability of resources after referral of high-risk persons. Finally, our model has not only the promise to target persons at risk, but could also serve to identify new and potentially modifiable risk factors at the level of companies or workplaces (e.g. physical fitness).10,30

\section{Conclusions}

We developed and validated a prediction model for long-term sickness absence in the coming year that showed good discrimination and calibration in a general population of working persons aged 45-64 years in the Netherlands. Future studies should investigate the transferability of this prediction model to other settings, age-groups and countries as well as the effects on clinical decision making and patient outcome. 


\section{REFERENCES}

1. World Health Organization. International classification of functioning, disability and health: ICF. World Health Organization. 2001. https://apps.who.int/iris/handle/10665/42407.

2. Fryers T. Work, identity and health. Clin Pract Epidemiol Ment Health 2006;2:12.

3. Katz P, Morris A, Gregorich S, et al. Valued life activity disability played a significant role in selfrated health among adults with chronic health conditions. J Clin Epidemiol 2009:62(2):158-66.

4. OECD. Social Expenditure Update 2019, Public social spending is high in many OECD countries. Paris: OECD Publishing; 2019. https://www.oecd.org/els/soc/OECD2019-Social-ExpenditureUpdate.pdf.

5. van Vilsteren $\mathrm{M}$, van Oostrom SH, de Vet HCW, et al. Workplace interventions to prevent work disability in workers on sick leave. Cochrane Database Syst Rev 2015;10:1465-858

6. Vooijs M, Leensen MCJ, Hoving JL, et al. Interventions to enhance work participation of workers with a chronic disease: a systematic review of reviews. Occup Environ Med 2015;72(11):820-6.

7. Organization for Economic Cooperation and Development. Sickness, disability and work: breaking the barriers. Paris: OECD Publishing; 2010.

8. Kant I, Jansen NW, van Amelsvoort LG, et al. Structured early consultation with the occupational physician reduces sickness absence among office workers at high risk for long-term sickness absence: a randomized controlled trial. J Occup Rehabil 2008;18(1):79-86.

9. Taimela S, Malmivaara A, Justen S, et al. The effectiveness of two occupational health intervention programmes in reducing sickness absence among employees at risk. Two randomized controlled trials. Occup Environ Med 2008;65(4):236-41.

10. Burdorf A. Prevention strategies for sickness absence: sick individuals or sick populations? Scand J Work Environ Health 2019:45(2):101-2.

11. Kant I, Jansen NW, van Amelsvoort LGPM, et al. Screening questionnaire Balansmeter proved successful in predicting future long-term sickness absence in office workers. J Clin Epidemiol 2009 Apr:62(4):408-414.e2

12. Koopmans PC, Roelen CAM, Groothoff JW. Frequent and long-term absence as a risk factor for work disability and job termination among employees in the private sector. Occup Environ Med 2008:65(7):494-9.

13. Roelen CA, Bultmann U, van Rhenen W, et al. External validation of two prediction models identifying employees at risk of high sickness absence: cohort study with 1-year followup. BMC Public Health 2013:13:105

14. Boot CR, van Drongelen A, Wolbers I, et al. Prediction of long-term and frequent sickness absence using company data. Occup Med (London) 2017:67(3):176-81

15. Lexis MA, Jansen NW, van Amelsvoort LGPM, et al. Prediction of long-term sickness absence among employees with depressive complaints. J Occup Rehabil 2012;22(2):262-9,

16. Roelen C, Thorsen S, Heymans M, et al. Development and validation of a prediction model for long-term sickness absence based on occupational health survey variables. Disabil Rehabil 2018:40(2):168-75

17. Airaksinen J, Jokela M, Virtanen $M$, et al. Prediction of long-term absence due to sickness in employees: development and validation of a multifactorial risk score in two cohort studies. Scand J Work Environ Health 2018;44(3):274-82.

18. Roelen CA, Bultmann U, Stapelfeldt CM, et al. Multicentre validation of frequent sickness absence predictions. Occup Med (London) 2016;66(1):69-71. 
19. Ybema JF, Geuskens GA, van den Heuvel SG, et al. Study on transitions in employment, ability and motivation (STREAM): the Design of a Four-year Longitudinal Cohort Study among 15,118 persons aged 45 to 64 years. British J Med Med Res 2014;4(6):1383-99.

20. Duijts SF, Kant IJ, Landeweerd JA, et al. Prediction of sickness absence: development of a screening instrument. Occup Environ Med 2006:63(8):564-9.

21. van Buuren S, Groothuis-Oudshoorn K. mice: Multivariate Imputation by Chained Equations in R. J Stat Softw 2011;1:3.

22. Hildebrandt VH, Bongers PM, van Dijk FJH, et al. Dutch Musculoskeletal Questionnaire: description and basic qualities. Ergonomics 2001;44(12):1038-55.

23. Ilmarinen J. Work ability--a comprehensive concept for occupational health research and prevention. Scand J Work Environ Health 2009:35(1):1-5.

24. Collins GS, Reitsma JB, Altman DG, et al. Transparent reporting of a multivariable prediction model for individual prognosis or diagnosis (TRIPOD): the TRIPOD statement. BMJ 2015:350:97594

25. Knies S, Candel MJJM, Boonen A, et al. Lost productivity in four European countries among patients with rheumatic disorders: are absenteeism and presenteeism transferable? Pharmacoeconomics 2012;30(9):795-807.

26. Howarth A, Quesada J, Mills PR. A global, cross cultural study examining the relationship between employee health risk status and work performance metrics. Ann Occup Environ Med 2017:29:17.

27. Knies S, Boonen A, Candel MJJM, et al. Compensation mechanisms for lost productivity: a comparison between four European countries. Value Health 2013:16(5):740-4.

28. Donders NC, Bos JT, van der Velden K, et al. Age differences in the associations between sick leave and aspects of health, psychosocial workload and family life: a cross-sectional study. BMJ Open 2012;2(4):e000960

29. Kappen $\mathrm{TH}$, van Klei WA, van Wolfswinkel L, et al. Evaluating the impact of prediction models: lessons learned, challenges, and recommendations. Diagn Prognostic Res 2018;2:11.

30. Rose G. Sick individuals and sick populations. Int J Epidemiol 1985;14(1):32-8. 


\section{SUPPLEMENTARY INFORMATION}

Supplementary Table 1. Description of the 27 candidate predictors included in the 'full statistical model'

\begin{tabular}{|c|c|c|}
\hline Domain & Description of predictor & Instrument \\
\hline Demographics & Gender & - \\
\hline Demographics & Age & - \\
\hline Demographics & Educational level & - \\
\hline Health \& well-being & Physical health & $\begin{array}{l}\text { SF-12 (Short Form Health } \\
\text { Survey) Physical Component } \\
\text { Score (PCS) }\end{array}$ \\
\hline Health \& well-being & Physical activity & - \\
\hline Health \& well-being & Mental health & $\begin{array}{l}\text { SF-12 (Short Form Health } \\
\text { Survey) Mental Component } \\
\text { Score (MCS) }\end{array}$ \\
\hline Health \& well-being & Vitality & $\begin{array}{l}\text { SF-36 (Medical Outcomes } \\
\text { Study 36-item Short-Form } \\
\text { Health Survey) }\end{array}$ \\
\hline Health \& well-being & Body mass index & - \\
\hline Health \& well-being & Diseases at baseline & $\begin{array}{l}\text { Netherlands Working } \\
\text { Conditions Survey (NWCS) }\end{array}$ \\
\hline Work-related factors & Physical job load & $\begin{array}{l}\text { Dutch Musculoskeletal } \\
\text { Questionnaire }\end{array}$ \\
\hline Work-related factors & Supervisory role & $\begin{array}{l}\text { Netherlands Working } \\
\text { Conditions Survey (NWCS) }\end{array}$ \\
\hline Work-related factors & Autonomy & $\begin{array}{l}\text { Job Content Questionnaire } \\
\text { (JCQ) }\end{array}$ \\
\hline Work-related factors & Job demands & $\begin{array}{l}\text { Job Content Questionnaire } \\
\text { (JCQ) }\end{array}$ \\
\hline Work-related factors & Emotional job demands & $\begin{array}{l}\text { Copenhagen Psychosocial } \\
\text { Questionnaire (COPSOQ) }\end{array}$ \\
\hline Knowledge \& skills & $\begin{array}{l}\text { Knowledge and skills match } \\
\text { the job }\end{array}$ & - \\
\hline Social factors & Major life events previous year & - \\
\hline Financial factors & Financial situation household & - \\
\hline Work ability & Work ability & Work Ability Index (WAI) \\
\hline Productivity & $\begin{array}{l}\text { Sickness absence previous } \\
\text { year }\end{array}$ & $\begin{array}{l}\text { Netherlands Working } \\
\text { Conditions Survey (NWCS) }\end{array}$ \\
\hline
\end{tabular}


Supplementary Table 1. Continued

\begin{tabular}{|c|c|c|}
\hline Domain & Description of predictor & Instrument \\
\hline $\begin{array}{l}\text { Employment status \& } \\
\text { transitions }\end{array}$ & Self-employment & - \\
\hline Motivation & Interesting at work & $\begin{array}{l}\text { Netherlands Working } \\
\text { Conditions Survey (NWCS) }\end{array}$ \\
\hline Motivation & Independence at work & $\begin{array}{l}\text { Netherlands Working } \\
\text { Conditions Survey (NWCS) }\end{array}$ \\
\hline Motivation & Atmosphere at work & $\begin{array}{l}\text { Netherlands Working } \\
\text { Conditions Survey (NWCS) }\end{array}$ \\
\hline Motivation & Good salary & $\begin{array}{l}\text { Netherlands Working } \\
\text { Conditions Survey (NWCS) }\end{array}$ \\
\hline Motivation & $\begin{array}{l}\text { Ability to change work hours } \\
\text { at work }\end{array}$ & $\begin{array}{l}\text { Netherlands Working } \\
\text { Conditions Survey (NWCS) }\end{array}$ \\
\hline Motivation & Job satisfaction & $\begin{array}{l}\text { Netherlands Working } \\
\text { Conditions Survey (NWCS) }\end{array}$ \\
\hline Other concepts & Mastery skills & Pearlin Mastery Scale (PMS) \\
\hline
\end{tabular}


Supplementary Table 2. Number of missingness for all candidate predictors in the development and validation cohort

\begin{tabular}{|c|c|c|}
\hline Variable & $\begin{array}{r}\text { Development } \\
\qquad n=11,221\end{array}$ & $\begin{array}{r}\text { Validation } \\
n=5,604\end{array}$ \\
\hline Gender & 0 & 0 \\
\hline Age & 0 & $1(0.02)$ \\
\hline Educational level & 0 & 0 \\
\hline SF-12 physical health & $318(2.83)$ & $189(3.37)$ \\
\hline Physical activity & $83(0.74)$ & $24(0.43)$ \\
\hline Physical job load & $31(0.28)$ & $6(0.11)$ \\
\hline Knowledge and skills match the job & $46(0.41)$ & $25(0.46)$ \\
\hline Major life events previous year & 0 & 0 \\
\hline Work ability & $27(0.24)$ & $15(0.27)$ \\
\hline Sickness absence days previous year & $37(0.33)$ & $27(0.48)$ \\
\hline Employment status & 0 & 0 \\
\hline SF-12 mental health & $318(2.83)$ & - \\
\hline SF-36 vitality index & $12(0.11)$ & - \\
\hline Body mass index & $135(1.20)$ & - \\
\hline Diseases at baseline & 0 & - \\
\hline Supervisory role in current position & $31(0.28)$ & - \\
\hline Autonomy & $14(0.12)$ & - \\
\hline Job demands & $48(0.43)$ & - \\
\hline Emotional job demands & $50(0.45)$ & - \\
\hline Financial situation in household & $40(0.36)$ & - \\
\hline Current job is interesting & $80(0.71)$ & - \\
\hline Independence at current job & $86(0.77)$ & - \\
\hline Atmosphere at current job & $86(0.77)$ & - \\
\hline Good salary at current job & $85(0.76)$ & - \\
\hline Ability to change work hours at current job & $83(0.74)$ & - \\
\hline Satisfaction with current job & $87(0.78)$ & - \\
\hline Mastery skills & $9(0.08)$ & - \\
\hline
\end{tabular}

Values are $n(\%)$ unless stated otherwise. SF = Short Form Health Survey 
Supplementary Table 3. Loss to follow-up in the development and validation cohort

Characteristic

Male

Age, mean (SD)

Educational levela

SF-12 physical health ${ }^{b}$, mean (SD

Physically active

Physical job load ${ }^{d}$, mean (SD)

Knowledge and skills match the job

Major life events previous year

Sickness absence days previous year, mean (SD)

Occupational status
Level

Complete

$n=8,681$

4943 (56.9)

53.7 (5.2)

Low

$2216(25.5)$

Medium

3359 (38.7)

High

3106 (35.8)

$52.5(6.9)$

3471 (40.3)

$1.8(0.9)$

$\mathrm{Bad} /$ mediocre

$355(4.1)$

Reasonable/good

8290 (95.9)

o

$4580(52.8)$

1

2766 (31.9)

$\geq 2$

1335 (15.4)

$8.1(1.3)$

$2.8(5.0)$

Employee

Self-employed
$7788(89.7)$

$893(10.3)$

a Low: lower general secondary educational, preparatory secondary vocational education. Medium: intermediate vocational training, higher general secondary education, pre-university education. High: higher vocational education, university education.

b Weighted summary score (range 0-100) assessing physical health using 6 items of the 12-Item Short-Form Health Survey. Higher scores indicating better perceived physical health.

c Intensive physical exercise $\geq 3$ days per week for $\geq 20$ minutes.

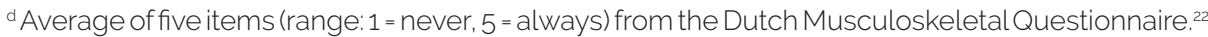


Development cohort $n=11,221$

Validation cohort $n=5,604$

\begin{tabular}{|c|c|c|c|c|}
\hline Missing at follow-up & $p$-value & Complete & Missing at follow-up & $p$-value \\
\hline$n=2,540$ & & $n=4,172$ & $n=1,432$ & \\
\hline $1459(57.4)$ & 0.65 & $2135(51.2)$ & 716 (50.0) & 0.44 \\
\hline $54.7(5.8)$ & $<0.001$ & $50.2(5.1)$ & $50.4(5.5)$ & 0.25 \\
\hline 708 (27.9) & 0.02 & $979(23.5)$ & 411 (28.7) & $<0.001$ \\
\hline 990 (39.0) & & $1685(40.4)$ & $568(39.7)$ & \\
\hline $842(33.1)$ & & $1508(36.1)$ & $453(31.6)$ & \\
\hline $51.9(7.4)$ & $<0.001$ & $52.2(7.3)$ & $52.0(7.4)$ & 0.48 \\
\hline $1031(41.0)$ & 0.53 & $1904(45.8)$ & $631(44.4)$ & 0.37 \\
\hline $1.8(0.9)$ & 0.11 & $1.9(0.9)$ & $1.9(1.0)$ & 0.55 \\
\hline $133(5.3)$ & 0.01 & $186(4.5)$ & $69(4.9)$ & 0.55 \\
\hline 2397 (94.7) & & 3971 (95.5) & $1352(95.1)$ & \\
\hline $1297(51.1)$ & 0.11 & 2426 (58.1) & $813(56.8)$ & 0.64 \\
\hline 811 (31.9) & & 1208 (29.0) & $432(30.2)$ & \\
\hline 432 (17.0) & & 538 (12.9) & $187(13.1)$ & \\
\hline $8.0(1.4)$ & 0.002 & $8.1(1.4)$ & $8.1(1.5)$ & 0.62 \\
\hline $3.0(5.2)$ & 0.05 & $2.6(4.8)$ & $2.9(5.2)$ & 0.03 \\
\hline 2278 (89.7) & 0.97 & $3773(90.4)$ & 1283 (89.6) & 0.36 \\
\hline $262(10.3)$ & & $399(9.6)$ & $149(10.4)$ & \\
\hline
\end{tabular}


Online Supplementary Table 4. Univariate associations and multivariable regression coefficients of the predictors in

\section{Predictor}

Female gender

Age, per year

Educational levelc (ref: low)

SF-12 physical healthd (ref: 1st quartile, poorest health)

Physically active ${ }^{e}$

Physical job load' (ref: $1^{\text {st }}-3^{\text {rd }}$ quartile, less demanding)

Knowledge and skills match the job (ref: bad/mediocre)

Major life events previous year (ref: none)

Work abilityg (ref: good)

Sickness absence days previous year (ref: none)
Level

$$
\begin{aligned}
& \text { Medium } \\
& \text { High } \\
& 2^{\text {nd }} \text { quartile } \\
& 3^{\text {rd }} \text { quartile } \\
& 4^{\text {th }} \text { quartile }
\end{aligned}
$$

$$
4^{\text {th }} \text { quartile }
$$

Reasonable/good

1

$\geq 2$

Average

Poor

$1-5$

$6-10$

$11-27$

Self-employed

Intercept

a Odds Ratio (95\% confidence interval); ${ }^{b}$ Regression coefficients and intercept; an individuals predicted probability can be computed using the logistic regression formula $\mathrm{P}(\mathrm{LTSA})=1 /(1+\exp (-$ LP), in which 'exp' denotes e-raised-to-the-power-of. The LP is the linear predictor, i.e. the linear sum of all predictor values multiplied by their regression coefficients, or $-2.01+0.08^{*}$ gender (female $=1$ ) $+0.003^{*}$ age (years) $-0.17^{*}$ education (medium education $=1$ ) $-0.21^{*}$ education (high education $=1)-0.63^{*}$ physical health $\left(2^{\text {nd }}\right.$ quartile $\left.=1\right)-0.91^{*}$ physical health $\left(3^{\text {rd }}\right.$ quartile $\left.=1\right)-0.94^{*}$ physical health $\left(4^{\text {th }}\right.$ quartile $\left.=1\right)-0.26^{*}$ physically active $($ yes $=1)+0.28^{*}$ physical job load $\left(4^{\text {th }}\right.$ quartile $=1$ ) $-0.43^{*}$ knowledge (reasonable/good $=1$ ) +0.08* major life events (one event $=1$ ) $+0.33^{*}$ major life events (two or more $=1)+0.12^{*}$ work ability (average $\left.=1\right)+0.82^{*}$ work ability (poor $\left.=1\right)+0.33^{*}$ sickness absence $(1-5$ days $=1)+0.92^{*}$ sickness absence $(6-10$ days $=1)+1.34^{*}$ sickness absence $(11-27$ days $=1$ ) $-0.55^{*}$ employment status (self-employed $=1$ ) 
the final model of the development cohort in the complete cases $(n=7.951)$

\begin{tabular}{|c|c|c|}
\hline \multirow{2}{*}{$\begin{array}{c}\text { Univariate } \\
\text { OR }(95 \% \mathrm{Cl})^{\mathrm{a}}\end{array}$} & \multicolumn{2}{|c|}{ Multivariable } \\
\hline & Odds ratio & Coefficient $^{b}$ \\
\hline $1.23(1.01-1.48)$ & 1.09 & 0.08 \\
\hline $1.00(0.99-1.02)$ & 1.00 & -0.003 \\
\hline $0.99(0.81-1.20)$ & 0.85 & -0.17 \\
\hline $0.74(0.60-0.91)$ & 0.81 & -0.21 \\
\hline $1.02(0.83-1.27)$ & 0.53 & -0.63 \\
\hline $0.52(0.41-0.66)$ & 0.40 & -0.91 \\
\hline $0.47(0.36-0.61)$ & 0.39 & -0.94 \\
\hline $0.73(0.60-0.90)$ & 0.77 & -0.26 \\
\hline $1.63(1.33-2.00)$ & 1.32 & 0.28 \\
\hline $0.45(0.32-0.64)$ & 0.65 & -0.43 \\
\hline $1.06(0.87-1.30)$ & 1.08 & 0.08 \\
\hline $1.58(1.26-2.00)$ & 1.39 & 0.33 \\
\hline $1.43(1.16-1.76)$ & 1.13 & 0.12 \\
\hline $4.76(3.50-6.48)$ & 2.27 & 0.82 \\
\hline $0.93(0.75-1.17)$ & 1.39 & 0.33 \\
\hline $2.25(1.75-2.90)$ & 2.50 & 0.92 \\
\hline $4.69(3.71-5.92)$ & 3.83 & 1.34 \\
\hline $0.50(0.33-0.75)$ & 0.57 & -0.55 \\
\hline & & -2.01 \\
\hline
\end{tabular}

c Low: lower general secondary educational, preparatory secondary vocational education. Medium: intermediate vocational training, higher general secondary education, pre-university education. High: higher vocational education, university education.

d Weighted summary score (range 0-100) assessing physical health using 6 items of the 12-Item Short-Form Health Survey. Higher scores indicating better perceived health. $1^{\text {st }}$ quartile $<46.1,2^{\text {nd }}$ quartile $=46.1-54.1 .3^{\text {rd }}$ quartile $=54.2-56.5 .4^{\text {th }}$ quartile $>=56.6$.

e Intensive physical exercise $\geq 3$ days per week for $\geq 20$ minutes.

f Average of five items (range: $1=$ never $-5=$ always) from the Dutch Musculoskeletal Questionnaire. ${ }^{22} 1^{\text {st }}-3^{\text {rd }}$ quartile $<2.4,4^{\text {th }}$ quartile $>=2.4 .{ }^{9}$ Measured with the first item of the Work Ability Index (WAI). ${ }^{23}$ Good $=8-10$, average $=6 / 7$, poor $=0-5$ 


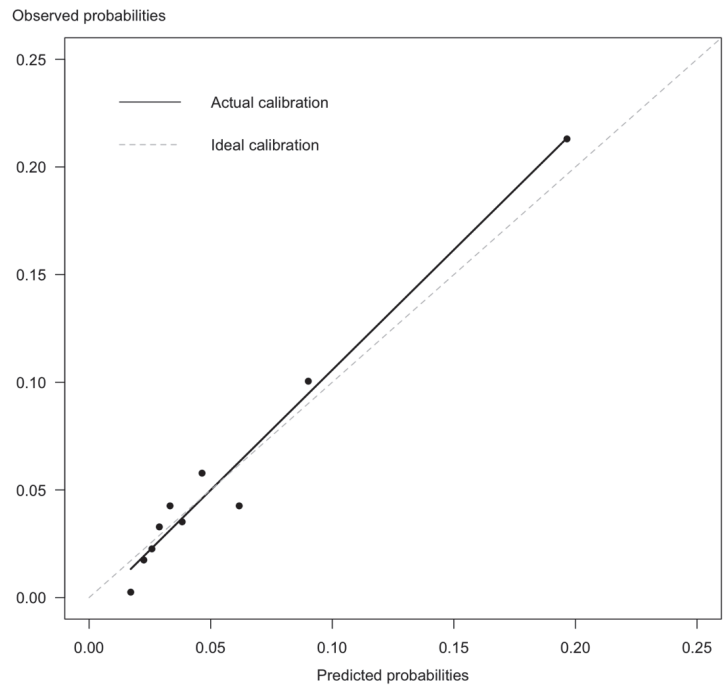

Supplementary Figure 1. Calibration plot visualizing the mean predicted LTSA-risk by the model against observed frequencies per decile of predicted risk in the complete cases ( $n=7.951)$ of the validation cohort. Hosmer-Lemeshow test: $p=1.00$ 




\section{COMPARATIVE CONSTRUCT}

VALIDITY OF THREE PRESENTEEISM INSTRUMENTS IN WORKERS WITH MUSCULOSKELETAL COMPLAINTS: A PROSPECTIVE COHORT STUDY

Lennart van der Burg

Alexandre Sepriano

Robert Landewé

Goedele Geuskens

Ramon Ottenheijm

Geert-Jan Dinant

Annelies Boonen

RMD Open 2020;6:e001281 


\section{ABSTRACT}

Objectives. To compare the construct validity of three presenteeism instruments, using health and economic outcomes as external references, among working persons reporting musculoskeletal complaints.

Methods. Data from the prospective Study on Transitions in Employment, Ability and Motivation were used. Presenteeism measurement comprised a global rating of workability, and two instruments indicating at-work productivity, and was assessed yearly over 6 years of follow-up. Longitudinal associations between measures of health and subsequent presenteeism, and between presenteeism and subsequent days of sick leave were assessed using generalised estimating equation models. The effect of groups of contextual factors (socio-demographic, lifestyle, personal and work-related factors) was investigated by assessing the change in explained variability.

Results. In total, 4523 persons were analysed. The association between physical health and work-ability was stronger than both at-work productivity measures; 10 points increase in physical health (0-100, higher is better) was associated with 0.79 points $(95 \% \mathrm{Cl} 0.75$ to 0.84) better work-ability (0-10, higher is better) in the subsequent year. Besides, workability best predicted sick leave; one point higher work-ability was associated with 4 days less sick leave (95\% Cl -5.09 to -3.63 ) the subsequent year. Personal factors improved model fit for models on health and work-ability, but conflicting results were seen for both at-work productivity instruments.

Conclusion. Work-ability showed higher construct validity against health and economic outcomes as compared to at-work productivity, which shows that work-ability is different to productivity (losses). Personal factors are especially relevant when interpreting the relation between health and work-ability or self-reported quantity of work. 


\section{INTRODUCTION}

Presenteeism among working persons with rheumatic and musculoskeletal (MSK) diseases is highly prevalent, and several studies related presenteeism to patients' health outcomes, as well as to an economic impact for the workplace and society. ${ }^{1-3}$ It has been suggested that the costs of presenteeism exceed the costs due to sick leave (i.e. absenteeism) and permanent work disability. ${ }_{4}^{4}$ Although there is still considerable debate on the definition of presenteeism, two main aspects can been distinguished, reflecting (1) the behaviour of attending work while ill and (2) the amount of impact on work when being ill at work.5.6

However, it has been insufficiently recognised that self-reported instruments measuring the amount of presenteeism operationalise presenteeism in different ways. Two broad approaches can be distinguished. While one group of instruments focuses on estimating the economic consequence (e.g. the productivity, quantity of work, efficiency, time being not productive), other instruments aim to assess person's difficulty or ability to perform paid work. This resulted in significant variations of effect sizes between presenteeism instruments and health or economic outcomes. ${ }^{1.5 .7}$ Other reasons for the variation in effect sizes can be attributed to differences in instrument properties (e.g. recall period, attribution to overall health or disease-specific restrictions), or the level in which approaches mix the behaviour to attend work with the level and type of impact (ability or productivity) while at work into one instrument. 5

Despite the large number of studies reporting on validation and psychometric properties of presenteeism instruments in rheumatology, there are still considerable knowledge gaps. First, few studies directly compared the validity (i.e. the degree to which an instrument measures the construct(s) it purports to measure) of different presenteeism instruments. ${ }^{1,8-10}$ This is relevant, as the different constructs used in available instruments might determine their use in future studies. Although it might be expected that presenteeism instruments addressing 'work-ability'-as compared to those measuring 'at-work productivity'-would correlate better with physical and mental health, this has never been formally tested (i.e. construct validity). In addition, it is unknown whether constructs differ in their ability to predict subsequent sick leave. Such knowledge is relevant, as it might determine their use in trials and even clinical practice. Second, there is limited evidence regarding the association between different presenteeism constructs and contextual factors (e.g. personal or work-related factors). The role of context seems especially important when interpreting work outcome studies.1.11 The aims of our study were twofold: (1) to investigate the construct validity of different approaches to measure presenteeism by associating these instruments with important measures of health and sick leave and (2) to explore the influence of contextual factors on these associations 


\section{METHODS}

\section{Data source and sample selection}

Study on Transitions in Employment, Ability and Motivation (STREAM) is a prospective cohort study of persons aged 45-64 years in the Netherlands stratified by age and employment status (i.e. employed, self-employed and unemployed). From the inception of the cohort in 2010 onwards, participants completed an online questionnaire every year on topics such as work characteristics, health and work productivity. A more detailed description of the STREAM design has been published elsewhere.12 At the time of the fifth time point (2015), a second cohort was initiated and linked to the first one, consisting of employed and unemployed persons aged 45-49 years and employed persons in the other age groups (50-54, 55-59, 60-64 years).

For this study, data from the first time point (2010) until the last available time point (2016) were used. We included persons employed or self-employed at baseline who completed the questionnaires on at least two consecutive time points and reported MSK complaints at $\geq 50 \%$ of the available time points. At each time point, the presence of MSK complaints was assessed and considered present if persons responded positively to at least one of the three options of the following question: 'Do you have one or more of the following long-standing diseases, conditions or handicaps?' (a) complaints of the hands or arms (also arthritis, repetitive strain injury (RSI)), (b) complaints of the legs and feet (also arthritis) and (c) complaints of the back or neck (also arthritis, RSI).12

The Medical Ethical Committee of the VU University Medical Center (Amsterdam, the Netherlands) declared that the Medical Research Involving Human Subjects Act does not apply to the STREAM, and indicated to have no objection to the execution of this research under the condition all data would be treated confidentially and stored in secured computer systems.

\section{Presenteeism instruments}

A variable addressing work-ability was obtained from the first item of the Work Ability Index, in which persons rate their 'current work-ability as compared to their lifetime best' (continuous, range 0-10, higher is better).13.14 In addition, two variables addressing at-work productivity were obtained. One assessing the quantity of work by the first item of the Quality and Quantity-method from Brouwer et al., which asks persons to rate 'how much work they have done in the last 4 weeks compared to normal' on days they actually worked (continuous, range $0-10$, higher is better). ${ }^{15}$ And the other, loss of productive time while at work in the past month due to presenteeism, was derived from three items of the 'Osterhaus-method' (continuous, range 0-30, higher is worse, not included at the 
first time point). ${ }^{6,17}$ To allow comparison of the Osterhaus-method with the other two presenteeism instruments, we standardised the Osterhaus-method by dividing values by three (new range 0-10). A more detailed description of the measurement characteristics of each instrument is shown in table 1.

\section{External measures}

Health variables

Physical and mental health were assessed at each time point by the 12-Item Short-Form Health Survey (SF-12), from which a physical component summary score and mental component summary score were calculated. ${ }^{18}$ To assess vitality, not included in the SF12, three items from the SF-36 (Medical Outcomes Study 36-item Short-Form Health Survey) were included, allowing computation of a weighted vitality domain score. ${ }^{19}$ For all three variables, higher scores indicate better perceived health/vitality (range 0-100).

Sick leave

Sick leave days in the past year (0-365) was assessed at each time point by the following open question: 'How many work days have you, during the past 12 months, been absent due to sickness?

\section{Contextual factors}

At each time point, four domains representing different types of contextual factors were collected, except the socio-demographic factors that were assessed at baseline only.

\section{Socio-demographic factors}

Three socio-demographic factors were included: age, gender and educational level. Age was dichotomised based on the median value ( $\leq 55$ vs $>55$ years). Education was categorised into three groups: (1) low (primary school, lower and intermediate secondary school or lower vocational training), (2) medium (higher secondary school or intermediate vocational training) and (3) high (higher vocational training, university or higher).

\section{Lifestyle factors}

Lifestyle factors comprised body mass index (in kg/m2), currently smoking (yes vs no) and weekly physical exercise (at least 3 days of intensive physical exercise for more than 20 min or more, yes vs no). 
Table 1. Characteristics of the three presenteeism instruments used in the STREAM-cohort

\begin{tabular}{|c|c|c|}
\hline $\begin{array}{l}\text { Instrument } \\
\text { construct }\end{array}$ & Instrumentalization & Score range \\
\hline $\begin{array}{l}\text { WAI }{ }^{12,13} \\
\text { work-ability }\end{array}$ & NRS single item & $0-10$, higher is better \\
\hline $\begin{array}{l}\text { QQ-method }{ }^{14} \\
\text { work productivity }\end{array}$ & $\begin{array}{l}\text { NRS single item; 'quantity of } \\
\text { work performed' }\end{array}$ & $0-10$, higher is better \\
\hline $\begin{array}{l}\text { Osterhaus-method }{ }^{15.16} \\
\text { work productivity }\end{array}$ & $\begin{array}{l}\text { Three items; 'loss of } \\
\text { productive time while at work' }\end{array}$ & $0-30$, higher is worse \\
\hline
\end{tabular}

Abbreviations; STREAM = Study on Transitions in Employment Ability and Motivation; WAI = Work-ability Index; NRS = numeric rating scale; $Q Q=$ Quality and Quantity questionnaire

\section{Personal factors}

Mastery, that is, the feeling to which a person perceives him/herself to be in control of events, was assessed with the Pearlin Mastery Scale (range 1-5, higher is better). Three different coping styles (i.e. active response, avoidant behaviour and seeking social support) were measured using the Utrecht Coping List. Mean values for each coping style were calculated (range 1-4, higher is better). Finally, self-efficacy in relation to work (learning new tasks/new employer) was measured using four newly constructed items based on the guidelines by Bandura et al., and mean values were calculated for each participant (range 1-5, higher is better).12

\section{Work-related factors}

Four work-related factors were collected: physical workload (five items, higher is worse), psychological job demands (three items, higher is worse), emotionaljob demands (three items, higher is worse) and autonomy (five items, higher is better). Mean values for each work-related factor were calculated (range 1-5).12

\section{Statistical analysis}

Descriptive statistics were used to report the baseline characteristics of the included participants. Spearman's ranked correlations were used for testing correlations across the three presenteeism instruments. The longitudinal association between the three presenteeism instruments and the four external measures was tested using autoregressive generalised estimating equation (GEE) models with 1-year time lags, first with no adjustment ('basic model'), and second with adjustment for a priori selected variables (contextual factors listed earlier). Time-varying variables were modelled as such. The 'exchangeable' correlation structure was found to be the most appropriate, in all GEE models, to take into account within-subject correlations over time. Of note, 


\section{Recall period Reference frame Anchors}

\begin{tabular}{llll} 
Current & Lifetime best & $\begin{array}{l}\text { Completely unable to work (0) - } \\
\text { work-ability at lifetime best (10) }\end{array}$ & No \\
Four weeks & $\begin{array}{l}\text { Compared to } \\
\text { normal }\end{array}$ & $\begin{array}{l}\text { Far less than normal (0) }- \\
\text { far more than normal (10) }\end{array}$ & No \\
\hline \multirow{2}{*}{ One month } & $\begin{array}{l}\text { Compared to } \\
\text { normal }\end{array}$ & $\begin{array}{l}\text { No interference (0) }- \\
\text { complete interference (30) }\end{array}$ & $\begin{array}{l}\text { Yes, physical/ } \\
\text { mental problems }\end{array}$ \\
\hline
\end{tabular}

GEE models are considered fairly robust with regard to missing data, and therefore no missing data were imputed. In the analyses exploring the association between health variables (physical and mental health, vitality) and presenteeism, the health variables were modelled as the explanatory variables and presenteeism as the outcome. In the analyses that included sick leave, the three presenteeism instruments were modelled as the explanatory variables and the total days of sick leave in the following year as the outcome. Interactions with age, gender, educational level and physical workload (all at baseline) were tested. Significant interactions $(p<0.10)$ were visualised in a graph, and if considered clinically relevant ( $>10 \%$ difference in slopes), the associations of interest were tested in stratified models. If proven not significant or relevant, variables were included as additional confounders in the adjusted models

Sensitivity analyses included GEE models assuming a negative binomial distribution for the analyses that included sick leave, which has a right-skewed distribution. Quasilikelihood under the Independence model Criterion (QIC) was used to gain insight into which domain of contextual factors has the largest impact on model fit (explained variability of the outcome by the model), with lower QICs reflecting better data fit. ${ }^{20}$ Contextual factors were added as one group from each domain separately to the basic model. $P$ values $<0.05$ were considered statistically significant. All analyses were done using Stata/SE version 15.1. 


\section{RESULTS}

\section{Descriptive statistics}

A total of 4523 participants were included in our analyses, of which 2986 started in 2010 (baseline first cohort) and 1537 participants in 2015 (baseline second cohort). No clinically important differences on baseline characteristics between the two cohorts were observed (data not shown), and these were therefore combined in all further analyses. The mean number of completed timepoints for the participants in the first cohort was 4.9 (SD 1.4) out of a maximum of six. Participants were on average 53 years old (SD 5.4), predominantly female (54\%) and MSK complaints were reported by 3440 (76\%) participants at baseline (see Table 2). No clinically important differences on baseline characteristics were found between completers and non-completers (data not shown).

Mean (SD) values were 7.6 (1.7) for work-ability, 5.7 (2.0) for quantity of work performed and 0.9 (1.6) for the standardised Osterhaus-method at the first available measurement for each instrument and remained stable at the group level across all timepoints (Table 2). Correlations between the three presenteeism instruments at each timepoint were significant but weak (r: -0.28 to 0.26$)$.

\section{Longitudinal association between health and presenteeism}

Statistically significant interactions between the health variables and the four prespecified effect modifiers were observed but were not considered clinically important. Thus, all models were fit without stratification. Most longitudinal associations between the health variables and the presenteeism instruments were statistically significant (Table 3). However, the associations of all health variables with work-ability were stronger as compared to the other two approaches to assess presenteeism. This was especially clear for the association between physical health and work-ability: an increase of 10 points in physical health is longitudinally associated with an increase of 0.79 points ( $95 \% \mathrm{Cl} 0.75$ to 0.84) in work-ability in the subsequent year. Similarly, for the 'quantity of work' instrument, an increase of 10 points in physical health is longitudinally associated with an increase of 0.53 points $(95 \% \mathrm{Cl} 0.47$ to 0.60 ) in the subsequent year, and for the standardised Osterhaus-method, this association was -0.41 (95\% Cl -0.46 to -0.37$)$.

\section{Longitudinal association between presenteeism and sick leave days}

All three presenteeism instruments showed a statistically significant association with the number of sick leave days in the subsequent year (see Table 4). However, work-ability showed a stronger association with sick leave as compared to the other two approaches; one point better work-ability was longitudinally associated with 4.36 ( $95 \% \mathrm{Cl}-5.09$ to $-3.63)$ less days sick leave in the subsequent year. This was 1.85 ( $95 \% \mathrm{Cl}$ : -2.30 to -1.40 ) 
less days sick leave for one point better on the 'quantity of work' instrument and 1.49 (95\% Cl: 0.88 to 2.11) more days sick leave for one point worse on the standardised Osterhausmethod. Sensitivity analyses assuming a negative binomial distribution of the outcome showed similar results (data not shown).

Table 2. Baseline characteristics of the study participants $(n=4523)$

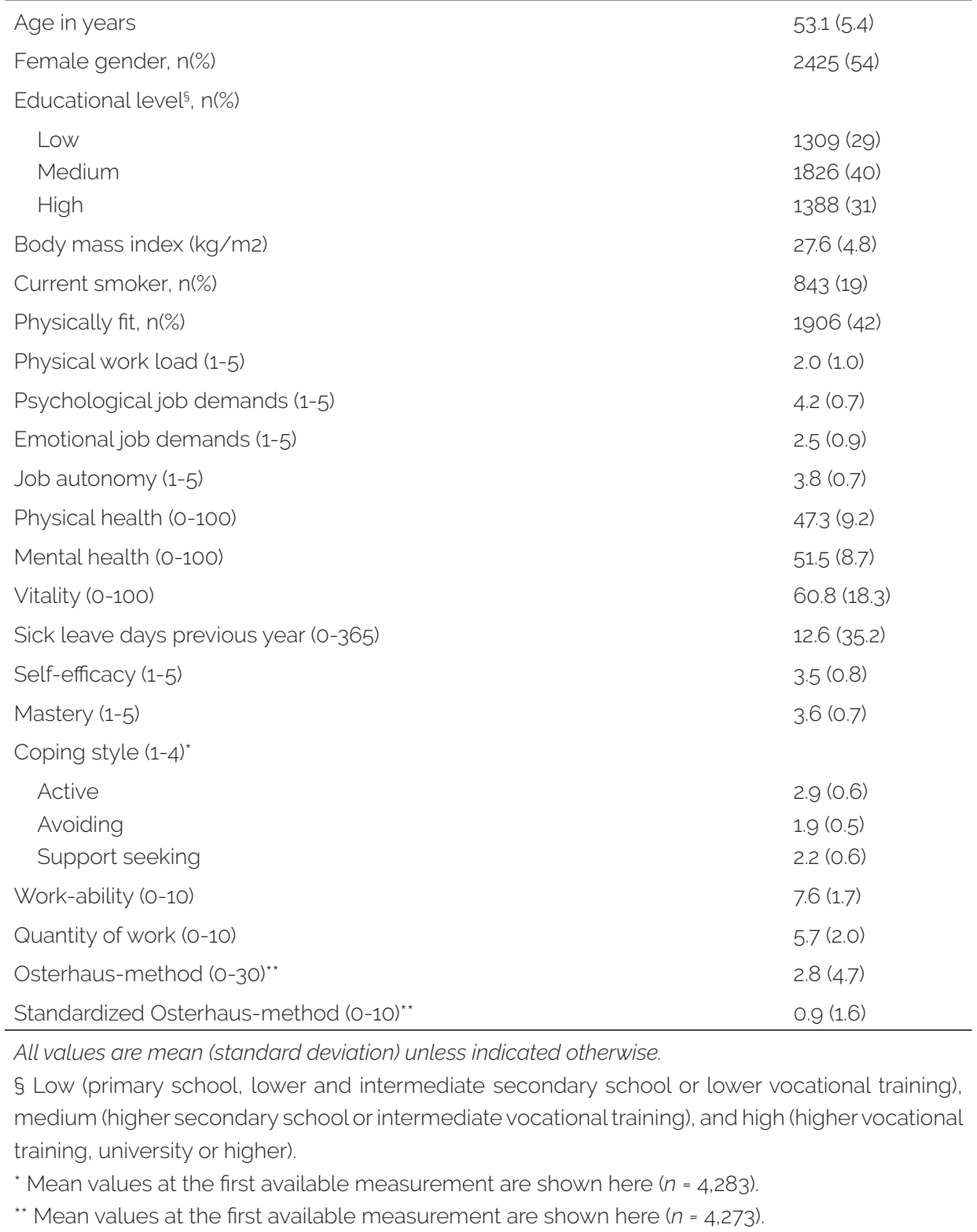


Table 3. Longitudinal association between health variables (independent variables) and three presenteeism instruments (outcomes) in working persons reporting MSK complaints ( $n=4523$ )

\begin{tabular}{|c|c|c|c|c|}
\hline & $\begin{array}{l}\text { Health } \\
\text { variables }\end{array}$ & Work-ability & $\begin{array}{l}\text { Quantity of work } \\
\text { performed }\end{array}$ & $\begin{array}{l}\text { Standardized }^{*} \\
\text { Osterhaus- } \\
\text { method }\end{array}$ \\
\hline & $(0-100)$ & $(0-10)$ & $(0-10)$ & $(0-10)^{* *}$ \\
\hline & & $\beta(95 \% \mathrm{Cl})$ & $\beta(95 \% \mathrm{Cl})$ & $\beta(95 \% \mathrm{Cl})$ \\
\hline \multirow[t]{3}{*}{ Basic model ${ }^{*}$} & Physical health & 0.08 (0.07; 0.08) & $0.05(0.05 ; 0.06)$ & $-0.04(-0.05 ;-0.04)$ \\
\hline & Mental health & $0.05(0.05 ; 0.06)$ & $0.03(0.02 ; 0.04)$ & $-0.02(-0.02 ;-0.01)$ \\
\hline & Vitality & $0.01(0.01 ; 0.01)$ & $0.00(-0.01 ; 0.00)$ & $-0.01(-0.01 ; 0.00)$ \\
\hline \multirow[t]{3}{*}{ Adjusted model ${ }^{\ddagger}$} & Physical health & 0.07 (0.07; 0.08) & $0.06(0.05 ; 0.06)$ & $-0.04(-0.05 ;-0.04)$ \\
\hline & Mental health & 0.05 (0.04; 0.06$)$ & $0.03(0.03 ; 0.04)$ & $-0.02(-0.02 ;-0.01)$ \\
\hline & Vitality & $0.01(0.01 ; 0.01)$ & $0.00(-0.01 ; 0.00)$ & $-0.01(-0.01 ; 0.00)$ \\
\hline
\end{tabular}

$¥$ Model not adjusted for confounders.

‡ Adjusted for age, gender, educational level, body mass index, smoking, physical fitness, physical load, psychological demands, emotional demands, autonomy, mastery, self-efficacy and coping styles (active, avoiding, support seeking)

* Standardized by dividing original values of the Osterhaus-method by three for comparison with other two instruments

"* Higher score is worse.

MSK = musculoskeletal; $\mathrm{Cl}=$ confidence interval

Table 4. Longitudinal association between three presenteeism instruments (independent variables) and sick leave days (outcome) in the subsequent year in working persons reporting MSK complaints $(n=4523)$

\begin{tabular}{|c|c|c|}
\hline & & $\begin{array}{l}\text { Sick leave days }(0-365) \\
\beta(95 \% \mathrm{Cl})\end{array}$ \\
\hline Work-ability (0-10) & $\begin{array}{l}\text { Basic model }{ }^{¥} \\
\text { Adjusted model }{ }^{\ddagger}\end{array}$ & $\begin{array}{l}-4.36(-5.09 ;-3.63) \\
-3.83(-4.60 ;-3.06)\end{array}$ \\
\hline Quantity of work performed (0-10) & $\begin{array}{l}\text { Basic model } \\
\text { Adjusted model }\end{array}$ & $\begin{array}{l}-1.85(-2.30 ;-1.40) \\
-1.74(-2.21 ;-1.27)\end{array}$ \\
\hline Standardized Osterhaus-method (0-10)* & $\begin{array}{l}\text { Basic model } \\
\text { Adjusted model }\end{array}$ & $\begin{array}{l}1.49(0.88 ; 2.11) \\
1.07(0.43 ; 1.71)\end{array}$ \\
\hline \multicolumn{3}{|c|}{$\begin{array}{l}¥ \text { Model not adjusted for confounders. } \\
\text { ₹ Adjusted for age, gender, educational level, body mass index, smoking, physical fitness, } \\
\text { physical load, psychological demands, emotional demands, autonomy, mastery, self-efficacy } \\
\text { and coping styles (active, avoiding, support seeking). } \\
\text { * Standardized by dividing original values of the Osterhaus-method by three for comparison with } \\
\text { other two instruments. Higher score is worse. } \\
\text { MSK = musculoskeletal; Cl = confidence interval }\end{array}$} \\
\hline
\end{tabular}




\section{Contextual factors}

The influence of socio-demographic, lifestyle and work-related factors was small in models exploring the influence of health on subsequent presenteeism, while considerable improvements in explained variability were observed when personal factors were added to the models for work-ability (relative QIC reduction of 26\%) or 'quantity of work' (relative QIC reduction 22\%) (Figure 1). The influence of personal factors in the analysis with the standardised Osterhaus-method was negligible (relative QIC reduction 1\%).

In the models exploring presenteeism as a predictor of subsequent sick leave, improvement in explained variability by any of the contextual factor domains was small (Figure 2).

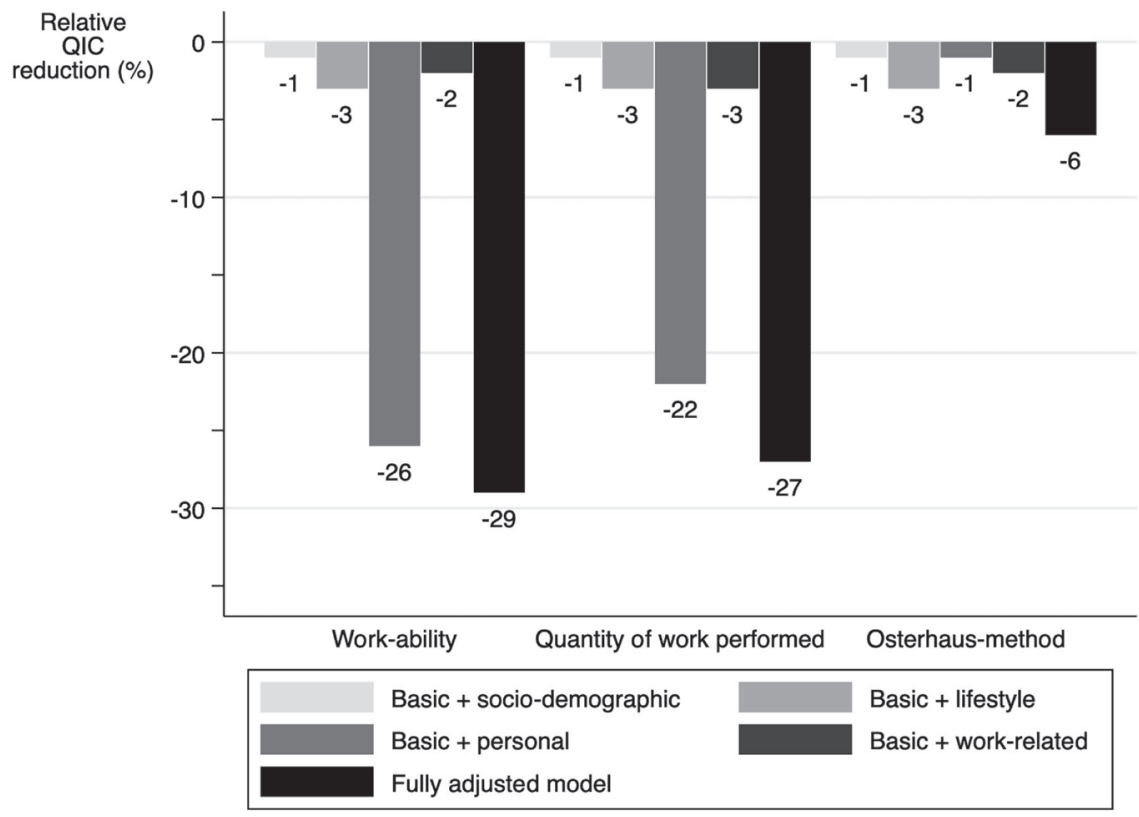

Figure 1. Comparison of improvement of model fit by adding contextual factors by domain as one group to the models that included all health variables (independent variables) and presenteeism (outcomes), separately for the three presenteeism instruments. Model fit improvement is shown as the relative improvement in QIC as compared to the 'basic model' (not adjusted for any contextual factors). Higher relative reduction of the QIC indicates a better model fit. QIC, Quasi-likelihood under the Independence model Criterion. 


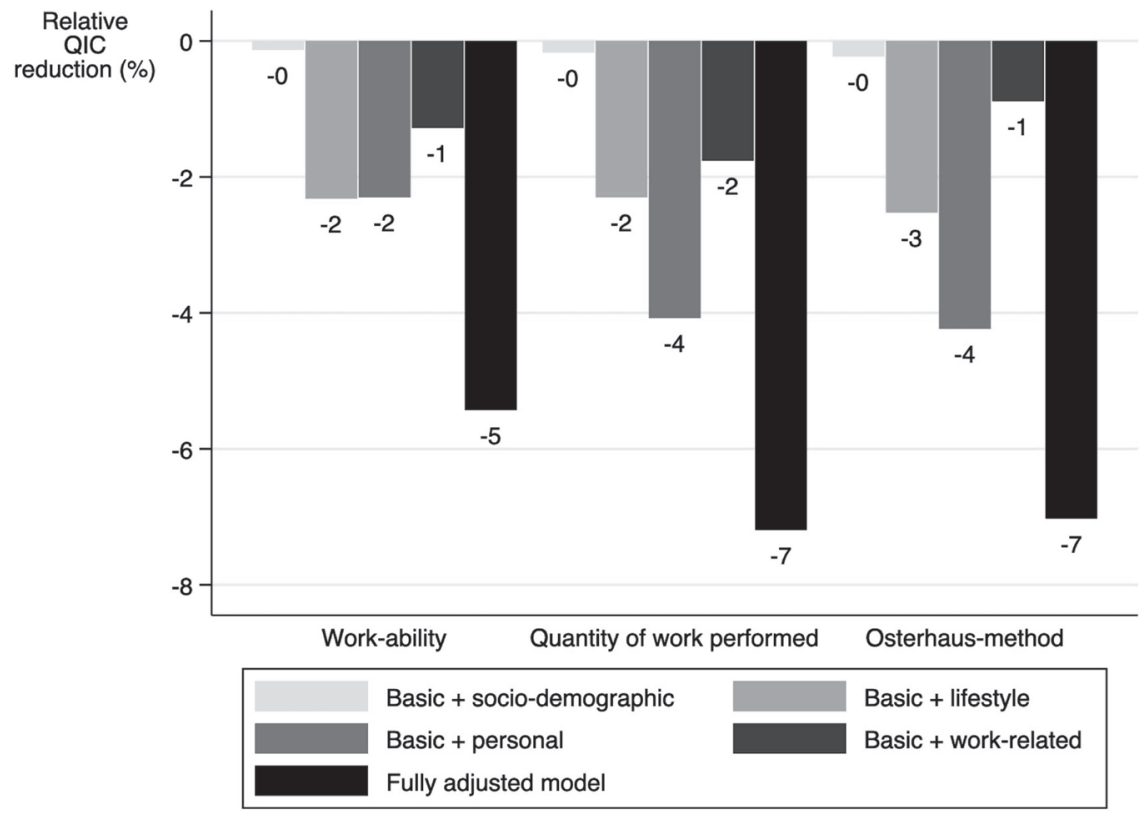

Figure 2. Comparison of improvement of model fit by adding contextual factors by domain as one group to the models that included the presenteeism instruments (independent variables) and sick leave (outcome), separately for the three presenteeism instruments. Health variables are not included in these models. Model fit improvement is shown as the relative improvement in QIC as compared to the 'basic model' not adjusted for any contextual factors. Higher relative reduction of the QIC indicates a better model fit. QIC, Quasi-likelihood under the Independence model Criterion 


\section{DISCUSSION}

This study compares the construct validity over time of three self-reported instruments that measure presenteeism through two different constructs, work-ability and at-work productivity, in working persons reporting MSK complaints. Overall, work-ability showed better longitudinal construct validity against health variables and sick leave as external measures.

Particularly, physical health had a higher impact on work-ability than on both at-work productivity instruments. This finding suggests that, despite the impact of disease on work-ability, persons with MSK complaints mostly succeed to avoid impact on productivity. Our data also confirm that work-ability and productivity are truly different consequences of disease on work, as was also shown by the poor intercorrelation of the three instruments.

In a recent cognitive debriefing study, it was revealed that patients correctly interpret 'productivity' as the amount of work accomplished in a specific period of time, while ability relates to the difficulties when performing work. ${ }^{8}$ Previous studies have shown that different contextual factors have an important impact on presenteeism. ${ }^{21-23}$ Interestingly, our study shows that personal contextual factors (i.e. mastery, coping and self-efficacy) had a larger impact on presenteeism than demographic, lifestyle and work-related contextual factors. These personal factors particularly impacted presenteeism when operationalised as work-ability or quantity of work, while this effect was less evident when presenteeism was measured as loss of productive time while at work (Osterhaus-method)

In this data set, we did not observe relevant effect modification of age, gender, education or physical workload on the relation between health and presenteeism. The absence of relevant effect modification by education or physical workload was somewhat surprising. as it is in contrast to some other studies in MSK disorders. ${ }^{11,24}$ It is of note that we had no information available on disease duration and we cannot exclude the contextual factors we explored, for example, coping, would have a different role in persons with shorter term opposed to chronic complaints. Also, other work-related factors such as adaptations at work or attitudes of colleagues might have modified the impact of health on presenteeism.

Our results add to the existing body of literature showing that presenteeism is a risk factor for subsequent (long-term) sick leave. ${ }^{25-28}$ However, in addition, we demonstrate that the impact of health on work-ability is more important than the perceived impact on productivity in contributing to take sick leave. Contextual factors had limited impact 
on the relation between presenteeism and subsequent sick leave. As discussed earlier, health is an important predictor of presenteeism, and presenteeism is in turn associated with subsequent sick leave. The relation between health and presenteeism is impacted by contextual factors, and therefore, contextual factors likely do not further impact the relation between presenteeism and sick leave. In other words, context is already implicitly included in those presenteeism instruments. This was also the reason not to adjust for the health variables in the analyses with presenteeism and sick leave, as it may lead to over-adjustment.

In the area of MSK and rheumatic disease, Outcome Measures for Arthritis Clinical Trials performed significant work regarding the evaluation of validity and clinimetric characteristics of presenteeism instruments. This previous work has primarily been based on cross-sectional data hampering the understanding of causal relationships with external measures, such as health variables and sick leave. ${ }^{1}$ The current study fills this knowledge gap by using a large prospective cohort study and including a comprehensive list of questionnaires, contextual factors and sick leave at the same time. The current study pinpoints to the poor intercorrelation and differences in longitudinal construct validity of the different self-reported presenteeism measurement instruments. It also makes clear that, for patients, work-ability is a more relevant measure of presenteeism to be included in clinical trials and can be used when aiming to identify those persons at risk for subsequent (long-term) sick leave. ${ }^{25}$ However, from an economic perspective, the method by Osterhaus et al. is a good choice, because it allows for the calculation of the costs associated with presenteeism based on the self-reported time lost while at work by each person. The frequently used Work Productivity and Activity Impairment Questionnaire, which was not included in this study, has the apparent advantage to measure presenteeism and sick leave in one instrument. However, presenteeism and sick leave appear to be two competing outcomes, which questions the validity of measuring these outcomes in one instrument.

A limitation of this study is that the time interval between two successive time points (i.e. 1 year) may have been too large, causing underestimation of the associations between the presenteeism instruments and external measures. Future studies using shorter time intervals between successive time points (e.g. several weeks) should be designed to validate our results. Second, the population used in this study was aged 45-67 years and including a younger population in future studies may be interesting, because adverse work outcomes may have long-term consequences and possibly other contextual factors play a more significant role in younger working persons. It would also be interesting to explore the mediating effects of presenteeism in the relation between health and sick leave. 
In conclusion, work-ability showed higher construct validity against health and economic outcomes as compared to the two at-work productivity instruments. Our findings suggest that work-ability is not equal to (loss of) at-work productivity and this is likely influenced by contextual factors. Especially, personal factors seem to be relevant when interpreting the relation between health and work-ability. The construct of instrument used in future studies to measure the concept of presenteeism is strongly dependent on the study type and objectives. 


\section{REFERENCES}

1. Beaton DE, Dyer S, Boonen A, et al. OMERACT filter evidence supporting the measurement of at-work productivity loss as an outcome measure in rheumatology research. J Rheumatol 2016;43:214-22.

2. van der Zee-neuen A, Putrik P, Ramiro S, et al. Work outcome in persons with musculoskeletal diseases: comparison with other chronic diseases \& the role of musculoskeletal diseases in multimorbidity. BMC Musculoskelet Disord 2017;18:10

3. Walker-Bone K, Black C. The importance of work participation as an outcome in rheumatology. Rheumatology (Oxford) 2016:55:1345-7.

4. Howard KJ, Mayer TG, Gatchel RJ. Effects of presenteeism in chronic occupational musculoskeletal disorders: stay at work is validated. J Occup Environ Med 2009;51:724-31.

5. McGregor A, Sharma R, Magee C, et al. Explaining variations in the findings of presenteeism research: a meta-analytic investigation into the moderating effects of construct operationalizations and chronic health. J Occup Health Psychol 2018;23:584-601.

6. Jones C, Payne K, Gannon B, et al. Economic theory and self-reported measures of presenteeism in musculoskeletal disease. Curr Rheumatol Rep 2016;18:8.

7. Miraglia M, Johns G. Going to work ill: a meta-analysis of the correlates of presenteeism and a dual-path model. J Occup Health Psychol 2016;21:261-83

8. Leggett S, van der Zee-neuen A, Boonen A, et al. Content validity of global measures for at-work productivity in patients with rheumatic diseases: an international qualitative study. Rheumatology (Oxford) 2016;55:1364-73

9. Leggett S, van der Zee-neuen A, Boonen A, et al. Test-retest reliability and correlations of 5 global measures addressing at-work productivity loss in patients with rheumatic diseases. $J$ Rheumatol 2016:43:433-9

10. Mokkink LB, Terwee CB, Patrick DL, et al. The COSMIN study reached international consensus on taxonomy, terminology, and definitions of measurement properties for health-related patient-reported outcomes. J Clin Epidemiol 2010;63:737-45

11. Stolwijk C, Castillo-Ortiz JD, Gignac M, et al. Importance of contextual factors when measuring work outcome in ankylosing spondylitis: a systematic review by the OMERACT worker productivity group. Arthritis Care Res (Hoboken) 2015;67:1316-27.

12. Ybema JF, Geuskens GA, van den Heuvel SG, et al. Study on Transitions In Employment, Ability and Motivation (STREAM): the design of a four-year longitudinal cohort study among 15,118 persons aged 45 to 64 years. Br J Med Med Res 2014:4:1383-99.

13. Itmarinen J. The work ability index (WAI). Occup Med (Chic IL) 2006:57:160-.

14. Ahlstrom L, Grimby-Ekman A, Hagberg M, et al. The work ability index and single-item question: associations with sick leave, symptoms, and health: a prospective study of women on long-term sick leave. Scand J Work Environ Health 2010;36:404-12.

15. BrouwerWB, Koopmanschap MA, Rutten FF. Productivity losses without absence: measurement validation and empirical evidence. Health Policy (New York) 1999:48:13-27.

16. van Roijen L, Essink-Bot ML, Koopmanschap MA, et al. Labor and health status in economic evaluation of health care. The health and labor questionnaire. Int J Technol Assess Health Care 1996;12:405-15

17. Osterhaus JT, Gutterman DL, Plachetka JR. Healthcare resource and lost labour costs of migraine headache in the US. Pharmacoeconomics 1992;2:67-76. 
18. Ware J, Kosinski M, Keller SD. A 12-item short-form health survey: construction of scales and preliminary tests of reliability and validity. Med Care 1996;34:220-33.

19. Ware JE, Sherbourne CD. The MOS. 36-item short-form health survey (SF-36). I. Conceptual framework and item selection. Med Care 1992;30:473-83.

20. Pan W. Akaike's information criterion in generalized estimating equations. Biometrics 2001:57:1205.

21. Webers C, Vanhoof L, van Genderen S, et al. Employment and the role of personal factors among patients with ankylosing spondylitis: a dutch cross-sectional case-control study. RMD Open 2018;4:e000680.

22. van den Berg TI, Elders $L A$, de Zwart $B C$, et al. The effects of work-related and individual factors on the work ability index: a systematic review. Occup Environ Med 2009;66:211-20.

23. Alavinia SM, Molenaar D, Burdorf A. Productivity loss in the workforce: associations with health, work demands, and individual characteristics. Am J Ind Med 2009:52:49-56.

24. Boonen A, Boone C, Albert A, et al. Contextual factors influence work outcomes in employed patients with ankylosing spondylitis starting etanercept: 2-year results from AS@Work. Rheumatology (Oxford) 2018;57:791-7.

25. van der Burg LRA, van Kuijk SMJ, ter Wee MM, et al. Long-term sickness absence in a general working population: development and validation of a risk prediction model in a large dutch prospective cohort. BMC Public Health 2020;20:699.

26. Tran-Duy A, Nguyen TT, Thijs $H$, et al. Longitudinal analyses of presenteeism and its role as a predictor of sick leave in patients with ankylosing spondylitis. Arthritis Care Res (Hoboken) 2015:67:1578-85.

27. Ter Wee MM, Lems WF, Usan $H$, et al. The effect of biological agents on work participation in rheumatoid arthritis patients: a systematic review. Ann Rheum Dis 2012;71:161-71.

28. van der Burg LR, Ter Wee MM, Boonen A. Effect of biological therapy on work participation in patients with ankylosing spondylitis: a systematic review. Ann Rheum Dis 2012;71:1924-33. 

SUMMARY AND

GENERAL DISCUSSION 



\section{SUMMARY AND GENERAL DISCUSSION}

The work presented in this thesis aimed to contribute to our understanding of the complex relationships between health, context and work participation in persons with rheumatic and musculoskeletal diseases (RMDs). In addition, approaches to improve early detection and treatment of adverse work outcomes in persons with RMDs have been described.

First, we explored the risk of developing cardiovascular co-morbidities in working persons with RMDs and its impact on mortality during working life. Secondly, we explored the additional impact of cardiovascular co-morbidities on work outcomes, i.e. sick leave and long-term work disability, in the same population of working persons with RMDs. Next, we were interested whether the high impact of axial spondyloarthritis (SpA) on presenteeism, sick leave and work disability would be attenuated by innovative treatment with biological disease modifying drugs (biological therapies). As long-term sickness absence and work disability in RMDs remain substantial despite earlier diagnosis and improved treatment, we aimed to identify working persons at risk for future long-term sickness absence. Lastly, to improve work outcome measurement, we directly compared the construct validity and characteristics of three presenteeism measurement instruments in RMDs.

Two large, prospective observational studies have been used to address the abovementioned research questions: the Maastricht Cohort Study for Chapters 2 and 3 and the Study on Transitions in Employment, Ability and Motivation (STREAM) for Chapters 5 and $6 .{ }^{1,2}$ In addition, published data were used to summarize the available knowledge about the effects of biological therapies on work outcomes in axial SpA in Chapter 4. The Maastricht Cohort Study was a prospective study starting in 1998 among 12,140 persons employed by 45 different companies located in the south of the Netherlands. It consisted of persons from all working-age categories, working in 678 different professions in many different sectors and trades. Participants were followed for more than a decade at the time of our studies, using extensive self-administered questionnaires on topics such as demographics, work-related factors, domestic and social factors, and health issues. ${ }^{1.3}$ The STREAM cohort is an ongoing prospective cohort study starting in 2010 among 15,118 persons aged 45 to 64 years in the Netherlands and working in many different sectors and trades. Participants were included from an online panel and complete online questionnaires on a yearly basis on topics addressing work characteristics, personal factors (e.g. coping, job satisfaction), health factors, employment status and transitions in employment, work-ability and productivity. 
In this final chapter, a summary of our main results is reported and these results are discussed in a broader scientific context. The possible implications of our findings for future research and methodological considerations are discussed, and suggestions for future studies are presented.

\section{Cardiovascular and rheumatic diseases in working persons}

The pathophysiologic link between systemic inflammation and cardiovascular diseases in the general population has been studied extensively in the past, ${ }^{4.5}$ and has been confirmed in clinical samples of patients with inflammatory RMDs in more recent years. ${ }^{6}$ However, such clinical samples usually include patients with more severe disease (i.e. higher disease activity at the start of therapy) and might not provide a realistic picture of the role of cardiovascular diseases on relevant clinical outcomes such as work participation.7.8 Knowledge about the presence of cardiovascular co-morbidities in a population of working persons with inflammatory RMDs is interesting for two reasons; 1) cardiovascular co-morbidities can lead to cardiovascular mortality during working life and result in premature exit from the work force, which makes cardiovascular morbidity an independent epidemiological contributor to reduced work participation, and 2) cardiovascular co-morbidities may lead to additional long-term restrictions in work participation across the entire continuum of work, more specifically sick leave and work disability, increasing the indirect costs of inflammatory RMDs for society.,10

In the Maastricht Cohort Study, half of the baseline population lived in the south of the Netherlands, which allowed us to verify self-reported RMDs and cardiovascular diseases in the medical charts of surrounding hospitals. We were able to confirm 35 diagnoses of inflammatory RMDs, i.e. rheumatoid arthritis, psoriatic arthritis and axial SpA, and 31 diagnoses of gout at baseline or during follow-up. This allowed us to describe work participation in these persons and follow the course of their working career for the next decade in Chapters 2 and 3. In Chapter 2 we used the verified diagnoses of inflammatory RMDs and gout at baseline to study the risk of developing cardiovascular diseases over the next ten years, as compared to persons without these diseases. This risk was increased more than twofold for inflammatory RMDs, though it did not reach statistical significance, probably due to low numbers. The presence of gout significantly increased the risk of developing cardiovascular diseases more than threefold during follow-up. By linking the Maastricht Cohort Study to the Dutch National Death registry, we were able to show this did not lead to increased cardiovascular-specific mortality during the course of this study. We concluded that the risk of developing cardiovascular morbidity was increased but the impact of cardiovascular mortality on premature exit from the labour force among working persons with inflammatory RMDs was limited in this cohort of relatively young participants (mean age 41.0 years). 
Next, in Chapter 3 we linked company records to the Maastricht Cohort Study, providing individual sick leave data for the first two and a half years of follow-up, to study the additional impact of cardiovascular diseases on sick leave. Our results showed that in working persons with self-reported RMDs the percentage of sick leave days (i.e. proportional to the total number of expected work days) in 2.5 years more than doubled, as compared to participants without self-reported RMDs. Self-reported cardiovascular diseases also increased the mean percentage of sick leave days almost twofold. The number of sick leave days increased further when self-reported RMDs and cardiovascular disease were both present by more than 2.5-fold, as compared to participants without these diseases. In the sample verified by clinical review, the percentage of sick leave days was increased more than twofold in those with confirmed inflammatory RMDs. No participants with confirmed inflammatory RMDs and co-existing cardiovascular diseases were present at baseline in the Maastricht Cohort Study. Similarly, we used self-reported data on work disability benefits from the entire length of follow-up to study the additional impact of cardiovascular diseases on the risk of work disability. Self-reported RMDs and cardiovascular disease increased the risk of work disability after ten years by more than 6.5-fold and 4-fold, respectively. Additive or synergistic effects were not found when both diseases were present. Similarly, the risk of work disability after ten years was increased for confirmed inflammatory RMDs more than eightfold and cardiovascular diseases almost fivefold. Confirmed gout also increased this risk fivefold, although this was not statistically significant, probably due to low numbers. Our results also show that working persons with confirmed osteoarthritis and fibromyalgia are especially at risk of work disability in the next ten years. The burden of the latter diseases on society may have been underestimated up until now. Given the high prevalence of osteoarthritis in the world, we believe extra attention should be directed towards prevention and treatment of adverse work outcomes resulting from osteoarthritis. ${ }^{11,12}$

A few considerations need to be taken into account to correctly interpret our findings presented in Chapters 2 and 3. First of all, we studied the additional impact of cardiovascular diseases on adverse work outcomes (i.e. sick leave, work disability), including mortality during working life, because of the direct pathophysiological link between systemic inflammation and cardiovascular diseases. ${ }^{4.5}$ Cardiovascular diseases frequently occur and are relevant co-morbidities in inflammatory RMDs. Therefore, cardiovascular risk management has become part of European League Against Rheumatism (EULAR) recommendations. ${ }^{13}$ Other co-occurring diseases (e.g. mental diseases) or multi-morbidity may be present but do not share the same pathophysiological link. Yet, these may be more detrimental for work participation in persons already suffering from RMDs. In the limited number of studies available in the literature, multi-morbidity has been shown to have important adverse effects on work outcomes. ${ }^{10,14}$ This seems especially important for 
co-existing mental diseases..$^{15-17}$ The cross-sectional Dutch population study by Van der Zee et al. reported that the specific combination of RMDs and mental diseases had one of the strongest associations with each of the four work outcomes studied: work disability, dependence on a living allowance, economic unemployment and sick leave. ${ }^{10}$ This study also showed an almost linear relation between each additional co-morbidity and the presence of work disability, dependence on living allowances and sick leave, but not with economic unemployment. The additional impact of cardiovascular co-morbidities on the risk of work disability in persons with RMDs was increased as compared to persons with only RMDs, but not for dependence on living allowances and economic unemployment. ${ }^{10}$ In other studies, the large impact of RMDs on increased sick leave, especially in those with mental diseases and RMDs, had already been identified.18.19 From a societal point of view, RMDs account for a major part of the expenditures for sick leave and work disability in absolute terms due to the high prevalence, while the relative impact of mental disease on adverse work outcomes is considerably higher..$^{10}$ It is important to keep in mind that with aging of the population, multimorbidity will become the rule rather than the exception, and special attention should be paid to preventing (the consequences of) multi-morbidity. Unfortunately, multi-morbidity is still poorly understood and should be better integrated into clinical practice and research.20

A second consideration are the 'healthy worker effect' and other modifying effects (i.e. confounding, effect modification) which may have masked some of the increased risks in our studies. The healthy worker effect is a type of selection bias in occupational cohorts occurring because less healthy individuals are more likely to be unemployed than healthy individuals. ${ }^{21}$ Most studies indicate that the healthy worker effect will reduce the association between exposure and outcome by an average of 20-30\%.22 The healthy worker effect may indeed play a role in the Maastricht Cohort Study, as indicated by the lower prevalence of RMDs and cardiovascular diseases, lower excess mortality, and the lack of (significant) additive or synergistic effects by cardiovascular co-morbidities on sick leave and work disability, as opposed to what we expected based on prevalence data. On the other hand, attenuation of studied associations by contextual factors (e.g. gender, age, type of job) seems especially important when interpreting work outcome studies.23.24 We were able to adjust for some confounders in our analyses in Chapters 2 and 3, but were limited in number and range of confounders (i.e. independent variables) that could be included in our analyses due to the small numbers of verified RMDs and cardiovascular diseases, i.e. small number of events per independent variable.25 We also cannot rule out that some unmeasured confounders may have attenuated our results. Lastly, certain subgroups may be especially at risk of adverse work outcomes (i.e. effect modification), such as persons working in physically demanding jobs or blue collar workers. ${ }^{26-28}$ These modifying effects should be explored further in complementary studies. 


\section{Prevention of adverse work outcomes}

Early interventions to prevent long-term adverse work outcomes are essential, because having work is associated with higher levels of a persons' health and wellbeing, and a reduced burden of disease on societal expenditures. ${ }^{29-31}$ This can be achieved by more intensive treatment strategies of the underlying disease to reduce disease activity and improve work outcomes. ${ }^{32}$ Another intervention is early detection of risk factors for adverse work outcomes, amongst other options not presented in this thesis., ${ }^{19.33}$

In Chapter 4 we report the results of a systematic literature review showing that biological therapies have promising beneficial effects on work outcomes in patients with axial SpA. ${ }^{34}$ We included two randomized clinical trials (RCTs) and seven observational cohorts, reporting on 39 comparisons in before-after or between-group comparisons and including a total of 961 patients ( $n=851$ (89\%) in cohort studies and $n=110$ (11\%) in RCTs). These patients were treated with three different tumour necrosis factor alpha inhibitors (TNFi, i.e. etanercept, infliximab and adalimumab). Most comparisons suggested a numerical positive change in work outcome (32/39 comparisons), but were often not tested for significance (14/32 comparisons) or proved not statistically significant (7/32 comparisons).

Presenteeism was studied by three uncontrolled cohort studies and both RCTs, all showing a numerical improvement in favour of biological therapies. However, not all comparisons were statistically significant or tested, and usually pertained to beforeafter analyses without between-group comparisons. For example, one open-label study showed a significant decrease in impairment in work productivity of 2.9 points on the Work Productivity and Activity Impairment - Specific Health Problem questionnaire (WPAI-SHP, score range 0-10) after 28 weeks of follow-up and compared with baseline.35

Absence from paid work (i.e. sick leave) was the outcome most often studied. Six out of seven cohorts and both RCTs reported on this outcome, and all cohorts and one RCT showed an improvement, although this was not always statistically tested. For example. one population-controlled cohort showed a significant within-patient reduction in sick leave after 52 weeks, expressed as the percentage of full-time at work and compared with treatment start. ${ }^{36}$ One RCT actually showed a deterioration in absenteeism, but this was not statistically significant. ${ }^{37}$

Changes in work status were reported in five cohort studies and by none of the RCTs. The results for work status were less often positive, but it should be noted that included studies dealt with patients with longstanding axial SpA (10.6-16.4 years since diagnosis), lacked power and had a relatively short follow-up to detect changes in employment (28 
to 156 weeks). The average age of patients in the cohort studies ranged from 39.5 to 49.9 years and in the RCTs this was 40.3 years. This suggests that the negative impact of the disease on employment status had already occurred before the start of TNFi, leaving limited opportunity for improvement by pharmacological interventions. Unfortunately, methodological limitations such as a lack of standardization of outcomes used and the limited number of studies included precluded a meta-analysis, but trends towards beneficial effects of biological therapies in longstanding axial SpA were seen on all work outcomes.

Since the publication of our review at least six new longitudinal studies have been published on this topic; 5 RCTs some including long-term extensions, and 1 observational cohort, all showing a positive influence of biological therapies on work-related outcomes in axial SpA. ${ }^{38-43}$ Some of these studies have recently been reviewed narratively by Nikiphorou et al. ${ }^{44}$ The study by Shim et al. is of particular interest because it provides reallife observational data investigating the impact of biological therapies on presenteeism and sick leave in the longer-term. ${ }^{38}$ They used the large British Society for Rheumatology Biologics Register (BSRBR, $n=577$ ) to show that axial SpA patients starting biological therapy at the time of recruitment experienced significantly greater improvements in work outcomes as compared to matched controls not treated with a biological. After twelve months, biological therapies had improved presenteeism, overall work impairment and overall activity impairment but did not improve absenteeism all measured on the WPAI. All analyses only included patients if they were employed at baseline and after twelve months, making it impossible to show changes in employment status. The positive effect on work productivity was further supported by pooled estimates from a meta-analysis of BSRBR data combined with four RCTs also measuring the WPAI. They showed a statistically significant improvement in favour of biological therapies for presenteeism and overall work impairment and concluded there is consistent evidence, across different study designs, that treatment with biological therapies significantly and meaningfully improves presenteeism in patients with axial SpA. ${ }^{38}$ In line with most of the more recent clinical trial data, the meta-analysis by Shim et al. did not show significant improvements in absenteeism with the use of biologics, despite improvements in presenteeism, work impairment and activity impairment. ${ }^{44}$ This is in contrast to our findings in Chapter 4, which were mainly based on observational studies and showed positive effects with the use of biological therapies, although not always statistically tested. Future real-life observational data from controlled cohort studies are necessary to clarify these conflicting results. In addition, there remains a substantial gap between axial SpA patients and the general population in terms of work participation, suggesting that pharmacological interventions alone are not enough and other (multidisciplinary) approaches are needed. ${ }^{31}$ 
In Chapter $\mathbf{5}$ we presented the results of the development and validation of a multivariable risk prediction model, discriminating between workers with high- and low-risk for longterm sickness absence in the coming year. We used data from 11,221 working persons in the STREAM cohort to develop this multivariable risk prediction model for long-term sickness absence lasting $\geq 28$ accumulated working days in the coming year. Logistic regression analysis using backward stepwise elimination was used to reduce the full statistical model including 27 pre-selected predictors to a more practical model including 11 predictors. This final model showed good discrimination (Area Under the Curve: 0.76) and good calibration (Hosmer-Lemeshow test: $p=0.41$ ) in a second validation cohort of 5,604 newly recruited working persons. Multivariable regression coefficients of the predictors in the final model of the development cohort revealed that poor self-rated physical health (measured with the Short Form-12 [SF-12] physical component score), poor self-rated work-ability (measured with one item from the Work Ability Index (WAI)) and a high number sickness absence days in the previous year showed the strongest associations with future long-term sickness absence. The level of perceived limitations in physical functioning predicted future long-term sickness absence better than the health condition possibly underlying these limitations, such as musculoskeletal disease or multimorbidity. These variables were eliminated from the full model that included self-reported physical health and physical job load. Mental health was not included as a predictor in our final model, but may be more important in specific working populations or sectors (e.g. younger persons, white collar workers). The importance of mental health problems for predicting long-term sickness absence was confirmed by other studies reporting on multifactorial risk prediction models. ${ }^{45-47}$ Other previously identified risk factors for future long-term sickness absence (i.e. social and financial factors, emotional job demands and autonomy) were excluded during statistical analyses using backward stepwise elimination to obtain a more practical model for clinical practice.45-47 Future studies validating and updating this prediction model are encouraged to determine if these factors add to the predictive validity of our model in other settings and populations where a more practical model is of less priority.

The strength of the STREAM cohort is that it collected a comprehensive set of potential predictors for long-term sickness absence, including variables not previously studied. We have found new factors which were important predictors of future long-term sickness absence, such as knowledge/skills matching the current job, the number of major life events in the previous year and self-employment. While our prediction model allows for the calculation of a risk-score by giving "statistical weight" to each risk factor, an optimal cutoff still needs to be determined. Such thresholds should balance between over- and underdiagnoses. This threshold may be different in RMD populations as compared to a general working population, because the a priori risk for long-term sickness absence 
is probably higher. We, however, believe that implicit use of the reported risk factors in clinical reasoning would perhaps be more desirable. The results from our prediction model have the potential to support healthcare professionals in determining which working persons should be targeted for tailored preventive interventions, but could also serve to identify new and potentially modifiable risk factors at the level of companies or workplaces (e.g. physical fitness). ${ }^{47.48}$ Unfortunately, work participation most often is of second-order priority to healthcare professionals in primary and secondary care and is not regarded as a clinical outcome. A simple and practical tool to predict long-term sick leave may increase the attention for work participation as an outcome in clinical practice. Yet, we also require high-quality work outcome measurements to reliably measure other aspects of work participation in clinical practice and research.

\section{Presenteeism - an outcome in clinical practice and research}

During the last decades, substantial work has been performed by the Outcome Measures in Rheumatology (OMERACT) initiative to identify and evaluate instruments for outcome measurement in rheumatology clinical trials. A measure is endorsed if it passes through the OMERACT Filter, which evaluates three component criteria: 'truth' (i.e. face, content, construct and criterion validity), discrimination (i.e. reliability and sensitivity to change) and feasibility (i.e. pragmatic reality of the use of the measure).50 The OMERACT Worker Productivity working group identified and evaluated several worker productivity (i.e. presenteeism) outcome measures in more recent years. ${ }^{23}$ One limitation they identified was that direct comparisons between different instruments in longitudinal studies were lacking.

Therefore, in Chapter 6 we used data from 4,523 working persons with musculoskeletal complaints in the prospective STREAM cohort to compare the construct validity of three presenteeism instruments. ${ }^{51}$ One presenteeism measurement instrument concerned a single item global rating of work-ability as part of the WAI, and two measurement instruments addressing at-work productivity, measured using the Quality and Quantity (QQ)-method and the Osterhaus-method. The longitudinal associations of the three presenteeism instruments with external measures of health and sick leave were assessed using Generalised Estimating Equation (GEE) models over a 6 -year follow-up period with one-year intervals. Predictive validity is part of the construct validity of an instrument and is used to determine whether the instrument measures what it is intended to measure when the outcome occurs in the future. Overall, the WAI ('the ability to work') showed stronger longitudinal associations with different health variables as compared to the other two measures operationalizing presenteeism as 'productivity while at work'. For example, the SF-12 physical component score was more strongly longitudinally associated with an increase on the WAI in the subsequent year, as compared to the QQ-method and 
Osterhaus-method. Similar differences between the three instruments in favour of the WAI were found for the longitudinal associations with mental health (SF-12 mental component score) and vitality (SF-36 vitality index). Sick leave days in the subsequent year were also more strongly associated with the WAI, as compared to the QQ-method and Osterhaus-method. Differences between the three instruments were also reflected in the weak inter-correlations at each timepoint, confirming that self-rated work-ability and work productivity are truly different consequences of disease on work. Work-ability showed higher construct validity against health and economic outcomes as compared to at-work productivity and is clearly more relevant to identify working persons at risk of subsequent sick leave, as for use in the prediction model we constructed in Chapter 5. On the other hand, the Osterhaus-method has (theoretically) higher face validity to estimate costs associated with presenteeism and seems more relevant from an economic perspective, although validation with an objective productivity outcome is still lacking. Clearly, the preferred construct (and thus instrument) selected in future studies to measure the concept presenteeism is dependent on the study type and objectives.

In Chapter 6 we also explored the impact of groups of contextual factors on the associations between health factors, presenteeism instruments and sick leave by testing changes in explained variability of the outcome by the model. This was expressed as relative Quasi-likelihood under the Independence model Criterion (QIC) and compared to a basic model without any contextual factors included, with lower QICs reflecting better data fit. We demonstrated that personal contextual factors (i.e. mastery, coping and selfefficacy) had the most substantial impact on the associations between health factors and the WAI and the QQ-method, but this effect was negligible for the Osterhaus-method. Demographic, lifestyle and work-related contextual factors had a much smaller impact on the associations between health factors and the three presenteeism instruments. The impact of all groups of contextual factors on the associations between the three presenteeism instruments and sick leave was small, possibly because context was already implicitly included in these presenteeism instruments. Personal factors are not routinely collected in occupational studies in RMD populations, but our results indicate that this should be encouraged to correctly interpret work outcome data. In the field of rheumatology, the OMERACT Contextual Factors working group performed significant work to provide guidance on addressing contextual factors in clinical trials and has published provisional generic contextual factor domains. ${ }^{52.53} \mathrm{We}$ believe that context is highly dependent on the setting it is intended for (e.g. clinical vs. occupational setting) and is outcome-specific (e.g. quality of life vs. pain). Personal factors may indeed prove to be more relevant for the interpretation of work participation data. Future studies should identify and characterize contextual factors specific to occupational settings and work outcomes. 


\section{Longitudinal analysis of work participation data}

This thesis is primarily based on work participation data from two prospective, occupational cohort studies in the Netherlands and methods used to address our research questions are mainly based on longitudinal data analyses. The key advantage of longitudinal over cross-sectional studies is the ability to show patterns of a variable over time. This knowledge is especially relevant for promoting sustainable employability where insight is needed in determinants of transitions in employment, productivity, and health. However, longitudinal studies are associated with high temporal and financial demands on the one hand. On the other hand, attrition or loss-to-follow-up are important methodological problems in longitudinal studies, resulting in missing data and biased estimates. ${ }^{54}$ Fortunately, two accepted methods to deal with missing data in longitudinal studies are available, which have been used for this thesis: multiple imputation techniques and GEE models. ${ }^{5}$ The way missing data is handled is different between these two methods.

The first step in multiple imputation is to create multiple copies of the dataset, with the missing values replaced by imputed values which are sampled from their predictive distribution based on the observed data. ${ }^{56}$ Appropriate variability is inserted into the multiple imputed values to account for the uncertainty in predicting the missing values. In the second step, standard statistical methods to fit the model of interest to each of the imputed datasets are used and averaged together to give overall estimated associations, including standard errors calculated using Rubin's rules. ${ }^{57}$

On the other hand, GEE models are considered fairly robust with regard to missing data. Previous simulation studies have shown that it is not necessary to impute missing data using multiple imputations before performing a GEE model analysis on longitudinal data.55.58 Apart from dealing with missingness, GEE models can take into account within-subject correlations over time and other clustered data. It is important to take this correlation into account, otherwise the standard errors of the parameter estimates will not be valid and hypothesis testing results will be non-replicable.

While both methods will give quite similar precise results and make all available data accessible for statistical modelling, the estimates may still be biased and lead to erroneous conclusions if missingness is caused by systematic mechanisms (and not completely at random). Therefore, before such statistical approaches are used, reasons for missingness should be explored.

The two cohorts used in this thesis have been designed with a broad questioning to allow different viewpoints on general working populations, but were not specifically intended for studies in RMD populations. If we would design a new study addressing 
(transitions in) work participation, effects of multi-morbidity and the role contextual factors specifically in RMD populations, how should this study be designed? Perhaps the STREAM cohort, used in Chapters 5 and 6, is a good example. The advantage of this cohort is that it is positioned in a large population of employed, self-employed and non-employed persons, who are prospectively followed over a long period of time, allowing the study of transitions in work participation. In addition, it collects a substantial number of contextual factors, morbidities and other health factors, by means of extensive self-administered questionnaires. It would be interesting to enrich a new cohort with a younger population and enroll all subjects within a restricted time period after inception (inception-type prospective cohort), before persons have lost employment. Ideally, this new cohort will eventually be linked to other datasets, such hospital records or social security data. In this thesis we have used different RMD populations, ranging from general working populations which can be found in general practice up till patients with axial SpA found at the out-patient clinic of rheumatologists. The setting from which participants are recruited for this new cohort importantly affects study results and generalizability and should therefore be chosen carefully.

\section{Final conclusions}

In conclusion, this thesis contributes to our understanding of the complex relationships between health, contextual factors and restrictions in work participation in persons with rheumatic and musculoskeletal diseases. It specifically adds to the body of evidence showing the impact of multi-morbidity and contextual factors on work outcomes, confirms the beneficial effects of biological therapies on work participation in axial spondyloarthritis and provides new opportunities to improve early detection and outcome measurement in rheumatic and musculoskeletal diseases. 


\section{REFERENCES}

1. Kant IJ, Bültmann U, Schröer KA, et al. An epidemiological approach to study fatigue in the working population: the Maastricht Cohort Study. Occup Environ Med 2003;60 Suppl 1(Suppl 1):i32-9.

2. Ybema JF, Geuskens GA, van den Heuvel SG, et al. Study on Transitions in Employment, Ability and Motivation (STREAM): The Design of a Four-year Longitudinal Cohort Study among 15,118 Persons Aged 45 to 64 Years. British Journal of Medicine and Medical Research 2014:4(6):1383-99.

3. Bültmann U, Kant I, van Amelsvoort LG, et al. Differences in fatigue and psychological distress across occupations: results from the Maastricht Cohort Study of Fatigue at Work. J Occup Environ Med 2001:43(11):976-83.

4. Kaplan RC, Frishman WH. Systemic inflammation as a cardiovascular disease risk factor and as a potential target for drug therapy. Heart Dis 2001;3(5):326-32.

5. Willerson JT, Ridker PM. Inflammation as a cardiovascular risk factor. Circulation 2004:109(21 Suppl 1):li2-10.

6. Castaneda S, Nurmohamed MT, Gonzalez-Gay MA. Cardiovascular disease in inflammatory rheumatic diseases. Best Pract Res Clin Rheumatol 2016;30(5):851-69.

7. Straaton KV, Maisiak R, Wrigley JM, et al. Barriers to return to work among persons unemployed due to arthritis and musculoskeletal disorders. Arthritis Rheum 1996:39(1):101-9.

8. Hoving JL, van Zwieten MC, van der Meer M, et al. Work participation and arthritis: a systematic overview of challenges, adaptations and opportunities for interventions. Rheumatology (Oxford) 2013:52(7):1254-64.

9. Pincus T, Gibson KA, Block JA. Premature Mortality: A Neglected Outcome in Rheumatic Diseases? Arthritis Care Res (Hoboken) 2015:67(8):1043-6.

10. van der Zee-Neuen A, Putrik P, Ramiro S, et al. Work outcome in persons with musculoskeletal diseases: comparison with other chronic diseases \& the role of musculoskeletal diseases in multimorbidity. BMC Musculoskelet Disord 2017:18(1):10.

11. Vos T, Abajobir AA, Abate $\mathrm{KH}$, et al. Global, regional, and national incidence, prevalence, and years lived with disability for 328 diseases and injuries for 195 countries, 1990-2016: a systematic analysis for the Global Burden of Disease Study 2016. The Lancet 2017:390(10100):1211-59.

12. Briggs AM, Woolf AD, Dreinhofer $K$, et al. Reducing the global burden of musculoskeletal conditions. Bull World Health Organ 2018:96(5):366-8.

13. Agca R, Heslinga SC, Rollefstad $\mathrm{S}$, et al. EULAR recommendations for cardiovascular disease risk management in patients with rheumatoid arthritis and other forms of inflammatory joint disorders: 2015/2016 update. Ann Rheum Dis 2017:76(1):17-28.

14. Ubalde-Lopez M, Delclos G, Gimeno D, et al. Multimorbidity as a determinant of incident sickness absence: Monica Ubalde-Lopez. European Journal of Public Health 2014:24(suppl_2).

15. Callhoff J, Albrecht $K$, Schett $G$, et al. Depression is a stronger predictor of the risk to consider work disability in early arthritis than disease activity or response to therapy. RMD Open 2015:1(1):e000020.

16. Matcham F, Rayner L, Steer S, et al. The prevalence of depression in rheumatoid arthritis: a systematic review and meta-analysis. Rheumatology (Oxford) 2013:52(12):2136-48.

17. Wynne-Jones G, Chen Y, Croft P, et al. Secular trends in work disability and its relationship to musculoskeletal pain and mental health: a time-trend analysis using five cross-sectional surveys (2002-2010) in the general population. Occup Environ Med 2018;75(12):877-83. 
18. Hubertsson J, Englund M, Hallgårde U, et al. Sick leave patterns in common musculoskeletal disorders--a study of doctor prescribed sick leave. BMC Musculoskelet Disord 2014:15:176.

19. Woolf AD, Pfleger B. Burden of major musculoskeletal conditions. Bull World Health Organ 2003:81(9):646-56.

20. Radner H, Yoshida K, Smolen JS, et al. Multimorbidity and rheumatic conditions-enhancing the concept of comorbidity. Nat Rev Rheumatol 2014;10(4):252-6.

21. Kirkeleit J, Riise T, Bjørge T, et al. The healthy worker effect in cancer incidence studies. Am J Epidemiol 2013:177(11):1218-24

22. Shah D. Healthy worker effect phenomenon. Indian J Occup Environ Med 2009:13(2):77-9.

23. Beaton DE, Dyer S, Boonen A, et al. OMERACT Filter Evidence Supporting the Measurement of At-work Productivity Loss as an Outcome Measure in Rheumatology Research. J Rheumatol 2016;43(1):214-22.

24. Stolwijk C, Castillo-Ortiz JD, Gignac M, et al. Importance of Contextual Factors When Measuring Work Outcome in Ankylosing Spondylitis: A Systematic Review by the OMERACT Worker Productivity Group. Arthritis Care Res (Hoboken) 2015:67(9):1316-27.

25. Austin PC, Steyerberg EW. The number of subjects per variable required in linear regression analyses. J Clin Epidemiol 2015;68(6):627-36.

26. Geuskens GA, Hazes JM, Barendregt PJ, et al. Work and sick leave among patients with early inflammatory joint conditions. Arthritis Rheum 2008;59(10):1458-66.

27. Verstappen SM, Bijlsma JW. Verkleij $\mathrm{H}$, et al. Overview of work disability in rheumatoid arthritis patients as observed in cross-sectional and longitudinal surveys. Arthritis Rheum 2004:51(3):48897.

28. Boonen $\mathrm{A}$, de Vet $\mathrm{H}$, van der Heijde $\mathrm{D}$, et al. Work status and its determinants among patients with ankylosing spondylitis. A systematic literature review. J Rheumatol 2001;28(5):1056-62.

29. Waddell G, Burton AK. Is work good for your health and well-being? Waddell G, Burton AK, editors. London, UK: The Stationery Office; 2006. 246 p.

30. Bevan S. Economic impact of musculoskeletal disorders (MSDs) on work in Europe. Best Pract Res Clin Rheumatol 2015:29(3):356-73.

31. Wilkie R, Bjork M, Costa-Black KM, et al. Managing work participation for people with rheumatic and musculoskeletal diseases. Best Pract Res Clin Rheumatol 2020;34(2):101517.

32. van Lunteren M, Ez-Zaitouni Z, Fongen $C$, et al. Disease activity decrease is associated with improvement in work productivity over 1 year in early axial spondyloarthritis (SPondyloArthritis Caught Early cohort). Rheumatology (Oxford) 2017:56(12):2222-8.

33. Laisné F, Lecomte C, Corbière M. Biopsychosocial predictors of prognosis in musculoskeletal disorders: a systematic review of the literature. Disability and Rehabilitation 2012:34(22):1912-41.

34. van der Burg LR, Ter Wee MM, Boonen A. Effect of biological therapy on work participation in patients with ankylosing spondylitis: a systematic review. Ann Rheum Dis 2012;71(12):1924-33

35. Haibel H, Rudwaleit M, Listing J, et al. Efficacy of adalimumab in the treatment of axial spondylarthritis without radiographically defined sacroiliitis: Results of a twelve-week randomized, double-blind, placebo-controlled trial followed by an open-label extension up to week fifty-two. Arthritis \& Rheumatism 2008:58(7):1981-91.

36. Kristensen LE, Petersson IF, Geborek P, et al. Sick leave in patients with ankylosing spondylitis before and after anti-TNF therapy: a population-based cohort study. Rheumatology (Oxford) 2012:51(2):243-9.

37. Barkham N. Coates LC, Keen H, et al. Double-blind placebo-controlled trial of etanercept in the prevention of work disability in ankylosing spondylitis. Ann Rheum Dis 2010;69(11):1926-8. 
38. Shim J, Jones GT, Pathan EMI, et al. Impact of biological therapy on work outcomes in patients with axial spondyloarthritis: results from the British Society for Rheumatology Biologics Register (BSRBR-AS) and meta-analysis. Ann Rheum Dis 2018;77(11):1578-84.

39. Dougados M, Tsai WC, Saaibi DL, et al. Evaluation of Health Outcomes with Etanercept Treatment in Patients with Early Nonradiographic Axial Spondyloarthritis. J Rheumatol 2015:42(10):1835-41.

40. Deodhar AA, Dougados M, Baeten DL, et al. Effect of Secukinumab on Patient-Reported Outcomes in Patients With Active Ankylosing Spondylitis: A Phase III Randomized Trial (MEASURE 1). Arthritis Rheumatol 2016;68(12):2901-10.

41. van der Heijde D, Braun J, Rudwaleit M, et al. Improvements in workplace and household productivity with certolizumab pegol treatment in axial spondyloarthritis: results to week 96 of a phase III study. RMD Open 2018;4(1):e000659

42. van der Heijde D, Joshi A, Pangan AL, et al. ASAS4O and ASDAS clinical responses in the ABILITY-1 clinical trial translate to meaningful improvements in physical function, health-related quality of life and work productivity in patients with non-radiographic axial spondyloarthritis. Rheumatology (Oxford) 2016:55(1):80-8.

43. van der Heijde D, Deodhar A, Braun J, et al. The effect of golimumab therapy on disease activity and health-related quality of life in patients with ankylosing spondylitis: 2-year results of the GO-RAISE trial. J Rheumatol 2014;41(6):1095-103.

44. Nikiphorou E, Ramiro S. Work Disability in Axial Spondyloarthritis. Curr Rheumatol Rep 2020;22(9):55.

45. Kant IJ, Jansen NW, van Amelsvoort LG, et al. Screening questionnaire Balansmeter proved successful in predicting future long-term sickness absence in office workers. J Clin Epidemiol 2009;62(4):408-14.e2.

46. Roelen C, Thorsen S, Heymans M, et al. Development and validation of a prediction model for long-term sickness absence based on occupational health survey variables. Disabil Rehabil 2018;40(2):168-75.

47. Airaksinen J, Jokela M, Virtanen M, et al. Prediction of long-term absence due to sickness in employees: development and validation of a multifactorial risk score in two cohort studies. Scand J Work Environ Health 2018;44(3):274-82.

48. Burdorf A. Prevention strategies for sickness absence: sick individuals or sick populations? Scand J Work Environ Health 2019:45(2):101-2.

49. Rose G. Sick Individuals and Sick Populations. International Journal of Epidemiology 1985:14(1):328.

50. Tugwell P, Boers M, Brooks P, et al. OMERACT: an international initiative to improve outcome measurement in rheumatology. Trials 2007:8:38.

51. van der Burg LRA, van Kuijk SMJ, Ter Wee MM, et al. Long-term sickness absence in a working population: development and validation of a risk prediction model in a large Dutch prospective cohort. BMC Public Health 2020;20(1):699.

52. Finger ME, Boonen A, Woodworth TG, et al. An OMERACT Initiative Toward Consensus to Identify and Characterize Candidate Contextual Factors: Report from the Contextual Factors Working Group. J Rheumatol 2017:44(11):1734-9.

53. Nielsen SM, Storgaard H, Ellingsen $\mathrm{T}$, et al. Population characteristics as important contextual factors in rheumatological trials: an exploratory meta-epidemiological study from an OMERACT Working Group. Ann Rheum Dis 2020;79:1269-76.

54. Caruana EJ, Roman M. Hernández-Sánchez J, et al. Longitudinal studies. J Thorac Dis 2015:7(11):E537-E540. 
55. Twisk J, de Vente W. Attrition in longitudinal studies. How to deal with missing data. J Clin Epidemiol 2002:55(4):329-37.

56. Sterne JAC, White IR, Carlin JB, et al. Multiple imputation for missing data in epidemiological and clinical research: potential and pitfalls. BMJ 2009;338:b2393.

57. Rubin DB. Multiple Imputation for Nonresponse in Surveys: Wiley: 1987. 258 p.

58. Twisk J, de Boer M, de Vente W, et al. Multiple imputation of missing values was not necessary before performing a longitudinal mixed-model analysis. J Clin Epidemiol 2013;66(9):1022-8. 



\section{Addendum}

IMPACT PARAGRAPH 



\section{IMPACT PARAGRAPH}

In the previous chapter the results presented in this thesis were primarily discussed in a broader scientific context. This concluding paragraph will be used to describe the impact of our findings on different stakeholders: patients and society as a whole, healthcare systems and research.

\section{Relevance of work participation for patients and society}

Participation in paid work is one of the most important social roles of individuals in our society. It is a source of income, protects against social exclusion and gives meaning to life..$^{1,2}$ In addition, employment enables individuals to actively participate in all aspects of life and be economically, socially and functionally independent. Therefore, it is not surprising employment is associated with higher levels of (health-related) quality of life. ${ }^{3}$

Rheumatic and musculoskeletal diseases (RMDs) are among the most prevalent diseases in the world and result in a substantial burden on societal expenditures. It is estimated that over 1,2 billion individuals are affected by RMDs worldwide, and the total costs (i.e. direct and indirect costs) for society associated with RMDs are as high as $2 \%$ of gross domestic product in most European countries. ${ }^{4.5}$ Although the direct medical costs of RMDs (e.g. treatments, hospital admissions) are substantial, the indirect costs due to lost work productivity and economic unemployment probably outweigh the direct costs considerably. ${ }^{6}$ Also in the Netherlands, RMDs account for the largest burden on expenditures for society in absolute terms, consisting of direct and indirect costs, but also the so-called intangible costs (i.e. monetary value of the inconvenience and difficulties due to RMDs). ${ }^{7}$ This large burden mainly results from the higher prevalence of RMDs in the population as compared to other diseases which are less prevalent but have a larger relative impact on expenditures (e.g. mental diseases). ${ }^{8}$

We are gaining increasingly better treatment options to control disease activity and are able to reduce functional limitations resulting from inflammatory RMDs. At the same time, we are faced with the fact that more (co-existing) diseases are present at an increasingly younger age and an aging population. ${ }^{9}$ The younger age of onset of RMDs, during peak income-earning years, will most likely increase the burden of RMDs on expenditures in the future. Multi-morbidity increases the risk of adverse work outcomes even more, likely resulting in additional pressure on societal expenditures. ${ }^{8}$ Co-existing diseases also significantly inhibit return to work when employment has been lost, creating an additional barrier for individuals with RMDs to start working again. ${ }^{10}$ 
The abovementioned emphasizes the relevance of work participation in RMDs from a personal and societal point of view. Recognition and support of vulnerable persons on the labor market with RMDs as a single disease, and in the context of multi-morbidity, is vital and a prerequisite for long-term participation of people with chronic diseases.

\section{Impact on the healthcare system}

Ultimately, contributing to improvement in health, quality of life and participation in paid work of patients with RMDs is the most important reason to conduct the research presented in this thesis. Work participation is generally not regarded as a clinical outcome and is not well integrated in routine clinical practice. In addition, healthcare professionals are usually not well-trained and have limited knowledge about the bidirectional relationship between chronic illness and work participation. The relationships between work, context (including legal and regulatory context) and health factors are complex and most of the times not fully understood, creating an additional barrier for integrating occupational health in routine medical care. Integration of occupational health into primary and secondary care could be beneficial for all aspects of a patient's life.

Our results increase the awareness among healthcare professionals of the importance to include work participation as a clinical outcome. This thesis also has the potential to support medical decision making by reporting on a tool predicting future long-term sickness absence. Next, we have shown that pharmacological treatment with biological therapies of axial spondyloarthritis improves work participation across the entire 'continuum of work' and can decrease indirect costs of disease and offset high drug costs. Lastly, we have shown the potential detrimental impact of cardiovascular co-morbidity on work outcomes in persons with inflammatory RMDs. Cardiovascular risk-management in persons with inflammatory RMDs is already part of several national and international guidelines, but these guidelines mainly focus on the adverse effects of cardiovascular co-morbidity on clinical outcomes and are not implemented as a signal in some patients for adverse work outcomes.

\section{Impact on research}

This thesis describes several findings which have (had) a beneficial impact on research. First of all, it emphasizes the negative impact of multi-morbidity on work participation and guides new research towards studying this concept, expanding outside of the single disease-based focus in current research and guidelines. Secondly, the methodological issues encountered when reviewing the literature in Chapter 4 were a reason and a source of evidence for an EULAR-taskforce (EUropean League Against Rheumatism) formulating 'Points to Consider' when designing, analyzing and reporting studies with work participation as an outcome among patients with inflammatory arthritis. ${ }^{11}$ The results 
described in Chapter 4 could serve as a basis for future health economic models to evaluate the cost-effectiveness of biological therapies in axial spondyloarthritis. Next, our prediction model described in Chapter 5 opens new opportunities to improve existing prediction models and study risk-based approaches to initiate tailored treatments which will improve work participation of persons with RMDs and multi-morbidity. In addition, Chapters 5 and 6 give more clarity about the role of contextual factors and this information will benefit interpretation of future work outcome studies and support an OMERACT (Outcome Measures in Rheumatology) initiative identifying and characterizing candidate contextual factors..$^{12}$ Lastly, in Chapter 6 we compared the construct validity of three presenteeism measurement instruments in working persons with RMDs. The results from our study will provide an evidence base for selection of standardized instruments to measure worker productivity and critical contextual factors in specific study settings and can inform the consensus process by the OMERACT Worker Productivity working group. ${ }^{13}$

\section{Impact on society and policy makers}

Pressure from policy makers emerged in more recent years to improve long-term participation of people with chronic diseases, including RMDs. With an aging population and increasing age of retirement this seems especially relevant. Unfortunately, previous guidelines for general practitioners ("NHG-standaarden") and rheumatologists in the Netherlands lacked attention for work and work rehabilitation. Because of the positive effects of work on health and quality of life, it became mandatory for all clinical GP guidelines to contain a paragraph about participation in work. ${ }^{14}$ Similarly, the Dutch Rheumatology Association has developed a multidisciplinary guideline, "Rheumatoid Arthritis and Participation in Work", to improve early recognition by healthcare providers of disease related problems in work participation and to guide the development of a work-directed individual treatment plan. ${ }^{15}$

Future studies should focus on a patient-centered approach, meeting the needs of people with multi-morbidity, and inform policy makers how our health system should be designed (disease-based vs. patient-centered approach). To be able to develop evidence-based guidelines for RMDs, multi-morbidity and work participation, we will need additional evidence from future studies on these topics. The results described in this thesis add to the growing body of evidence regarding multi-morbidity and work participation in RMDs.

\section{Final conclusions}

The negative impact of rheumatic and musculoskeletal diseases on the individual and society as a whole is considerable but may be (partly) reversible or preventable if appropriate actions are taken. Improving our understanding of the complex relationship 
between rheumatic and musculoskeletal diseases, context and restrictions in work participation will result in better approaches to improve early detection and tailored treatments. Finally, this thesis has the goal to raise awareness about the role of general practitioners and rheumatologists in dealing with work-related problems and improve participation in paid work of their patients 


\section{REFERENCES}

1. Fryers T. Work, identity and health. Clin Pract Epidemiol Ment Health 2006 May 31:2:12.

2. Katz P, Morris A, Gregorich S, et al. Valued life activity disability played a significant role in selfrated health among adults with chronic health conditions. J Clin Epidemiol 2009;62(2):158-66.

3. Waddell G, Burton AK. Is work good for your health and well-being? London, UK: The Stationery Office; 2006. 246 p.

4. Vos T, Abajobir AA, Abate KH, et al. Global, regional, and national incidence, prevalence, and years lived with disability for 328 diseases and injuries for 195 countries, 1990-2016: a systematic analysis for the Global Burden of Disease Study 2016. The Lancet 2017:390(10100):1211-59.

5. Bevan S. Economic impact of musculoskeletal disorders (MSDs) on work in Europe. Best Pract Res Clin Rheumatol 2015:29(3):356-73

6. Howard KJ. Howard JT, Smyth AF. The Problem of Absenteeism and Presenteeism in the Workplace. In: Gatchel RJ, Schultz IZ, editors. Handbook of Occupational Health and Wellness. Boston, MA: Springer US; 2012. p. 151-79.

7. van den Akker-van Marle ME, Chorus AM, Vliet Vlieland TP, et al. Cost of rheumatic disorders in the Netherlands. Best Pract Res Clin Rheumatol 2012 Oct;26(5):721-31.

8. van der Zee-Neuen A, Putrik P, Ramiro S, et al. Work outcome in persons with musculoskeletal diseases: comparison with other chronic diseases \& the role of musculoskeletal diseases in multimorbidity. BMC Musculoskelet Disord 2017:18(1):10

9. Radner H, Yoshida K, Smolen JS, et al. Multimorbidity and rheumatic conditions-enhancing the concept of comorbidity. Nat Rev Rheumatol 2014:10(4):252-6.

10. Hoving $\mathrm{JL}$, van Zwieten MC, van der Meer M, et al. Work participation and arthritis: a systematic overview of challenges, adaptations and opportunities for interventions. Rheumatology (Oxford) 2013:52(7):1254-64.

11. Alunno A, Marques ML, Boonen A, et al. Methodological aspects of design, analyses, and reporting of studies with work participation as outcome domain in patients with inflammatory arthritis: results of two systematic literature reviews informing EULAR Points to Consider. [abstract] Ann Rheum Dis 2020:79:1879-80.

12. Finger ME, Boonen A, Woodworth TG, et al. An OMERACT Initiative Toward Consensus to Identify and Characterize Candidate Contextual Factors: Report from the Contextual Factors Working Group. J Rheumatol 2017:44(11):1734-9

13. Beaton DE, Dyer S, Boonen A, et al. OMERACT Filter Evidence Supporting the Measurement of At-work Productivity Loss as an Outcome Measure in Rheumatology Research. J Rheumatol 2016:43(1):214-22.

14. de Kock CA (2020). GPs@Work (Huisartsenwerk). The role of GPs in work-related problems (Doctoral dissertation). (ISBN no. 978-94-028-2023-2)

15. Boonen A, Lems W. Worker participation as a treatment goal: new guideline "Rheumatoid Arthritis and Participation in Work".'larticle in Dutch] Ned Tijdschr Geneeskd 2015;159:A9593. 



\section{Addendum}

NEDERLANDSE SAMENVATTING 



\section{NEDERLANDSE SAMENVATTING}

Reumatische en andere chronische musculoskeletale aandoeningen komen veel voor in de werkende bevolking en kunnen leiden tot verminderde productiviteit op het werk, korte of langdurige afwezigheid op het werk, verlies van werk en hoge maatschappelijke kosten. Onder de noemer van reumatische aandoeningen vallen bijvoorbeeld reumatoïde artritis, axiale spondyloartritis en artrose. Ander chronische musculoskeletale aandoeningen zijn bijvoorbeeld chronische lage rug- of nekklachten. Pijn, stijfheid en toenemende functionele beperkingen, veelvoorkomende klachten bij deze aandoeningen, kunnen zorgen voor verlies van gezonde levensjaren en van sociaalmaatschappelijke onafhankelijkheid. Omdat reumatische en andere chronische musculoskeletale aandoeningen zich vaak voor het eerst presenteren tijdens het werkzame leven zijn ze één van de belangrijkste oorzaken van verminderde werk participatie. Dit resulteert in een substantiële druk op patiënten, hun families, werkgevers en de maatschappij als geheel.

Langdurige deelname van chronisch zieken op de arbeidsmarkt is met het ouder worden van de gemiddelde bevolking in Nederland een steeds belangrijker punt van aandacht bij beleidsmakers en gezondheidsprofessionals. Om participatie van kwetsbaren op de arbeidsmarkt, zoals ouderen en mensen met gezondheidsproblemen, mogelijk te maken dienen we onze kennis uit te breiden over de complexe relaties tussen gezondheid, context en werk participatie bij personen met reumatische en chronische musculoskeletale aandoeningen. Verder is er vooralsnog beperkte kennis over de mogelijkheden van vroege detectie en behandeling van nadelige werkuitkomsten bij mensen met reumatische en chronische musculoskeletale aandoeningen. Het is daarbij essentieel om deelname aan het arbeidsproces en het verlies aan productiviteit of werkvermogen ook correct te kunnen meten.

\section{Hart- en vaatziekten bij werkenden met reumatische aandoeningen}

De relatie tussen ontsteking in het lichaam en hart- en vaatziekten is in het verleden uitgebreid bestudeerd in de algemene bevolking. Deze relatie is de afgelopen jaren vervolgens bevestigd voor diverse reumatische ontstekingsziekten (bijv. reumatoïde artritis, artritis psoriatica en axiale spondyloartritis). Het belang van uitbreiding van onze kennis over de invloed van hart- en vaatziekten bij werkenden met reumatische aandoeningen is tweeledig; 1) hart- en vaatziekten kunnen leiden tot toegenomen sterfte tijdens het werkzame leven en hierdoor resulteren in het vroegtijdig verlaten van de arbeidsmarkt, waardoor sterfte door hart- en vaatziekten een onafhankelijke epidemiologische bijdrage levert aan verminderde werk participatie, en 2) hart- en vaatziekten kunnen leiden tot additionele langdurige beperkingen in werk participatie, 
zoals langdurig ziekteverzuim en arbeidsongeschiktheid, waardoor de indirecte kosten (bijv. inkomensverlies als gevolg van ziekte) van reumatische ontstekingsziekten voor de samenleving kunnen toenemen.

Daarom hebben wij in Hoofdstuk 2 allereerst het risico op het ontwikkelen van harten vaatziekten en de sterfte in de eerste tien jaar van de Maastricht Cohort Studie bestudeerd, waarbij wij werkenden met reumatische ontstekingsziekten (d.w.z. reumatoïde artritis, artritis psoriatica en axiale spondyloartritis) of jicht (een ander type reumatische aandoening dat ook geassocieerd is met een verhoogd risico op hart- en vaatziekten) bij aanvang van deze studie vergeleken met werkenden zonder deze aandoeningen. Wij maakten hierbij gebruik van werkende deelnemers uit dit cohort waarvan wij de zelf-gerapporteerde diagnoses konden bevestigen in de patiëntendossiers van de omliggende ziekenhuizen. Dit was mogelijk bij ongeveer 50\% van de deelnemers. Zo konden wij met zekerheid vaststellen dat deze personen daadwerkelijk reumatische ontstekingsziekten, jicht of hart- en vaatziekten hadden.

Het risico op het ontwikkelen van hart- en vaatziekten was meer dan verdubbeld voor reumatische ontstekingsziekten. Ook de aanwezigheid van jicht bij de start van de studie verdrievoudigde het risico op het ontwikkelen van hart- en vaatziekten gedurende tien jaar follow-up. Door vervolgens de Maastricht Cohort Studie te koppelen aan het Nederlandse Overlijdensregister konden we aantonen dat dit verhoogde risico op harten vaatziekten tijdens de observatieperiode van de studie niet leidde tot een verhoogde sterfte in dezelfde periode. We concludeerden dat, alhoewel het risico op het ontwikkelen van hart- en vaatziekten was verhoogd, dit niet leidde tot vervroegde sterfte. Sterfte door hart- en vaatziekten draagt dus niet bij aan het vroegtijdig verlaten van de arbeidsmarkt onder werkende personen met reumatische ontstekingsziekten in dit cohort van relatief jonge deelnemers (gemiddelde leeftijd 41 jaar).

Vervolgens hebben we in Hoofdstuk $\mathbf{3}$ bedrijfsgegevens over het individuele ziekteverzuim van de deelnemers in de eerste tweeënhalf jaar van follow-up werden verstrekt, gekoppeld aan de Maastricht Cohort Studie. Hiermee konden we de additionele impact van hart- en vaatziekten op ziekteverzuim bij personen met al aanwezige reumatische aandoeningen bestuderen. Onze resultaten toonden aan dat bij werkende personen met zelf-gerapporteerde reumatische aandoeningen het percentage ziekteverzuimdagen (d.w.z. evenredig met het totale aantal verwachte werkdagen) in 2,5 jaar meer dan verdubbelde, vergeleken met personen zonder deze zelf-gerapporteerde reumatische aandoeningen. Ook zelf-gerapporteerde hart- en vaatziekten deden het gemiddelde percentage ziekte-verzuimdagen bijna verdubbelen. Het aantal ziekteverzuimdagen nam tot een factor 2.5 toe wanneer zelf-gerapporteerde reumatische aandoeningen en hart- 
en vaatziekten beiden aanwezig waren, in vergelijking met werkende personen zonder deze aandoeningen. In de steekproef die werd geverifieerd in de patiëntendossiers van omliggende ziekenhuizen, was het percentage ziekteverzuimdagen bij degenen met bevestigde reumatische ontstekingsziekten meer dan verdubbeld. Er waren geen personen met zowel bevestigde reumatische ontstekingszieken als hart- en vaatziekten bij aanvang van de Maastricht Cohort Studie, zodat de invloed hiervan op verzuim niet kon worden nagegaan.

Daarnaast hebben we zelf-gerapporteerde gegevens over arbeidsongeschiktheidsuitkeringen van de volledige tien jaar follow-up gebruikt om de additionele impact van hart- en vaatziekten op het risico van arbeidsongeschiktheid te bestuderen bij werkenden met reumatische aandoeningen. Zelf-gerapporteerde reumatische aandoeningen en hart- en vaatziekten verhoogden het risico op arbeidsongeschiktheid na tien jaar met respectievelijk een factor 6,5 en 4. Additieve of synergetische effecten werden niet gevonden wanneer beide ziekten aanwezig waren. Bovendien was het risico op arbeidsongeschiktheid na tien jaar meer dan achtvou dig verhoogd voor bevestigde reumatische ontstekingsziekten en voor hart- en vaatziekten bijna vervijfvoudigd. Bevestigde jicht verhoogde dit risico ook vijfvoudig, hoewel dit niet statistisch significant was, waarschijnlijk vanwege het lage aantal deelnemers met bevestigde jicht in de Maastricht Cohort Studie. Wij concludeerden dat hart- en vaatziekten het risico op arbeidsongeschiktheid na tien jaar bij werkenden met reumatische aandoeningen niet substantieel lijkt te verhogen in dit cohort. Een mogelijke verklaring hiervoor zou kunnen zijn dat we hart- en vaatziekten bij deze patiëntenpopulatie al optimaal behandelen. Onderzoek om deze gegevens te bevestigen en de rol van gelijktijdig aanwezige ziekten (ook wel multimorbiditeit genoemd) op werk participatie van mensen met chronische reumatische aandoeningen is daarom nodig.

\section{Preventie van nadelige werkuitkomsten}

Vroegtijdige interventies om de nadelige invloed van ziekte op werk participatie op de lange termijn te voorkómen zijn belangrijk. Het niet hebben van werk is namelijk geassocieerd met een slechtere gezondheid en een slechter welzijn en vergroot de druk op maatschappelijke uitgaven aan ziekte. Deze nadelige invloed kan worden voorkómen door een intensievere behandeling van de ziekte. Een andere interventie is vroegtijdige identificatie van risicofactoren voor verminderde werk participatie in de toekomst.

In Hoofdstuk 4 rapporteren we de resultaten van een systematische literatuurstudie die aantoont dat biologische therapieën veelbelovende gunstige effecten hebben op de werkuitkomsten bij patiënten met axiale spondyloartritis. We hebben twee gerandomiseerde klinische studies en zeven observationele cohort studies geïncludeerd. 
die rapporteren over 39 vergelijkingen in voor/na vergelijkingen of tussen groepen, met in totaal 961 patiënten. Deze patiënten werden behandeld met drie verschillende biologische therapieën (etanercept, infliximab en adalimumab). Het viel op dat veel patiënten in de werkzame leeftijd reeds geen werk meer hadden. Wat betreft de effecten van de behandeling, suggereerden de meeste vergelijkingen een positieve verandering in de werkresultaten (32/39 vergelijkingen), maar werden regelmatig niet getest op statistische significantie (14/32 vergelijkingen) of bleken niet statistisch significant (7/32 vergelijkingen). Helaas maakten methodologische beperkingen een meta-analyse onmogelijk, zoals een gebrek aan standaardisatie van de gemeten uitkomsten en het beperkte aantal opgenomen onderzoeken in onze literatuurstudie. Er werden echter wel aanwijzingen gezien voor gunstige effecten van biologische therapieën bij lang bestaande axiale spondyloartritis op productiviteit en ziekteverzuim, maar dit effect was nog relatief klein en onzeker wat betreft het voorkómen van arbeidsongeschiktheid.

In Hoofdstuk 5 presenteren we de resultaten van de ontwikkeling en validatie van een model om het risico op langdurig ziekteverzuim te voorspellen. Hiermee kan onderscheid worden gemaakt tussen werknemers met een hoog of een laag risico op langdurig ziekteverzuim (d.w.z. 28 werkdagen of meer per jaar) in het komende jaar. We gebruikten gegevens van 11.221 werkende personen in het STREAM-cohort om dit risicovoorspellingsmodel te ontwikkelen. Logistische regressieanalyse met behulp van achterwaartse stapsgewijze eliminatie werd gebruikt om het volledige statistische model, inclusief 27 vooraf geselecteerde voorspellers, terug te brengen tot een praktischer model met 11 voorspellers. Dit uiteindelijke model toonde een goede discriminatie (vermogen om verschil te maken tussen hoog- en laag-risico op langdurig verzuim) en een goede kalibratie (overeenstemming tussen geobserveerde en voorspelde risico) in een tweede validatiecohort van 5.604 nieuw aangeworven werkende personen binnen het STREAMcohort. De belangrijkste voorspellers in het uiteindelijke model waren een slechte beoordeling van de eigen fysieke gezondheid (gemeten met de Short Form-12 fysieke componentscore), een slechte beoordeling van het eigen werkvermogen (gemeten met één item uit de Work Ability Index [WAI]) en een hoog aantal ziekteverzuimdagen in het voorgaande jaar, doordat deze de sterkste associaties lieten zien met toekomstig langdurig ziekteverzuim.

Daarnaast hebben we nieuwe onafhankelijke risicofactoren gevonden die belangrijke voorspellers zijn van toekomstig langdurig ziekteverzuim; ten eerste het gebrek aan kennis en vaardigheden die passen bij de huidige baan, ten tweede het aantal grote levensgebeurtenissen in het voorgaande jaar (bijv. overlijden van een naaste) en ten derde bleek zelfstandig ondernemerschap dit risico te verlagen. Hoewel ons risicovoorspellingsmodel de berekening van een risicoscore mogelijk maakt door 
aan elke risicofactor een "statistisch gewicht" te geven, moet er nog een optimale afkapwaarde worden bepaald voor de totale risicoscore om accuraat patiënten te identificeren met hoog dan wel laag risico op langdurig verzuim. Bij de keuze van een afkapwaarde moeten onderzoekers kiezen of men vooral over- of onderdiagnose wil voorkomen. De resultaten van ons risicovoorspellingsmodel hebben de potentie om zorgprofessionals te ondersteunen bij het bepalen bij welke werkende personen gerichte preventieve interventies moeten worden uitgevoerd, maar kunnen ook dienen om nieuwe en potentieel aanpasbare risicofactoren op het niveau van bedrijven of werkplekken te identificeren (bijv. fysieke fitheid stimuleren via het werk).

\section{Presenteeïsme - een uitkomst in de klinische praktijk en onderzoek}

De afgelopen decennia is er substantieel werk verricht door het Outcome Measures in Rheumatology (OMERACT) initiatief om instrumenten voor het meten van uitkomsten in klinische onderzoeken in de reumatologie te identificeren en evalueren. Binnen OMERACT is er een werkgroep die verschillende uitkomstmaten identificeerde en evalueerde om de productiviteit van werknemers (d.w.z. presenteeïsme, wel aanwezig op het werk maar minder productief) te meten. Een beperking die ze ontdekten was dat directe vergelijkingen tussen verschillende meetinstrumenten in longitudinale studies ontbraken.

Daarom hebben we in Hoofdstuk 6 gegevens van 4.523 werkende personen met musculoskeletale klachten uit het STREAM-cohort gebruikt om de validiteit van drie presenteeïsme meetinstrumenten te vergelijken. Eén meetinstrument betrof een globale zelfbeoordeling van 'werkvermogen' door middel van een enkel item dat onderdeel is van de Work Ability Index. De twee andere meetinstrumenten betroffen de 'Quality-Quantity (QQ)-methode' en de 'Osterhaus-methode'. Deze laatste twee meetinstrumenten zijn een zelfbeoordeling van de geleverde 'productiviteit op het werk'. Over het algemeen vertoonde de WAI ('het vermogen om te werken') sterkere associaties met verschillende gezondheidsfactoren in vergelijking met de andere twee meetinstrumenten, die presenteeïsme als 'productiviteit op het werk' hebben gemeten. De Short Form-12 score voor fysieke gezondheid was bijvoorbeeld sterker geassocieerd met een toename van de WAI in het daaropvolgende jaar, in vergelijking met QQ-methode en de Osterhausmethode. Vergelijkbare verschillen tussen de drie instrumenten ten gunste van de WAI werden gevonden voor de associaties met mentale gezondheid (Short Form-12 mentale component score) en vitaliteit (Short Form-36 vitaliteitsindex). Daarnaast waren ziekteverzuimdagen in het daaropvolgende jaar waren ook sterker geassocieerd met de WAl dan met de QQ- en Osterhaus-methode. Wij concludeerden dat het werkvermogen (gemeten met de WAI) een betere validiteit toonde ten opzichte van externe factoren voor gezondheid en ziekteverzuim, in vergelijking met de twee meetinstrumenten voor de 'werkproductiviteit'. De WAI is duidelijk relevanter voor het identificeren van werkende 
personen met een hoog risico op toekomstig ziekteverzuim, zoals wij reeds aantoonden in het risicovoorspellingsmodel in Hoofdstuk 5. Aan de andere kant lijkt de Osterhausmethode relevanter vanuit een economisch perspectief omdat de kosten voor de maatschappij ten gevolge van presenteeïsme kunnen worden ingeschat.

In Hoofdstuk 6 hebben we daarnaast de invloed onderzocht van groepen van contextuele factoren op de associaties tussen gezondheidsfactoren, presenteeïsme en ziekteverzuim. We toonden aan dat persoonlijke contextuele factoren (bijv. coping) de grootste impact hadden op de associaties tussen gezondheidsfactoren en de WAl en de QQ-methode, maar dit effect was verwaarloosbaar voor de Osterhaus-methode. Demografische, leefstijl- en werk gerelateerde contextuele factoren hadden een veel kleinere impact op de associaties tussen gezondheidsfactoren en de drie gebruikte presenteeïsme-instrumenten. Wij concludeerden dat persoonlijke contextuele factoren nog te vaak ongemeten of onbekend zijn, maar wel degelijk een belangrijke rol spelen bij de interpretatie van werkuitkomsten in wetenschappelijk onderzoek en in de klinische praktijk.

\section{Impact van dit proefschrift}

De negatieve impact van reumatische en andere chronische musculoskeletale aandoeningen op het individu en de samenleving als geheel is aanzienlijk, maar kan (gedeeltelijk) omkeerbaar of te voorkomen zijn als de juiste maatregelen worden genomen. Verbetering van ons begrip van de complexe relatie tussen reumatische en andere chronische musculoskeletale aandoeningen, context en beperkingen in werk participatie kan resulteren in betere benaderingen om vroege opsporing en op maat gemaakte behandelingen mogelijk te maken. Daarnaast kan het verkrijgen van meer inzicht in de verschillen tussen meetinstrumenten (construct validiteit) leiden tot verbetering van de kwaliteit van onderzoek. Ten slotte kan dit proefschrift enerzijds een bijdrage leveren aan het doel om het bewustzijn te vergroten over de rol die huisartsen en reumatologen hebben bij het omgaan met werk gerelateerde problemen en anderzijds de deelname aan betaald werk van hun patiënten verbeteren.

\section{Eindconclusies}

Dit proefschrift draagt bij aan ons begrip van de complexe relaties tussen gezondheid, contextuele factoren en beperkingen in arbeidsparticipatie bij personen met reumatische en andere chronische musculoskeletale aandoeningen. Het draagt specifiek bij aan de hoeveelheid bewijs die de impact van multimorbiditeit en contextuele factoren op werkresultaten aantoont, bevestigt de gunstige effecten van biologische therapieën op arbeidsparticipatie bij axiale spondyloartritis en biedt nieuwe mogelijkheden om vroege detectie en uitkomstmeting bij reumatische en andere chronische musculoskeletale aandoeningen te verbeteren. 




\section{Addendum}

CURRICULUM VITAE 



\section{CURRICULUM VITAE}

Lennart van der Burg werd op 27 januari 1989 geboren in Valkenswaard. Na het behalen van zijn VWO diploma aan Scholengemeenschap Were Di in Valkenswaard in 2007, verhuisde hij naar Leuven (België) om aan de Katholieke Universiteit Leuven de opleiding Biomedische Wetenschappen te volgen. Na één jaar startte hij aan de Universiteit van Maastricht met zijn opleiding Geneeskunde, welke hij in 2015 succesvol afrondde. Tijdens zijn bachelor volgde hij het Honoursprogramma 'Research' (begeleiders: Prof. dr. Annelies Boonen, Prof. dr. Robert Landewé en Dr. Ludovic van Amelsvoort), waaruit drie in dit boek beschreven onderzoeken voortvloeiden. Vanaf 2015 werkte hij als arts-onderzoeker in het laboratorium van de afdeling Maag-, Darm- en Leverziekten in het Leids Universitair Medisch Centrum (LUMC). Hij begon in 2018 met de huisartsopleiding aan de Universiteit van Maastricht en combineerde dit met een promotietraject ('Arts In Opleiding Tot Huisarts Onderzoeker', AIOTHO) onder leiding van Prof. dr. Annelies Boonen en Prof. dr. Geert-Jan Dinant. Gedurende de jaren dat hij betrokken is geweest bij wetenschappelijk onderzoek volgde hij diverse cursussen om zijn wetenschappelijke competenties te verbeteren. De onderzoeksresultaten beschreven in dit proefschrift werden op meerdere nationale en internationale congressen gepresenteerd.

Lennart werkte tijdens het eerste jaar van zijn huisartsopleiding bij Huisartsenpraktijk Hobma-Cals-Machielsen te Sittard (opleider: Dr. Sjoerd Hobma), en werkt op dit moment tijdens het laatste jaar van zijn opleiding bij Gezondheidscentrum Heer te Maastricht (opleider: Drs. Jeroen Smeets). Op 1 september 2021 verwacht hij zijn opleiding tot huisarts af te ronden. 



\section{Addendum}

LIST OF PUBLICATIONS 



\section{LIST OF PUBLICATIONS}

van der Burg LRA*, Ter Wee MM*, Boonen A. Effect of biological therapy on work participation in patients with ankylosing spondylitis: a systematic review. Ann Rheum Dis 2012;71:1924-33 *authors contributed equally

van der Burg LRA, Boonen A, van Amelsvoort LGPM, Jansen NWH, Landewé RBM, Kant IJ. The effects of cardiovascular co-morbidities on work participation in rheumatic diseases: A prospective cohort study among working individuals. Arthritis Care Res (Hoboken) 2014:66:157-63

Kroon FPB*, van der Burg LRA*, Buchbinder R, Osborne RH, Johnston RV, Pitt V. Selfmanagement education programmes for osteoarthritis. Cochrane Database Syst Rev 2014:CD008963 "authors contributed equally

van der Burg LRA, van Amelsvoort LGPM, Boonen A, Jansen N, Kant IJ, Landewé RBM. Cardiovascular morbidity and premature mortality among working individuals with rheumatic disease: results from a large prospective cohort study. J Clin Rheumatol 2015:21:359-363

Kroon FPB, van der Burg LRA, Ramiro S, Landewé RBM, Buchbinder R, Falzon L, van der Heijde D. Non-steroidal anti-inflammatory drugs (NSAIDs) for axial spondyloarthritis (ankylosing spondylitis and non-radiographic axial spondyloarthritis). Cochrane Database Syst Rev 2015:CD010952

Kroon FP, van der Burg LR, Ramiro S, Landewé RB, Buchbinder R, Falzon L, van der Heijde D. Nonsteroidal Antiinflammatory Drugs for Axial Spondyloarthritis: A Cochrane Review. J Rheumatol 2016;43:607-17

Jiménez-Martínez M, Ostalé CM, van der Burg LR, Galán-Martínez J, Hardwick JCH, López-Pérez R, Hawinkels LJAC, Stamatakis K, Fresno M. DUSP10 is a regulator of YAP1 activity promoting cell proliferation and colorectal cancer progression. Cancers (Basel) 2019;11:1767

van der Burg LRA, van Kuijk SMJ, Ter Wee MM, Heymans MW. De Rijk AE, Geuskens GA, Ottenheijm RPG, Dinant GJ, Boonen A. Long-term sickness absence in a working population: development and validation of a risk prediction model in a Dutch population cohort. BMC Public Health 2020;20:699 
van der Burg L, Sepriano A, Landewé R, Geuskens G, Ottenheijm R, Dinant GJ, Boonen A. Comparative construct validity of three presenteeism instruments in workers with musculoskeletal complaints: a prospective cohort study. RMD Open 2020;6:e001281

Ouahoud S, Voorneveld PW, van der Burg LRA, Jonge-Muller ESM, Schoonderwoerd MJA, Paauwe M, de Wit S, van Pelt G, Mesker W, Hawinkels LJAC, Hardwick JCH. Bidirectional tumour-stroma crosstalk promotes metastasis in mesenchymal colorectal cancer. Oncogene 2020;39:2453-2466

Ouahoud S, Jacobs RJ, Kodach LL, Voorneveld PW, Hawinkels LJAC, Weil NL, van Vliet B, Herings RM, van der Burg LRA, van Wezel T, Morreau H, Slingerland M, Bastiaannet E, Putter $\mathrm{H}$, Hardwick JCH. Statin use is associated with a reduced incidence of colorectal cancer expressing SMAD4 (submitted for publication) 




\section{Addendum}

DANKWOORD 



\section{DANKWOORD}

Het voltooien van dit proefschrift zou zonder de steun van collega's, vrienden en familie nooit zijn gelukt. Daarom wil ik iedereen bedanken die direct of indirect heeft bijgedragen aan de totstandkoming van dit proefschrift. Graag benoem ik hieronder een aantal personen in het bijzonder.

Allereerst mijn dank aan mijn promotieteam. Prof. dr. Boonen, beste Annelies, vanaf het moment dat ik als onervaren geneeskundestudent jouw kamer binnenliep ben je een grote bron van inspiratie voor mij. Ik kan met trots zeggen dat jij voor een groot deel hebt bijgedragen aan mijn wetenschappelijk vorming, met als kers op de taart dit proefschrift. Bedankt voor de diepgaande discussies, jouw toewijding en enthousiasme voor wetenschappelijk onderzoek dat je iedere keer weer op mij en anderen weet over te brengen. Daarnaast toonde je altijd interesse in mijn leven buiten mijn werk.

Prof. dr. Dinant, beste Geert-Jan, van jou heb ik geleerd oog te hebben voor het plaatsen van mijn resultaten in de juiste context en altijd terug te grijpen naar het belang van mijn bevindingen voor de klinische praktijk. Hierbij waardeerde ik jouw aandacht voor mijn persoonlijke ontwikkeling als huisarts, onderzoeker en als mens. Bedankt voor je vertrouwen en interesse in mij. Dr. Ottenheijm, beste Ramon, bedankt voor de interessante discussies en jouw klinische blik die dit proefschrift beter hebben gemaakt.

Beste dr. Amelsvoort en Prof. dr. Landewé, dit avontuur begon ooit met een project als onderzoeksstudent met een samenwerking tussen de vakgroepen Epidemiologie en Reumatologie. Vanaf het eerste moment hebben jullie mij het volledige vertrouwen en de ruimte gegeven om mijn wetenschappelijke vaardigheden te ontwikkelen. Bedankt voor deze geweldige kans!

Lieve mede-promovendi van zowel de huisartsgeneeskunde als de reumatologie. Schipperen tussen twee afdelingen is niet altijd makkelijk, zeker niet wanneer je promotieonderzoek ook nog combineert met een opleiding tot huisarts. Op beide vakgroepen heb ik mij vanaf moment één onderdeel van de groep gevoeld, ook al was ik niet vaak fysiek aanwezig. Ik wil jullie bedanken voor de fijne tijd en hoop in de toekomst nog vaker met jullie samen te mogen werken.

Beste huisartsopleiders, beste Sjoerd en Jeroen, een belangrijk deel van mijn wetenschappelijke vorming vond plaats tijdens mijn opleiding tot huisarts. Ik kan met trots zeggen dat ik met twee geweldige opleiders heb gewerkt die met veel enthousiasme 
mijn kritisch denken over mijn medisch handelen naar een hoger niveau hebben gebracht. Bedankt voor deze leerzame en vooral ook gezellige tijd. Ik waardeer ook erg de ruimte die ik van jullie kreeg om naast mijn opleiding dit proefschrift af te ronden.

Lieve vrienden, wat een voorrecht om zoveel lieve mensen in mijn leven te hebben. Bij jullie kon ik altijd terecht voor een luisterend oor of voor afleiding van het wetenschappelijk onderzoek. Ook hebben wij samen veel mooie momenten beleefd; reisjes naar bijvoorbeeld Rome of Utrecht, sportieve momenten op de wielrenfiets of tijdens het hardlopen, culinaire avonden thuis of in een sjiek restaurant, bonte ET-dagen op een camping en de geboortes van jullie prachtige kinderen. Bedankt voor al deze mooie momenten.

Lieve papa en mama, ik heb van jullie in mijn leven altijd alle mogelijkheden gekregen om mijzelf te ontplooien tot de persoon die ik vandaag de dag ben. Een veilig en welkom thuis, aandacht voor warmte, empathie en gelijkheid waren hierbij vanzelfsprekend. Als puber probeer je zoveel mogelijk anders te lijken dan je ouders; nu zie ik in dat ik heel veel op jullie lijk en nooit anders zou willen zijn. Lieve Mathijs en Anke, ook al hebben we alle drie een compleet ander pad gekozen in ons leven, toch weten we met veel interesse en waardering elkaar altijd weer te vinden. Ik wil jullie bedanken voor de onvoorwaardelijke liefde en steun. Lieve schoonfamilie, inmiddels ben ik al lange tijd onderdeel van jullie familie. We hebben samen veel mooie dingen meegemaakt en steunden elkaar op momenten dat het even wat minder ging. Bedankt dat ik altijd welkom was voor wijze raad. Ik kan me geen fijnere schoonfamilie voorstellen.

Lieve paranimfen, Patrick en Lawrence, wat vind ik het toch fijn dat jullie vandaag naast mij staan. Pat, jou heb ik leren kennen tijdens een wetenschappelijke cursus en je bleek al snel net zo gek op sporten als ik. Lawrence, jou leerde ik juist kennen op de atletiekbaan, maar je weet mij tot op de dag van vandaag regelmatig gevraagd en ongevraagd van nieuwe ("wetenschappelijke") feitjes te voorzien. Met jullie beide heb ik de liefde voor het sporten gemeen, maar bovenal zijn jullie hele goede vrienden waar ik altijd terecht kan. Samen sporten gaf mijn gedachten de ruimte om op de juiste plek te vallen én de broodnodige ontspanning om mijn promotietraject tot een succesvol einde te brengen. Bedankt voor alle mooie momenten, ik hoop dat we er in de toekomst nog veel meer gaan beleven.

Liefste Féline, zo verschillend en toch zo één. De kracht van onze relatie zin hem denk ik in het overbruggen van deze verschillen, waarbij wij altijd veel respect, empathie en warmte naar elkaar tonen. Nog iedere dag geniet ik van jouw aanwezigheid in mijn leven en maak je mij gelukkig. Ik zou je nooit anders dan anders willen. 



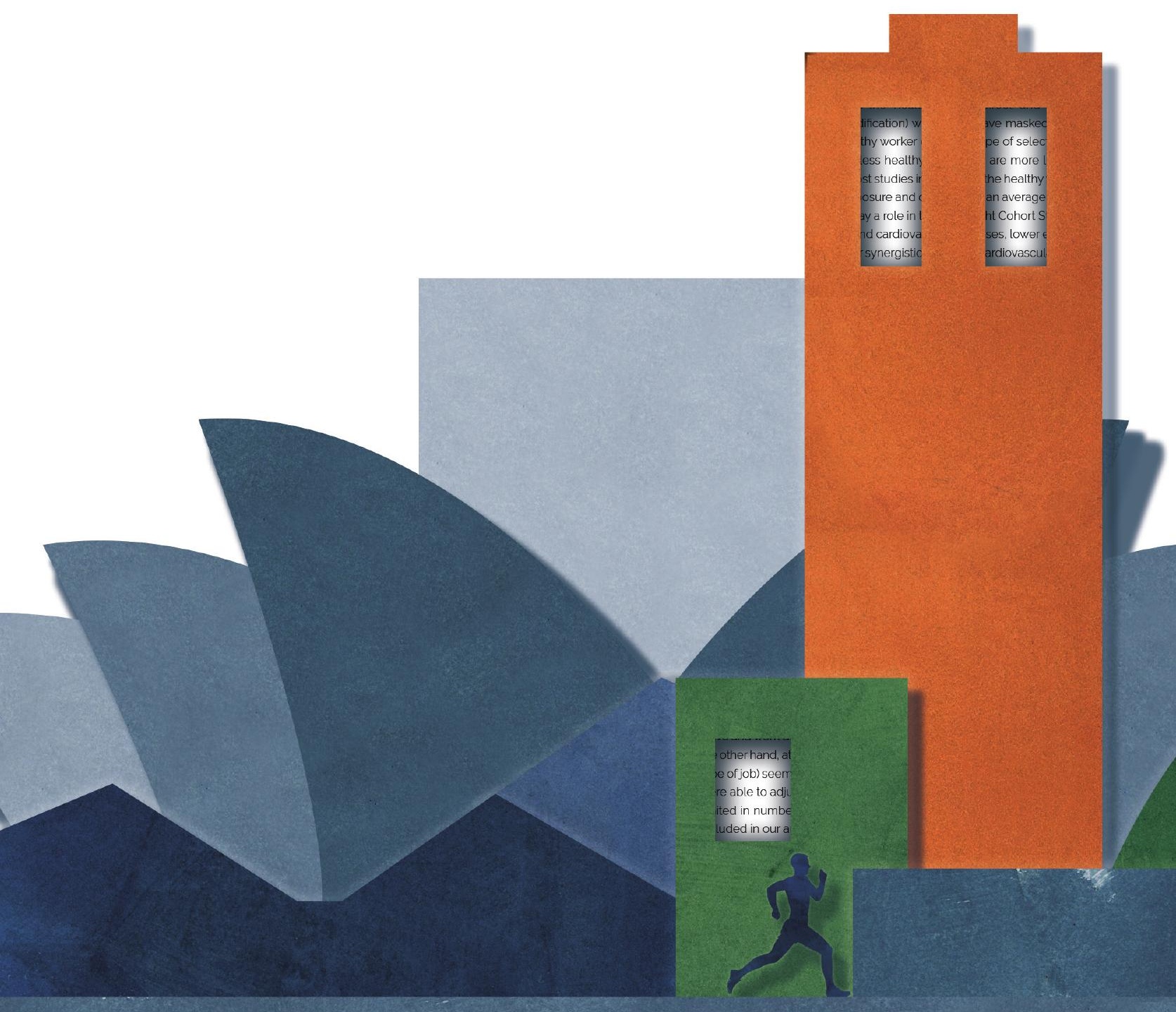

